\title{
Canadians' Attitudes Toward Immigrants Who Claim Employment Discrimination
}

Natalia Lapshina, The University of Western Ontario

Supervisor: Dr. Victoria M. Esses, The University of Western Ontario

A thesis submitted in partial fulfillment of the requirements for the Doctor of Philosophy degree in Psychology

(C) Natalia Lapshina 2015

Follow this and additional works at: https://ir.lib.uwo.ca/etd

Part of the Social Psychology Commons

\section{Recommended Citation}

Lapshina, Natalia, "Canadians' Attitudes Toward Immigrants Who Claim Employment Discrimination" (2015). Electronic Thesis and Dissertation Repository. 2949.

https://ir.lib.uwo.ca/etd/2949

This Dissertation/Thesis is brought to you for free and open access by Scholarship@Western. It has been accepted for inclusion in Electronic Thesis and Dissertation Repository by an authorized administrator of Scholarship@Western. For more information, please contact wlswadmin@uwo.ca. 
CANADIANS' ATTITUDES TOWARD IMMOGRANTS WHO CLAIM EMPLOYMENT DISCRIMINATION

(Thesis format: Monograph)

\author{
by \\ Natalia Lapshina \\ Graduate Program in Psychology
}

A thesis submitted in partial fulfillment of the requirements for the degree of Doctor of Philosophy

The School of Graduate and Postdoctoral Studies

The University of Western Ontario

London, Ontario, Canada

(c) Natalia Lapshina 2015 


\section{Abstract}

This dissertation examined how prejudice may operate in the treatment of immigrants when they claim workplace discrimination. In line with the Justification-Suppression Model of the Expression of Prejudice (JSM; Crandall \& Eshleman, 2003), I expected more negative attitudes toward an immigrant claimant from a dissimilar culture (Iran) compared to an immigrant claimant from a similar culture (Britain) and a second generation Iranian Canadian. All three studies utilized experimental design. The results of Study 1 demonstrated that the Iranian claimant was especially likely to be seen as not having experienced discrimination, more deserving of and responsible for the dismissal, and was especially likely to be derogated, compared to an Iranian Canadian claimant. Attributions of personal responsibility mediated the effect of country of origin on target derogation and outcome deservingness. In Study 2, the claimant from Iran elicited more negative attitudes than a claimant from Britain. Moreover, participants who suppressed their prejudice less reported more bias against the claimant from Iran as compared to the Iranian Canadian claimant. In addition to the country of origin, Study 3 manipulated a source of attributions for discrimination. To do so, in addition to situational ambiguity, Study 3 added two other explanations for the discrimination claimant's contract termination - one considered to be internal to the claimant and the other external. The results demonstrated suppression of prejudice against the claimant from Iran in all conditions. When the claimant was clearly unskilled for the job, there was evidence of a "black sheep effect"- more negative attitudes toward the British claimant. Finally, in the situation with an authority figure responsible for discrimination, the second generation Iranian Canadian elicited more negativity. These effects may be explained by attributions of personal responsibility and judgements of outcome deservingness. Taken together, these studies demonstrate that prejudice toward skilled immigrants from dissimilar cultures may contribute not only to employment discrimination, but also interfere with their attempts to seek justice when they proceed with a claim of discrimination. 


\section{Keywords}

Prejudice, employment discrimination, discrimination claim, minorities, dissimilar culture 


\section{Acknowledgments}

I would like to express my sincere gratitude to my supervisor and mentor, Dr. Victoria M. Esses. I am immensely grateful for your expertise on the topic and support of my research endeavours. Thank you for an opportunity to learn on a broad range of topics well beyond the focus of my dissertation, and for challenging me to grow as a researcher. Thank you for always having your door open to me, and providing advice on not only academic challenges, but also sharing your wisdom on everyday life matters.

I would like to thank my committee members, Dr. James Olson and Dr. William Fisher for your valuable suggestions and the time.

I would also like to extend my gratitude to Dr. Zenaida Ravanera for providing me with an opportunity to work with you on several projects. Your expertise and guidance allowed me to acquire valuable research skills and to look at the field of migration and ethnic relations from different angles.

To my lab mates in the Esses Lab for the Study of Intergoup Relations. It has been a great pleasure working with you, sharing ideas, and getting support.

To an army of dedicated research assistants, for their hard work on data collection for a number of projects, and their thoughts and suggestions on these projects.

To my close friend, Alexandra Bozheva, thank you for always being ready to listen and share with me my happiest and difficult moments. I am incredibly grateful to have you as a friend and a research partner.

To my fantastic son, Michael, you make my life more meaningful! Thank you for motivating me to start and finish this journey and for providing necessary distractions, and most importantly, for keeping me strong and positive. 


\section{Table of Contents}

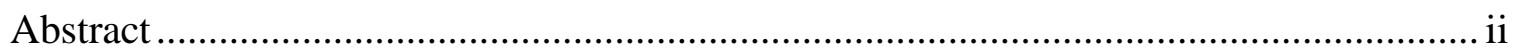

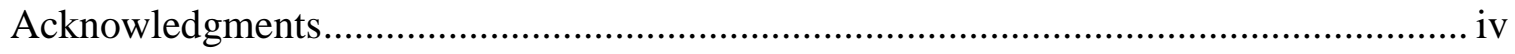

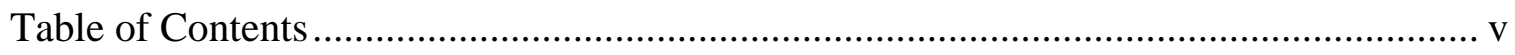

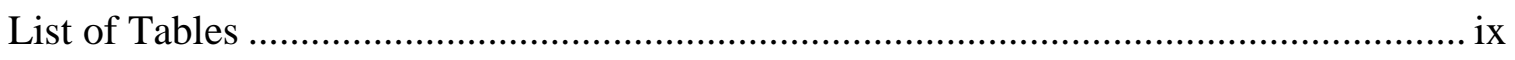

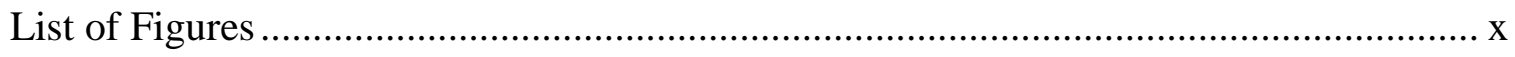

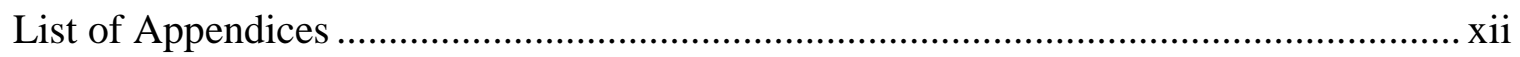

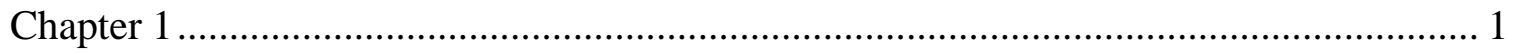

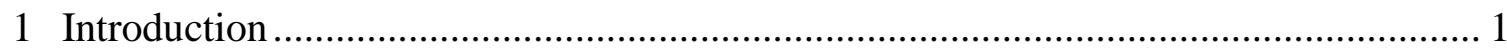

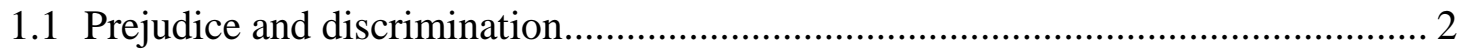

1.1.1 Expression of prejudice............................................................... 2

1.1.2 Employment discrimination....................................................... 3

1.1.3 Prejudice and discrimination against immigrants ............................ 4

1.1.4 Claiming discrimination.................................................................. 5

1.2 The Justification-Suppression Model of the Expression of Prejudice .................. 7

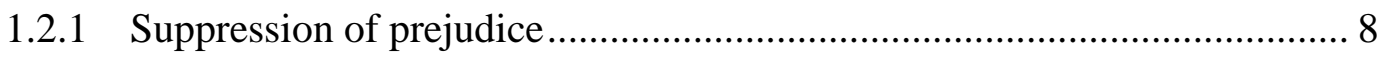

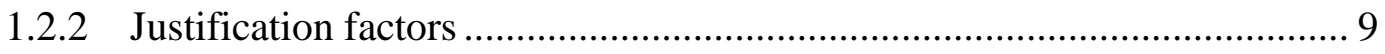

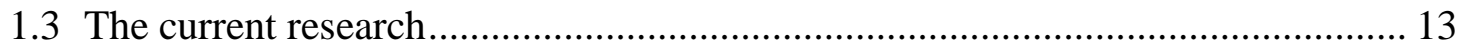

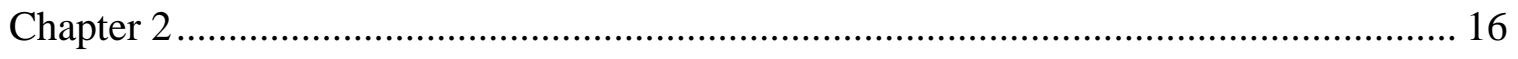

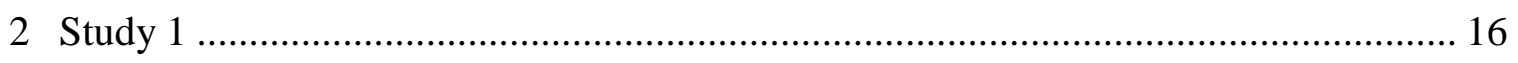

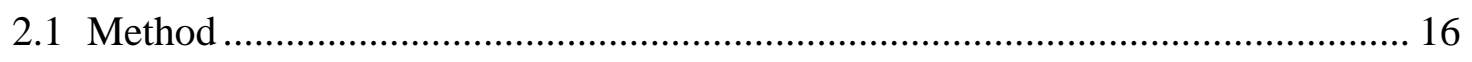

2.1.1 Participants and design .............................................................. 16

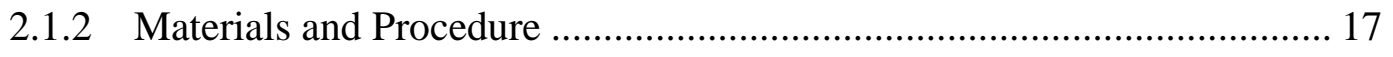

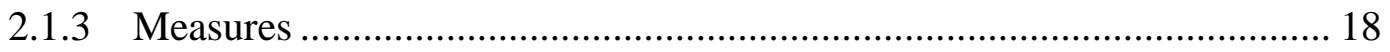




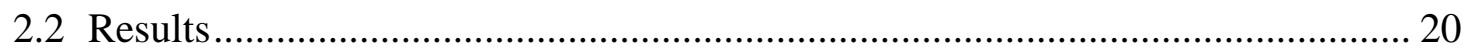

2.2.1 Gender effects ................................................................................ 20

2.2.2 Perceptions of claimant's ethnic background .......................................... 20

2.2.3 Correlations between the outcome variables ........................................... 23

2.2.4 Manipulation check ............................................................................ 25

2.2.5 Perceptions of discrimination in the situation......................................... 25

2.2.6 Perceived similarity in values ............................................................ 25

2.2.7 Main outcome variables...................................................................... 26

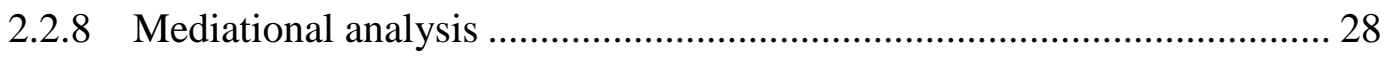

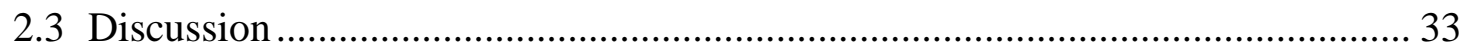

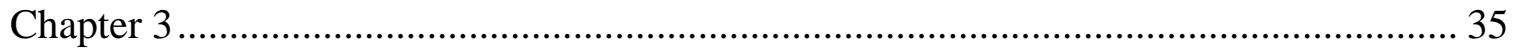

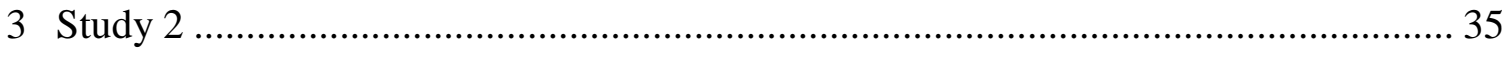

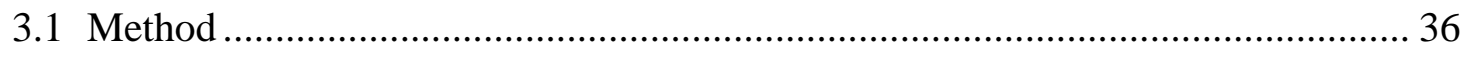

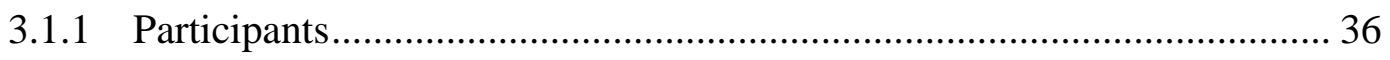

3.1.2 Materials and Procedure ………………………................................. 36

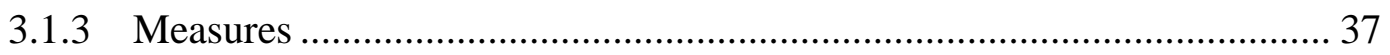

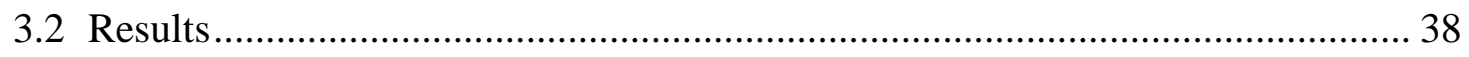

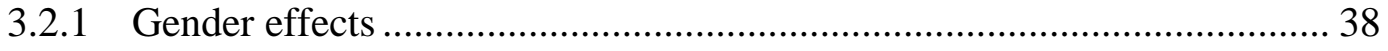

3.2.2 Perceptions of claimant's ethnic background ........................................... 38

3.2.3 Correlations between the outcome variables ............................................ 40

3.2.4 Manipulation check.......................................................................... 42

3.2.5 Perceptions of discrimination in the situation.......................................... 42

3.2.6 Perceived similarity in values ................................................................ 42

3.2.7 Main outcome variables .................................................................... 42

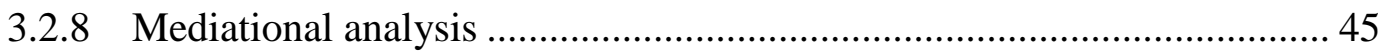




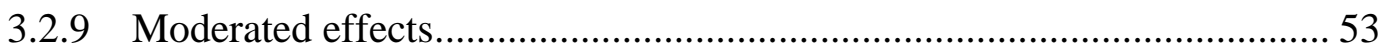

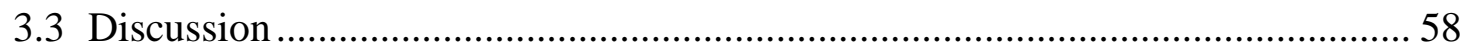

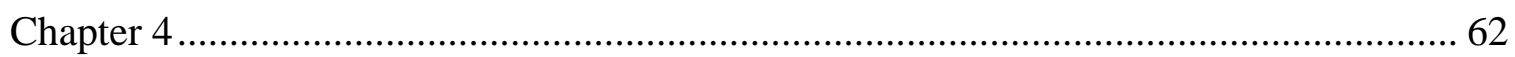

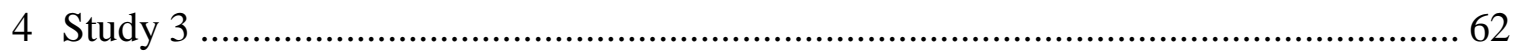

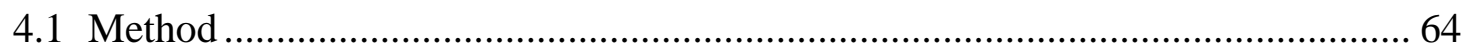

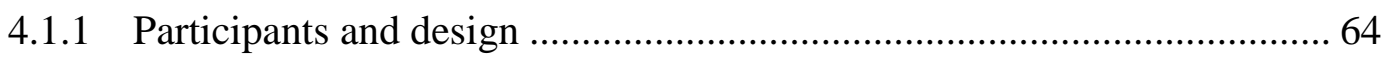

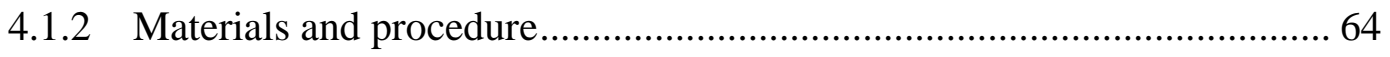

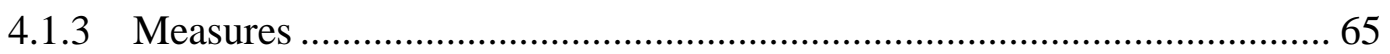

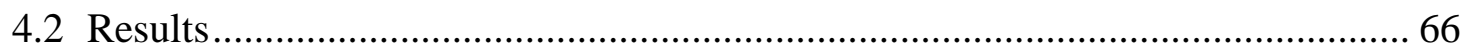

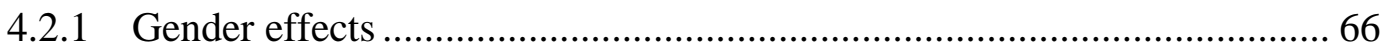

4.2.2 Perceptions of claimant's ethnic background ........................................... 66

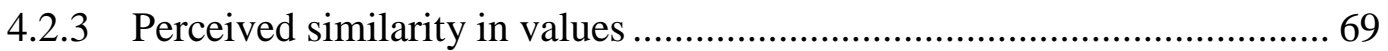

4.2.4 Correlations between the outcome variables ............................................. 69

4.2.5 Effects of attribution type and country of origin on the dependent

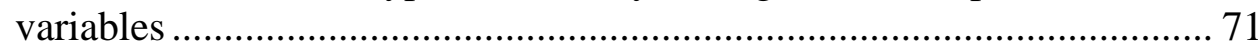

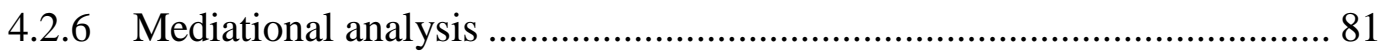

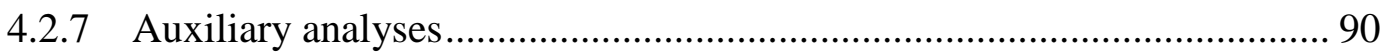

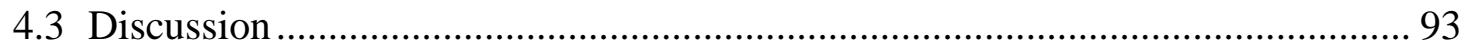

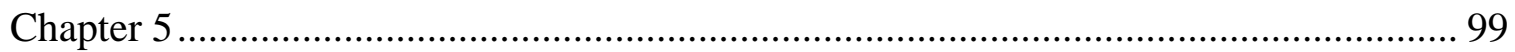

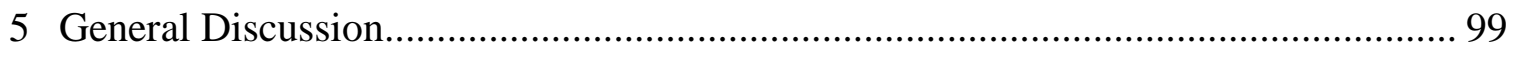

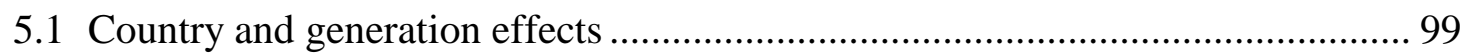

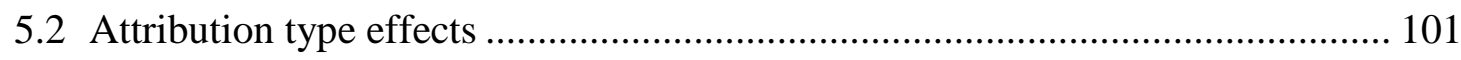

5.3 Explanatory variables..................................................................................... 103

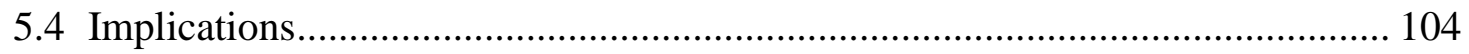

5.4.1 Theoretical implications......................................................................... 104

5.4.2 Practical implications..................................................................... 105 


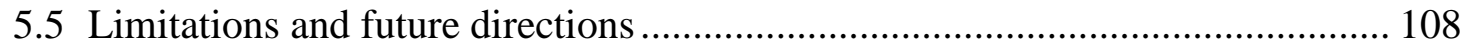

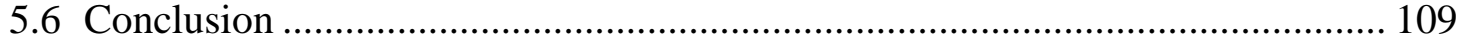

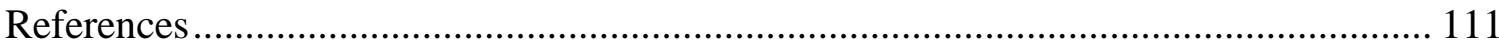

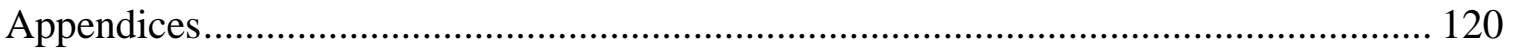

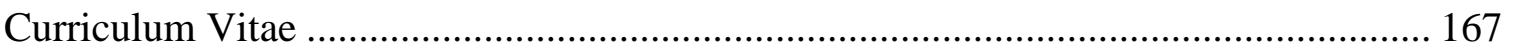




\section{List of Tables}

Table 1 Frequencies of Perceptions of Claimant's Ethnic Background as a Function of

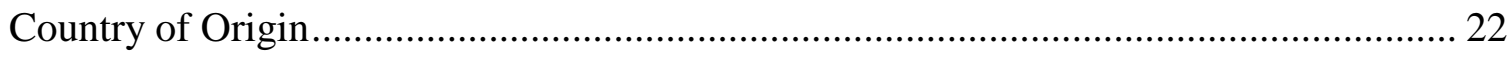

Table 2 Bivariate Correlations Between Outcome Variables ...................................... 24

Table 3 Descriptive Statistics (M, SD), F-tests, and $\eta^{2}$ of Perceptions of Discrimination in the Situation and the Main Outcome Variables...................................27

Table 4 Frequencies of Perceptions of Claimant's Ethnic Background as a Function of

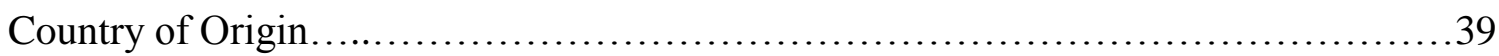

Table 5 Bivariate Correlations Between Outcome Variables ...................................... 41

Table 6 Descriptive Statistics (M, SD), F-tests, and $\eta^{2}$ of the Main Outcome Variables..44

Table 7 Frequencies and Percentages of Perceptions of Claimant's Ethnic Background as

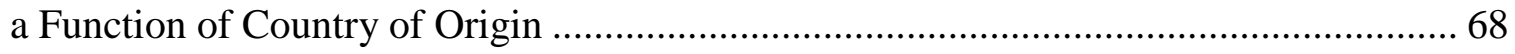

Table 8 Bivariate Correlations Between Outcome Variables ........................................ 70 


\section{List of Figures}

Figure 1: Mediational effects of country of origin on target derogation through attributions of personal responsibility

Figure 2: Mediational effects of country of origin on outcome deservingness through attributions of personal responsibility

Figure 3: Mediational effects of country of origin on target derogation through attributions of personal responsibility.

Figure 4: Mediational effects of country of origin on outcome deservingness through attributions of personal responsibility

Figure 5: Mediational effects of country of origin on outcome deservingness through perceived discrimination

Figure 6: Mean perceived discrimination in individuals high and low in concern with acting prejudiced depending on the claimant's country of origin

Figure 7: Mean outcome deservingness in individuals high and low in concern with acting prejudiced depending on the claimant's country of origin.

Figure 8: Mean target derogation depending on the attribution type and claimant's country of origin

Figure 9: Mean outcome deservingness depending on the attribution type and claimant's country of origin.

Figure 10: Mean perceived responsibility depending on the attribution type and claimant's country of origin

Figure 11: Mean perceived similarity depending on the attribution type and claimant's country of origin. 
Figure 12: Mediational effects of country of origin on target derogation through attributions of personal responsibility in the internal attribution condition........................ 84

Figure 13: Mediational effects of country of origin on target derogation through attributions of personal responsibility in the external attribution condition ...................... 85

Figure 14: Mediational effects of country of origin on outcome deservingness through attributions of personal responsibility in the internal attribution condition....................... 88

Figure 15: Mediational effects of country of origin on outcome deservingness through attributions of personal responsibility in the external attribution condition ...................... 89

Figure 16: Mediational effects of attribution type on empathy through perceptions of discrimination 


\section{List of Appendices}

Appendix A: Ethics Approvals for Studies 1-3 ........................................................... 120

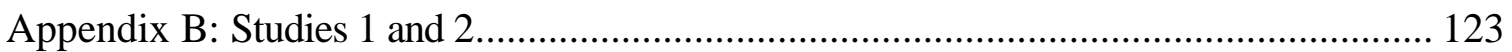

Appendix C: Studies 1 and 2 Manipulation Articles and Measures ............................ 125

Appendix D: Studies 1 and 2 Feedback Sheet .................................................... 134

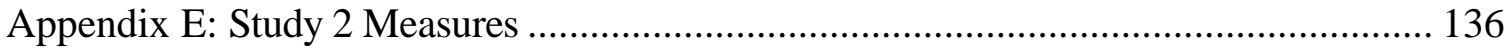

Appendix F: Study 3 Letter of Information and Consent Form.................................. 138

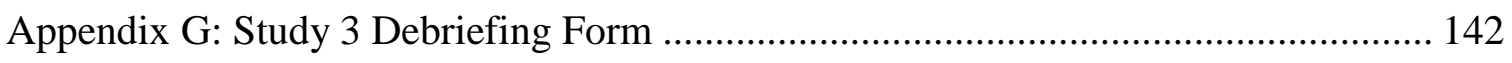

Appendix H: Study 3 Manipulation Articles and Measures ...................................... 144 


\section{Chapter 1}

\section{Introduction}

Immigration drives economic growth; indeed, it is currently the largest source of labour force growth in Canada (Citizenship and Immigration Canada, 2013). Accordingly, recent changes to Canadian immigration policy have favored skilled immigrants: those immigrants who have advanced education and foreign work experience (Citizenship and Immigration Canada, 2012; Picot, Hou \& Coulombe, 2007). Skilled immigrants seek opportunities to use their skills and education in order to achieve higher economic standards of living (Picot et al., 2007).

Although the human capital theory suggests that better skills and higher education are the most valuable characteristics of economic migrants that increase their employment prospects, such oversimplification ignores structural and socio-cultural barriers that economic migrants face once they arrive in the host country (Syed, 2007). In the Canadian labour market, these challenges include demands for Canadian job experience, lack of a Canadian accent, and credentials recognized by Canadian institutions (Creese \& Wiebe, 2009). Due to these barriers, the perceived job market "value" of immigrants' skills may vary depending on their socio-cultural background, leading to discrimination toward certain immigrant groups.

While the Canadian government tries to encourage reporting of employmentrelated and other forms of discrimination, it is often the case that in general, individuals who perceive themselves to be targets of discrimination are reluctant to share their experiences with others (Kaiser \& Major, 2006). When immigrants blame poor outcomes such as unemployment, lower salary, or not being promoted on discrimination, it may lead people to perceive them negatively or derogate them even when the claim is well justified (see also Kaiser \& Miller, 2001, 2003).

The current research examines Canadians' perceptions of immigrants of various ethno-cultural backgrounds who claim employment-related discrimination in terms of 
attitudes toward these individuals and attributions of personal responsibility, and explores factors that may contribute to these attitudes. I will start by discussing and summarizing current theoretical approaches to prejudice and discrimination against immigrants. Specifically, I will focus on how negative reactions toward an individual, such as target derogation and outcome deservingness, depend on an immigrant's country of origin and generation, and how attributions of personal responsibility for negative outcomes, perceived discrimination, and perceived similarity may explain these effects. In addition to the country of origin, Study 3 manipulates a source of attributions for discrimination. To do so, in addition to situational ambiguity, in Study 3 I added two other explanations for the discrimination claimant's contract termination - one considered to be internal to the claimant and the other external. A general discussion will follow the three studies, along with implications, limitations, and overall conclusion.

\subsection{Prejudice and discrimination}

\subsubsection{Expression of prejudice}

The categorization of oneself and others as members of an in-group (i.e., a group of people who share a sense of common identity), in comparison with an out-group (i.e., a group that is perceived as distinct or different from one's own group; Turner, 1982) can affect perceptions and the interpretation of social situations (Tajfel \& Turner, 1979; Turner, Hogg, Oakes, Reicher, \& Wetherell, 1987). In turn, a distinction between members of the in-group and out-group impacts a range of social behaviours, from antisocial (e.g., wars, genocide, aggression) to prosocial (e.g., helping; see Dovidio, Gaertner, Validzic, Matoka, Johnson, \& Frazier, 1997; Halabi, Dovidio, \& Nadler, 2008; Stürmer \& Snyder, 2010).

Prejudice is defined as a negative attitude toward a social group (Dovidio \& Hebl, 2005). Although sometimes prejudice gets expressed blatantly, such expression is not common in contemporary western society because western society generally promotes equality as a fundamental cultural value (Pearson, Dovidio, \& Gaertner, 2009). However, more subtle forms of prejudice still exist, and can have equally detrimental 
effects on the targeted individuals or groups (Dovidio \& Gaertner, 1998). Aversive racism refers to the feelings of discomfort, disgust, or uneasiness that Whites may experience in the presence of Blacks, despite endorsement of egalitarian values and beliefs (Dovidio, Gaertner, Kawakami, \& Hodson, 2002; Hodson, Dovidio, \& Gaertner, 2002). This discomfort may result in avoidance of the target group or other behaviors that may be interpreted as non- racist, meaning that they may typically be justified or rationalized by non-prejudicial arguments (i.e., factors other than race, gender, etc.; Dovidio \& Gaertner, 1998). Modern racism refers to Whites' denial of the existence of racism, and perceptions that the continuing demand for equality by Blacks is unjustified. At the same time, Blacks perceive this Whites' resistance as proof of racism (McConahay, Hardee, \& Batts, 1981).

Discrimination is defined as unfair behavioural biases demonstrated against out-group members (Dipboye \& Colella, 2005). Like prejudice, discrimination may be obvious or occur in subtle forms, such as social exclusion and avoidance (Dipboye \& Colella, 2005). Discrimination can be expressed in a variety of forms, such as whether one will help a member of a group (homosexuals, single mothers, Native CanadiansJackson \& Esses, 1997; immigrants- Cunningham \& Platow, 2007; Jackson \& Esses, 2000; students from an out-group university - Tarrant, Dazeley, \& Cottom, 2009), to employment (Dovidio, Gaertner, Kawakami, \& Hodson, 2002; Petersen \& Dietz, 2005). Not surprisingly, research has found that visible minorities in Canada report experiences of discrimination twice as often as non-visible minorities: $81 \%$ of visible minorities felt that they had experienced discrimination because of their race or ethnic origin (Perreault, 2008).

\subsubsection{Employment discrimination}

In the employment context, people who express modern or aversive racism use various factors to legitimize discrimination, including business reasons (Petersen \& Dietz, 2005), or ambiguity regarding the quality of the minority group members' qualifications (Dovidio, Gaertner, Kawakami, \& Hodson, 2002). Discrimination against out-group members may happen at any stage of the employment process — during selection, appraisal, promotion, or training (Dipboye \& Colella, 2005). 


\subsubsection{Prejudice and discrimination against immigrants}

Oftentimes, as out-group members, immigrants become targets of prejudice and discrimination from members of the host society. In terms of employment outcomes, the unemployment rate among recent immigrants in Canada is twice as high as those born in Canada (Ostrovsky, 2008; Statistics Canada, 2015). Likewise, immigrants are twice as likely as non-immigrants to be underemployed (Li, Gervais \& Duval, 2006; Lo, Damsbaek, Phan, Kelly, Lemoine, Fang, Preston, \& Tufts, 2010; Reitz, 2013), meaning that they are often unsuccessful in getting skilled jobs that match their qualifications. Moreover, immigrants are also underpaid: they get paid less than Canadian-born individuals for the same type of work (Dovidio \& Esses, 2001; Galarneau \& Morisette, 2004). Not surprisingly, unemployment rates vary depending on immigrants' country of origin. Higher unemployment rates than Canadian-born have been reported for immigrants from Asia (excluding Southeast Asia) and the Middle East, Latin America, Europe and Africa. The highest unemployment rate among very recent immigrants (5 years or less), 19.7\%, was reported for immigrants from Iran (Gilmore, 2009).

A variety of psychological factors can contribute to poor employment outcomes for certain immigrant groups, including situational ambiguity, perceptions of cultural dissimilarity, negative emotions, and stereotypes (Dovidio \& Esses, 2001; Stephan, Renfro, Esses, Stephan, \& Martin, 2005). For instance, if immigrants' foreign-based training introduces ambiguity regarding the quality of their credentials, this may result in skill devaluation among those who endorse modern (subtle) racist views (Esses, Dietz, \& Bhardwaj, 2006)

Interestingly, foreign training may be seen as an asset for job applicants who represent racial or religious majority (White, Christian), whereas for minority applicants it may be used as a justification for not hiring. This was true in relation to perceptions of skills of White, as opposed Chinese and East Indian, physicians trained in Singapore or other health professionals who were either Christian or Muslim trained in Cyprus (Esses, Dietz, Bennett-Abuayyash, \& Joshi, 2007). 
Employment audit studies provide further evidence of immigrant employment discrimination in Canada. For instance, Oreopoulos (2009) conducted an audit study in which he sent thousands of resumes in response to real job openings across multiple occupations in Toronto. In the resumes, he varied the names of applicants so that they sounded Chinese, Indian, Pakistani, or British. He also manipulated whether they were born in Canada or overseas, their education level, and proficiency in other languages. The results showed employment discrimination against applicants with Asian-sounding names or with foreign acquired experience. Very similar results were reported for audit studies conducted in the United States (Widner \& Chicoine, 2011) and Australia (Booth, Leigh, Varganova, 2010): ethnic minority candidates with Chinese, Middle Eastern, or Arabsounding names received significantly fewer invitations for an interview by employers than applicants with typically White-sounding names.

Therefore, there is considerable evidence that immigrants, especially ethnic minority immigrants, are more likely to experience discrimination at every step of employment from hiring to wage gaps, promotions, or being laid off. If immigrants are experiencing employment discrimination, the next question is: do they proceed with a formal complaint about the discrimination and if so, what are the outcomes of such claims?

\subsubsection{Claiming discrimination}

In some cases, former employees indeed make a decision to proceed with a formal complaint regarding their employment discrimination experiences. Goldman (2001) examined predictors of claiming discrimination by 439 terminated employees in the United States. Among other variables, social guidance - claimants receiving advice from their friends, family and coworkers that encouraged filing a discrimination claim - was one of the main predictors of actual filing. Interestingly, Whites were more likely to claim discrimination than racial minorities. This study demonstrates the importance of guidance and support from other individuals in promoting claims of discrimination, as well as suggesting that minorities, despite being more discriminated against, are less likely to complain about their experiences than are White individuals. 
What happens when ethnic and racial minorities decide to proceed with a formal complaint regarding employment discrimination? Even when they open a legal case on employment discrimination and the case is reviewed by a court, the actual outcome may not always be positive in terms of the court decision and job outcomes. To illustrate, a review of recent legal cases on racial discrimination in Canada demonstrated that the majority of complaints were related to treatment discrimination that happened after hiring (Al-Waqfi \& Jain, 2008). The authors argued that changes in employment equity policies and human rights legislation have been more effective against "access discrimination" (during hiring) than "treatment discrimination", which is more subtle and thus harder to eliminate. Moreover, already employed individuals can potentially lose more than those who are just applying for a job because of the risk of being laid off and the possibility of worsening relationships with coworkers and employers. This can make them more likely to accept the discriminatory treatment without complaint. Despite this, some employees who experience racial discrimination do proceed with legal action. In some cases, the outcomes of legal claims have not been positive: given an increasing number of complaints in public administration organizations, such cases took many years, if ever, to reach a settlement agreement (Al-Waqfi \& Jain, 2008). What is more concerning is that in a few examples, when former laid-off employees won legal cases and their employers were ordered to accept them back for the same position, they faced even more harassment and negative treatment from their bosses (Al-Waqfi \& Jain, 2008). Clearly, this legal evidence demonstrates that taking legal action to combat employment discrimination in some cases may indeed lead to a number of negative consequences for the claimant.

Many factors may contribute to such negative outcomes, including absence or presence of formal anti-discrimination policies, the immigrant's occupation and ethnic background, and so on. The present dissertation will address some of the gaps in research by examining psychological factors, such as attributions and personal responsibility, perceptions of deservingness of negative outcome and perceptions of job fit that may result in negative attitudes toward the discrimination claimant. 


\subsection{The Justification-Suppression Model of the Expression of Prejudice}

Previous research has demonstrated that the relation between attitudes and behaviour is complex, with relatively low correlation between the two at a given moment (Ajzen \& Fishbein, 2005; Wicker, 1969). That is, prejudice may not always be readily expressed and result in discrimination. Rather, the expression of prejudice depends on a number of factors, including context, individual differences, and other factors.

Many approaches exist to explain prejudice and discrimination in modern society. This research is based on a theoretical framework provided by the JustificationSuppression Model of the Expression of Prejudice (JSM; Crandall \& Eshleman, 2003). In this framework, Crandall and Eshleman have integrated many psychological approaches to prejudice that have received considerable empirical support (e.g., Dovidio \& Gaertner, 2004; Dovidio \& Hebl, 2005).

The JSM differentiates between "genuine" prejudice, which refers to the immediate affective evaluation of a group, and the manifestation of genuine prejudice through expression of bias. Psychological processes that cause genuine prejudice directly create negative affect toward groups. Family environment, direct cultural learning, social categorization and identity, group contact, and intergroup conflict (including intergroup competition) may directly cause prejudice (Crandall \& Eshleman, 2003).

The expression of prejudice is controlled by two processes, namely, suppression and justification. Oftentimes, individuals suppress their genuine prejudice, due to cultural norms, egalitarian values, and beliefs that promote social equality. Therefore, the assessment of prejudice and what we see in everyday life is the result of both the "genuine" prejudice and suppressive forces. At the same time, individuals are more likely to display discriminatory behaviour if it can be justified or rationalized (Crandall \& Eshleman, 2003). 


\subsubsection{Suppression of prejudice}

The JSM defines suppression as an attempt to reduce prejudice expression or awareness, which may be externally or internally motivated or controlled, and requires attention and mental energy (Crandall \& Eshleman, 2003). External motivation refers to social norms and standards that do not support prejudice expression or the presence of other individuals in a situation (Crandall \& Eshleman, 2003). Similar to Plant and Devine (1998), they propose that violations of external motivation to control prejudice may lead to feelings of frustration, anger, and external threat, whereas violations of own standards of nonprejudice may result in guilt and self-criticism.

The JSM conceptualizes suppression as a unitary concept, in that regardless of the source of motivation for suppression, the outcome is the same - non-prejudiced appearance, either for the self or others. Suppression helps individuals to maintain a nonprejudiced self-concept, which is important in contemporary society (Crandall \& Eshleman, 2003), as well as to deny prejudice in society, either directed to others or themselves. It results in favourable attitudes toward minorities; yet, despite such positive attitudes, racial discrimination and hate crimes still happen in our society. Moreover, a decline in self-reported of prejudice over the past decades may be explained by conformity to non-acceptance of prejudice and discrimination in the society rather than personal values and beliefs (Crandall, Eshleman, \& O’Brien, 2002).

People vary in the extent to which they are motivated to control their prejudiced reactions. Even though social categorization and attitude activation may be automatic, the degree of their expression depends on a level of willingness to inhibit these initial reactions. Fazio and Dunton (1997) examined how participants categorized photos of individuals who varied in race, gender, and occupation in terms of similarity. Participants with automatically activated racial attitudes paid more attention to race as opposed to gender or occupation when they viewed Black faces in the pictures. However, participants with higher motivation to control prejudice actively resisted using race as a basis of categorization. Likewise, automatically activated racial attitudes and race-related trait inferences get corrected in individuals with higher motivation to control prejudiced 
reactions; this applies to those with more negative and those with more positive attitudes (Olson and Fazio, 2004).

Dunton and Fazio (1997) found that when participants viewed pictures with Black faces, an interaction emerged between automatically activated attitudes and concern with acting prejudiced (a subscale of the Motivation to Control Prejudiced Reactions scale) when predicting modern racism scores. Specifically, in participants with lower concern with acting prejudiced, automatically activated attitudes and modern racism scores were more strongly related such that more negative automatically activated attitudes were related to higher modern racism scores. Concern with acting prejudiced did not play a role in participants with low or no automatically activated negativity in response to Black faces. However, participants with automatically activated negative attitudes demonstrated a different pattern, in that participants with low motivation to suppress prejudice did not inhibit their negativity and felt free to express their prejudice toward Blacks. At the same time, individuals who were more concerned with acting prejudiced inhibited their negative reactions and reported lower scores on modern racism scale. Thus, low prejudice as measured by modern racism scale can be reported by individuals with positive automatically activated attitudes but also by those who are highly concerned about acting prejudiced and therefore successfully inhibit their negative automatically activated reactions.

\subsubsection{Justification factors}

The JSM defines justification as a psychological or social process that can lead to the expression of genuine prejudice without external or internal punishment (Crandall \& Eshleman, 2003). Unlike genuine prejudice, which is primarily affective and nonverbal in nature, justifications are explanatory, meaning they explain why prejudicial behaviour is acceptable. Justifications can take many forms, such as social norms, ideologies, attributions, and beliefs. Justifications that are the most relevant for the present research are reviewed below. 


\subsubsection{Attributions and personal responsibility}

Attributions are defined as causal judgments about why a particular event or behaviour has happened (Heider, 1958). Several models of motivation and behaviour stress the importance of attributions of control and personal responsibility for outcomes in predicting attitudes and behaviours toward an individual in question (Hewstone, 1990; Kaiser, Dyrenforth, \& Hagiwara, 2006; see Rudolph, Roesch, Greitemeyer, Weiner, 2004 for a review).

Interestingly, discrimination attributions are interpersonal in nature, and involve both a claimant and an audience (Kaiser, Dyrenforth, \& Hagiwara, 2006). For a discrimination claimant, such attributions may be an example of both internal (a cause related to one's social identity) and external attributions (external cause related to another's prejudice; Kaiser, Dyrenforth, \& Hagiwara, 2006). It means that when individuals explain negative outcomes such as unemployment, lower salary, or not being promoted by attributing these outcomes to discrimination, such explanations involve their identity as out-group members, and negative attitudes toward their group in society. Explaining the cause of failure as due to others' prejudice rather than one's own actions may be beneficial for members of minority groups because it can help to maintain their self-esteem (Crocker \& Major, 1989; Major, Kaiser, \& McCoy, 2003).

At the same time, how does the audience perceive and react to discrimination claims made by out-group members? Clearly, attributions to discrimination are interpersonally costly: individuals who claim being discriminated against may risk being labeled as hypersensitive, emotional, and unlikeable (Feagin \& Sikes, 1994), which may harm their social and professional relationships (Haslett \& Lipman, 1997). Individuals who blame their failures on discrimination are perceived as unable to take responsibility for outcomes compared to those who blame their failure on themselves (Garcia, Horstman Reser, Amo, Redersdorff, \& Branscombe, 2005). For instance, in a study by Kaiser and Miller (2001), White participants read a vignette about a Black student who attributed his low test grade either to discrimination, poor answer quality (an internal attribution), or the difficulty of the test (an external attribution). A student 
who made an attribution to discrimination was derogated more (e.g., perceived as a troublemaker), and seen as less likeable than when he attributed his grade to his answer quality or test difficulty.

How do perceptions of controllability relate to prejudice and discrimination? The JSM views attributions of control and judgments of responsibility as justifications of expressed prejudice and discrimination. In other words, the judgment that an individual is responsible for his or her fate helps to justify and thus leads to the expression of prejudice (Crandall \& Eshleman, 2003).

To explain why attributions of responsibility help to release prejudice, Crandall and Eshleman (2003) use Heider's (1958) concept of perceptual unit. They argue that an attribution of controllability and responsibility converts a person and an outcome into a single perceptual unit. Therefore, a perception of an individual or a group as responsible for the outcome reflects their character: in the case of a negative outcome they become bad, perceived as deserving of their fate and, thus, prejudice and discriminatory treatment become justified.

As an example, in a study on attitudes toward stigmatized groups, Hegarty and Golden (2008) first assessed participants' prejudice levels, then manipulated their attributions through information regarding stigmatized traits, namely homosexual orientation, obesity, depression, and alcoholism. After that participants wrote down their thoughts about what they just read to assess their attributional thinking. In line with the JSM, participants who were initially prejudiced listed more thoughts related to perceptions of controllability of stigmatized conditions.

\subsection{Group membership and attributions}

Does it matter who the claimant of discrimination is in terms of his or her group membership? Can biases toward out-groups reveal themselves in causal attributions and behaviours? In fact, in-group members give themselves credit for positive acts, and make less internal attribution for negative acts; they also attribute out-group failure to lack of ability (Hewstone, 1990). Furthermore, causal attributions vary depending on the status 
of a particular out-group in a society: some groups may be blamed more for their unfortunate outcomes than others. For example, welfare recipients are blamed more and seen as more responsible for their impoverished state and thus elicit more negative reactions than poor people (Henry, Reyna, \& Weiner, 2004).

In Canada, Jackson and Esses (1997) have demonstrated that for such social groups as Native Canadians, homosexuals, single mothers and students, higher attributions of personal responsibility for unemployment predicted higher endorsement of a belief that the target group members should change themselves in order to solve their problem and deserve less help in the form of empowerment. Empowerment refers to the creation of programs that would help individuals to solve the unemployment problem by themselves, such as provision of small business incentives.

Therefore, attributions of personal responsibility and controllability may depend on the target's group membership. However, it still remains unclear whether this type of relation is applicable to such out-groups as skilled immigrants of various ethno-cultural backgrounds as perceived by Canadian-born individuals.

In addition, a covering justification helps to release genuine prejudice when an alternative plausible motivation that is personally or socially acceptable is available. Situational ambiguity is an example of a covering justification; in this case, discriminatory behavior can be construed as an action that is neutral, socially acceptable, or benevolent. Situational ambiguity removes the need to suppress prejudice because ambiguity essentially makes a wide range of responses acceptable (Crandall \& Eshleman, 2003; Gaertner \& Dovidio, 1986). Thus, ambiguity regarding immigrant qualifications may plausibly explain the expression of negative behaviours toward them.

\subsubsection{Belief incongruence}

Another justification that may be used to explain discriminatory treatment is a belief incongruence, which is based on the assumption of dissimilarity, or the belief that attitudes, norms, and values of some immigrants are different from those of Canadians. Skills of immigrants from dissimilar cultures may be perceived as less valuable compared 
to skills of immigrants from similar cultures (e.g., Western Europe) and Canadian-born applicants (Esses et al., 2006). Along these lines, Kaiser, Dyrenforth, and Hagiwara (2006) demonstrated a relation between system-justifying beliefs and negative attitudes toward Blacks who blamed negative events on discrimination, but not with negativity toward Blacks who blamed negative events on other causes. Moreover, the effect of system-justifying beliefs on negative attitudes toward Black discrimination claimants was mediated by perceptions that the claimant held dissimilar values and the claimant failed to take personal responsibility for outcomes. These results are in line with the JSM in that perceptions of dissimilarity and judgments of personal responsibility justified negative attitudes toward discrimination claimants.

Based on these findings, it would be logical to expect that members of dissimilar out-groups would elicit more prejudice when they try to voice complaints about unfair treatment, especially when the situation is ambiguous and can be interpreted against them in a socially acceptable way.

\subsection{The current research}

Studies to date provide considerable evidence regarding more negative perceptions of complaints about discrimination compared to other explanations of negative outcomes, such as poor answer quality, difficulty of the test (Kaiser, Dyrenforth, \& Hagiwara, 2006; Kaiser \& Miller, 2001, 2003), or making an internal attribution (Garcia, Horstman Reser, Amo, Redersdorff, \& Branscombe, 2005). That is, previous studies evaluated responses to a variety of types of attributions (internal, external, as opposed to discrimination).

However, most of this research has been conducted in the United States and thus focused on evaluations of such complaints voiced by African Americans. There has been a relative paucity of research that has evaluated Canadians' attitudes toward complaints about unfair treatment voiced by immigrants. Going one step further, instead of varying types of attributions, it would be interesting to see whether reactions to the same 
attribution - claiming discrimination- would vary depending on who makes such claims. This raises some interesting questions.

First, based on the evidence of negative attitudes toward and existing employment discrimination toward certain immigrant groups, it would be logical to expect that members of immigrant out-groups that are perceived as more dissimilar to Canadians would elicit more prejudice even when they try to voice complaints about unfair treatment, especially when a situation is ambiguous and can be interpreted against them in a socially acceptable way.

Next, the role of an immigrant's generation - that is, whether the individual was born in Canada or the children of immigrants - in Canadians' attitudes and discriminatory tendencies remains unexplored. For the purposes of this dissertation, second-generation refers to immigrant children who were born in Canada from parents who immigrated here. Despite the fact that they get exposed to and raised in the Canadian mainstream culture, the economic and employment outcomes of certain groups are comparable or in some cases even worse than those of their parents (Hou \& Coulombe, 2010; Skuterud, 2010). Therefore, in some cases, second-generation immigrants also face biases and experience employment discrimination. At the same time, because they were born and raised in Canada, they might be perceived as less dissimilar to Canadians in terms of cultural values, norms and beliefs. As a result, they might be seen as members of the ingroup, which might lead to more positive attitudes and lower discriminatory tendencies, compared to the first-generation immigrants of a culturally dissimilar background.

Finally, the present research looks at factors that may contribute to and explain these attitudes, including perceptions of discrimination, attributions of personal responsibility for the outcome, and perceptions of similarity. Thus, the current research extends the previous research by using immigrants of various ethno-cultural backgrounds and generations as target groups, and by exploring possible mechanisms that may explain prejudicial attitudes toward immigrants who claim employment discrimination.

Study 1 examines perceptions of an immigrant from a similar culture (Britain), dissimilar culture (Iran), and a second generation Canadian of a dissimilar culture (Iran) 
who claims employment discrimination in terms of attitudes, attributions of personal responsibility, and behavioural intentions. Study 2 extends the first study by exploring perceptions of discrimination and perceptions of similarity with the claimant as potential mediators. It also evaluates the role of an individual difference - motivation to control prejudiced reactions - as a potential moderator of the relation between country of origin of the claimant and main outcomes. In addition to the country of origin, Study 3 manipulated attributions for discrimination. To do so, in addition to an ambiguous condition, Study 3 added two other conditions that provided explanations for the claimant's contract termination - one that could be considered internal to the claimant and the other external. 


\section{Chapter 2}

\section{Study 1}

Study 1 examined whether Canadians' attitudes towards immigrants who claim that they have been discriminated against at work depend on immigrants' country of origin and generation. It also explored factors that may contribute to these attitudes, particularly attributions of personal responsibility. In line with prior research (Crandall \& Eshleman, 2003; Kaiser, Dyrenforth, \& Hagiwara, 2006; Kaiser \& Miller, 2001), it was expected that:

1. There would be a difference in perceptions of an immigrant applicant claiming discrimination as a function of similarity of culture. Specifically, an immigrant from a dissimilar culture (Iran) would be derogated more, and perceived as more personally responsible and deserving the treatment than an immigrant from a similar culture (Britain) or a second generation Iranian Canadian immigrant.

2. Attributions of personal responsibility would mediate the effect of country of origin on attitudes toward the discrimination claimant. Specifically, it was hypothesized that perceptions of responsibility would account for the relation between the immigrant's country of origin and target derogation and outcome deservingness. In other words, a claimant who was perceived as more personally responsible for the negative outcome would be more derogated and seen as more deserving of the outcome.

\subsection{Method}

\subsubsection{Participants and design}

A sample of first year Canadian-born introductory psychology students $(N=78)$ was invited through the online sign-up system to take part in a laboratory study looking at media perceptions. Participants ranged in age from 17 to 31 years $(M=18.63, S D=$ 2.69), with $53.8 \%$ being female. The majority of participants $(76.9 \%)$ were of White 
ethnic background, thus representing the general population in the area. In addition, 9.0\% of participants were Asian, 9.0\% East Indian, 3.8\% Black, and 1.3\% Hispanic. Participants were randomly assigned to one of three experimental conditions, which manipulated the country of origin of the claimant: Britain $(N=24)$, Iran $(N=27)$, or a second-generation immigrant from $\operatorname{Iran}(N=27)^{1}$. Due to an interval level of measurement for the main outcome variables, the effect of experimental conditions on the main outcomes was analyzed using a one-way ANOVA between-subjects design. Participants received 1\% credit toward their final introductory psychology grade for the study lasting approximately 45 minutes of their time.

\subsubsection{Materials and Procedure}

Prior to data collection, the study was approved by the University of Western Ontario, Department of Psychology Research Ethics Board (see Appendix C). Participants were invited to participate in a study on "Media perceptions". They were told that they would be asked to read a recently published article randomly selected from a pool of articles on social issues, and answer a number of questions related to the article.

After completing an informed consent form (Appendix A), participants were asked to read one of three fictitious newspaper articles describing a claim of employment-related discrimination by an individual (see Appendix B). The text of the article was identical, including the name of the main character (Sam Barzun), except the first sentence which stated the immigrant's country of origin: he was either a recent immigrant from Britain, Iran, or born in Canada to parents who immigrated from Iran 30 years ago. The claimant's photograph was also identical; it was in black and white, with a face of a young gentleman looking down. The picture of the claimant was unclear in terms of his ethnicity. The article described a young individual who just finished his undergraduate studies and got a position in a management trainee program in the Links

\footnotetext{
${ }^{1}$ A fourth condition, Canadian claimant, was initially included. Due to evidence of confusion about this condition and very high variability in responses, the data collection for this condition was discontinued and it was excluded from further analyses.
} 
Company in Burlington, Ontario. At the beginning, the program director was satisfied with him and he successfully passed the first two evaluations. Later on, however, he started to get remarks regarding missing the training and being late on several occasions. Although he put a lot of effort into the training, the director was not happy with him, evaluated him unfavourably and terminated his contract. At the end of the article, Sam claimed that he experienced discrimination. The story was ambiguous and inconclusive to increase the chances of the expression of prejudicial attitudes if participants held such attitudes, and support the reliance on stereotypes related to immigrant groups based on the perceived ethnic background of the claimant. Upon completion of the article, participants were asked to complete the dependent measures to assess their reactions to the article and their perceptions of the individual in question. Finally, participants were fully debriefed regarding the purpose of the study (Appendix D).

\subsubsection{Measures}

\subsubsection{Perceptions of claimant's ethnic/racial background}

Participants answered the question: "Which of the following best describes Sam's racial background?", with the following options provided: White, Asian, Black, Latin American, Arab, East Indian, other (please specify). Participants selected the one item that they thought best reflected the claimant's background. Frequencies of selected choices were used in subsequent analyses (Appendix C).

\subsubsection{Manipulation check}

To assess whether participants perceived the trainee as blaming his outcome on discrimination, participants answered a statement "The trainee blamed termination of his employment on discrimination", on a 7-point Likert scale with options ranging from strongly disagree (1) to strongly agree (7). The variable served as a manipulation check to determine whether participants noticed that the trainee blamed his termination on discrimination. 


\subsubsection{Perceptions of discrimination in the situation}

Perceptions of discrimination in the situation was assessed with two items that I developed for this research, using a 7-point Likert scale running from strongly disagree (1) to strongly agree (7): "Please indicate the extent to which the program director discriminated against the trainee", and "Please indicate the extent to which you personally believe the trainee experienced discrimination", from not at all (1) to extremely (7). Mean scores were calculated, with higher scores indicating higher perceptions of discrimination (Cronbach's $\alpha=.91$ ).

\subsubsection{Perceived similarity in values}

Perceived similarity in values was measured with the Connectedness Among Nations Scale (Matheson \& Cole, 2007). The scale assesses perceptions of commonalities in values between Canadians and 15 national groups (e.g., Australians, Israelis, Iranians, British, North Koreans), ranging from nothing at all in common (1) to a lot in common (7). Higher scores reflect more perceived similarity in values. The scores of two national groups that were of particular interest for this study- British and Iranians- were analyzed to assess the perceived difference in values from Canadians.

\subsubsection{Target derogation}

Participants completed a six-item scale (Kaiser \& Miller, 2001, 2003) to assess willingness to derogate the claimant, i.e., perceive him as emotional, irritating, hypersensitive, complainer, trouble maker, and argumentative. Responses ranged from not at all (1) to extremely (7). Mean scores were calculated, with higher numbers representing higher derogation (Cronbach's $\alpha=.84$ ).

\subsubsection{Outcome deservingness}

Outcome deservingness was assessed with a scale that consisted of three items developed for the current research, e.g., "Do you agree or disagree that the trainee got what he deserved?". Responses ranged from strongly disagree (1) to strongly agree (7). 
Mean scores were calculated, with higher scores indicating a higher perception of outcome deservingness (Cronbach's $\alpha=.82$ ).

\subsubsection{Attributions of personal responsibility}

Participants completed a five-item scale (modified from Kaiser et al, 2006) to assess perceptions of claimant's control and responsibility for the negative outcome, e.g., "The trainee should have taken more personal responsibility for the negative outcome described in the article." Responses ranged from strongly disagree (1) to strongly agree (7). Mean scores were calculated, with higher scores indicating a higher perception of personal responsibility (Cronbach's $\alpha=.82$ ).

\subsubsection{Support of government policy to protect immigrant victims of discrimination}

Participants answered one item developed for the current research, "If you were asked to sign a petition in support of government policies to protect immigrant victims of discrimination, would you sign it?", with responses ranging from would definitely not sign it (-4) to would definitely sign it (+4). The answers were recoded to a Likert-type scale ranging from 1 to 9 , where higher scores indicate more support for the government policy.

\subsection{Results}

\subsubsection{Gender effects}

Participants' gender did not affect any dependent measures and thus was not included further in the description of results.

\subsubsection{Perceptions of claimant's ethnic background}

Given that perceptions of claimant's ethnic background represented categories, frequencies of perceived ethnicities were calculated for each experimental condition. After that, the differences between conditions were examined using a chi-square test. 
Table 1 presents the frequencies of the claimant's perceived ethnic background as a function of condition. It is evident that these perceptions varied as a function of his country of origin as indicated in the article. In particular, when the claimant was from Iran, he was perceived mostly as Arab and East Indian and as being of an other ethnicity in two cases ${ }^{2}$. When he was from Britain, he was perceived again of being of Arab and East Indian background, but also as being White or Latin American. The background of the Iranian Canadian claimant was predominantly Arab or East Indian, with a few cases of other perceived background.

To ascertain whether the difference in the perceived ethnic background as a function of country of origin was present, a Likelihood Ratio test was utilized instead of a Pearson chi-square test due to a small sample size. It indicated that indeed there was a significant association between the perceived ethnic background of the claimant and his country of origin as indicated in the article, $X^{2}(8)=30.20, p<.001$, Cramer's $v=.423$. A follow-up post-hoc test revealed that when participants were reading about the immigrant from Britain, he was perceived as being of the European/North American background more frequently than would be expected by chance, $z(78)=2.8, p<.01$.

\footnotetext{
2 It should be noted though that the ethnic background of Iranians is not Arabic but is Persian (Hassan,
} 2007). Nonetheless, the general idea that the claimant would be seen as Middle Eastern was supported. 
Table 1

Frequencies of Perceptions of Claimant's Ethnic Background as a Function of Country of Origin

\begin{tabular}{|c|c|c|c|}
\hline Condition & Ethnic Background & Count & Percent \\
\hline \multirow[t]{4}{*}{ Britain } & East Indian & 9 & 37.5 \\
\hline & Arab & 8 & 33.3 \\
\hline & White & 5 & 20.8 \\
\hline & Latin American & 2 & 8.3 \\
\hline \multirow[t]{3}{*}{ Iran } & Arab & 20 & 74.1 \\
\hline & East Indian & 5 & 18.5 \\
\hline & Other & 2 & 7.4 \\
\hline \multirow[t]{3}{*}{ Iranian Canadian } & Arab & 14 & 51.9 \\
\hline & East Indian & 7 & 25.9 \\
\hline & Other & 6 & 22.2 \\
\hline
\end{tabular}




\subsubsection{Correlations between the outcome variables}

Table 2 presents Pearson's bivariate correlations between the outcome variables. The main outcomes - perceptions of discrimination, target derogation, outcome deservingness, and attributions of personal responsibility- were moderately to strongly related to each other. As expected, perceptions of discrimination were negatively associated with the other outcomes. 
Table 2

Bivariate Correlations Between Outcome Variables $(N=78)$

\begin{tabular}{lccc}
\hline Dependent Variable & 1 & 2 & 3 \\
\hline 1 Perceptions of Discrimination & - & & \\
2. Target Derogation & $-.47^{* * *}$ & - & - \\
3. Outcome Deservingness & $-.72^{* * *}$ & $.47^{* * *}$ & $.65^{* * *}$ \\
4. Personal Responsibility & $-.65^{* * *}$ & $.42^{* * *}$ & \\
\hline
\end{tabular}

Note. $* p<.05, * * p<.01, * * * p<.001$. 


\subsubsection{Manipulation check}

A one-way between-subjects ANOVA was conducted on the question regarding whether the trainee blamed the termination of his employment on discrimination. As seen in Table 2, the claimant from Iran was perceived as blaming his termination on discrimination more than the second-generation Iranian-Canadian; the claimant from Britain did not differ from the Iranian or Iranian Canadian claimants.

\subsubsection{Perceptions of discrimination in the situation}

To examine the effect of condition on perceptions of discrimination, a one-way betweensubjects ANOVA was conducted on the perception of discrimination. As seen in Table 3, the claimant from Iran was perceived as less discriminated against than the secondgeneration Iranian-Canadian. The British claimant fell between the ratings for the claimant from Iran and the Iranian Canadian so that he did not differ from either.

\subsubsection{Perceived similarity in values}

To find out whether perceptions of value similarity to Canadians differ between British and Iranians, one-sample t-tests were conducted because they allowed me to test whether the sample means for British and Iranians were significantly different from the value for Canadians, which was assumed to be the maximum score (7). To do that, the values for British $(M=5.76, S D=.96)$ and Iranians $(M=3.00, S D=1.07)$ were compared to the maximum score (7). Both British, $t(77)=-11.49, p<.001$, and Iranians, $t(77)=-33.05$, $p<.001$, were perceived as holding different values than Canadians. Moreover, the difference in perceptions of value difference between British and Iranians was also significant, $t(77)=19.16, p<.001$. These results show that indeed there is a perceived value difference between Canadians, British, and Iranians, with higher perceptions of difference for Iranians. 


\subsubsection{Main outcome variables}

To determine the effect of condition on target derogation, outcome deservingness, attributions of personal responsibility, and support for the government policy to protect immigrant victims of discrimination, one-way between-subjects ANOVAs were conducted with country of origin as a between-subjects factor. All main effects were statistically significant. Follow-up post-hoc analyses with Bonferroni correction for each of the dependent variables indicated that as predicted, the claimant from Iran was derogated more, was perceived as more deserving of job termination, and was seen as more personally responsible for the situation than was the second generation Iranian Canadian immigrant, with the claimant from Britain again often falling in between the two (see Table 3). The immigrant from Iran also elicited less support for the government policy to protect immigrant victims of discrimination than the British immigrant (see Table 3). Thus, the results supported Hypothesis 1 in that the claimant from Iran elicited more negative attitudes than the second generation Iranian Canadian claimant, and than the claimant from Britain in terms of attributions of personal responsibility and behavioural tendencies. At the same time, no support was found for more favourable attitudes toward the claimant from Britain in terms of target derogation and outcome deservingness. 
Table 3

Descriptive Statistics (M, SD), F-tests, and $\eta^{2}$ of Perceptions of Discrimination in the Situation and the Main Outcome Variables

\begin{tabular}{|c|c|c|c|c|c|}
\hline \multirow[t]{3}{*}{ Dependent Variable } & \multicolumn{3}{|c|}{ Country of Origin } & \multirow{3}{*}{$F$} & \multirow{3}{*}{$\eta^{2}$} \\
\hline & Britain & Iran & Iranian Canadian & & \\
\hline & $(M, S D)$ & $(M, S D)$ & $(M, S D)$ & & \\
\hline \multirow[t]{2}{*}{ Manipulation Check } & $6.17_{\mathrm{ab}}$ & $6.59 \mathrm{a}$ & $5.25 \mathrm{~b}$ & $5.41 * *$ & .128 \\
\hline & $(.98)$ & $(1.01)$ & $(2.17)$ & & \\
\hline Perceived & $3.65_{\mathrm{ab}}$ & $3.09 \mathrm{a}$ & $4.20_{b}$ & $4.69 *$ & .111 \\
\hline Discrimination & $(1.08)$ & $(1.31)$ & $(1.55)$ & & \\
\hline \multirow[t]{2}{*}{ Target Derogation } & $3.60_{\mathrm{ab}}$ & $4.10_{\mathrm{a}}$ & $3.23 \mathrm{~b}$ & $5.33 * *$ & .124 \\
\hline & $(.98)$ & $(1.03)$ & $(.94)$ & & \\
\hline \multirow[t]{2}{*}{ Outcome Deservingness } & $3.42_{\mathrm{ab}}$ & $4.00_{\mathrm{a}}$ & $3.10_{b}$ & $4.83 *$ & .114 \\
\hline & $(1.09)$ & $(.95)$ & $(1.18)$ & & \\
\hline \multirow[t]{2}{*}{ Personal Responsibility } & $3.98 \mathrm{a}$ & $4.75 b$ & $3.84 \mathrm{a}$ & $7.38 * * *$ & .164 \\
\hline & $(.95)$ & $(.85)$ & $(1.00)$ & & \\
\hline \multirow{2}{*}{$\begin{array}{l}\text { Support of Government } \\
\text { Policy }\end{array}$} & $8.25 \mathrm{a}$ & $6.52_{b}$ & $7.70_{\mathrm{ab}}$ & $6.01 * *$ & .138 \\
\hline & $(1.07)$ & $(2.75)$ & $(1.07)$ & & \\
\hline
\end{tabular}


Note. Scores ranged from 1 to 7, except for support of government policy which ranged from 1 to 9 , with higher scores indicating higher endorsement of scales' items. $* p<.05$, $* * p<.01, * * * p<.001$.

\subsubsection{Mediational analysis}

To test the second hypothesis, a series of mediational analyses using bootstrapping procedures (Hayes, 2009; Preacher \& Hayes, 2004) was performed to assess whether attributions of personal responsibility would explain the effects of country of origin. For these analyses, the MEDIATE SPSS macro (Hayes \& Preacher, 2014) was used because it handles mediation with multicategorical predictor variables, along with generation of bootstrap confidence intervals for indirect effects. Bootstrapping has been recommended as a valid and powerful method for testing intervening variable effects (Hayes, 2009), in part because it is a non-parametric method based on resampling with replacement, and this does not require a normal data distribution.

To perform the mediation analyses, two dummy variables were created from the three-level country of origin variable, wherein the claimant from Iran was used as a reference category. Thus, in the analyses, British and Iranian Canadian claimants were compared to the claimant from Iran.

\subsubsection{Target derogation}

The direct effect of country of origin on target derogation was significant for the Iranian Canadian claimant, $\beta=-.87, S E=.27, t(75)=-3.26, p=.0017$. However, the direct effect was not significant for the British claimant, $\beta=-.49, S E=.28, t(75)=-1.80, n s$; for this reason, it was not further investigated.

At the next step, Iranian Canadian as a country of origin significantly predicted the mediator (perceived responsibility), $\beta=-.91, S E=.25, t(75)=-3.58, p=.0006$. In turn, the mediator (attributions of personal responsibility) positively predicted target derogation, $\beta=.34, S E=.12, t(74)=2.98, p=.0039$. With the inclusion of attributions 
of personal responsibility in the model, the effect of country of origin on target derogation remained significant, $\beta=-.56, S E=.28, t(74)=-2.02, p=.047$, though weaker. Finally, the indirect effect of attributions of personal responsibility was significant, $\beta=-.31, S E=.14,95 \% \mathrm{CI}(-.67,-.09)$.

To rule out the possibility of the outcome "causing" the mediator, the mediator (attributions of personal responsibility) and the dependent variable (target derogation) were switched, so that target derogation served as a mediator between the country of origin and attributions of personal responsibility. With the inclusion of target derogation in the model, the effect of country of origin on attributions of personal responsibility stayed significant for the Iranian Canadian claimant, $\beta=-.64, S E=.26, t(74)=-2.48, p=$ .0155 . The indirect effect was significant, $\beta=-.27, S E=.13,95 \% \mathrm{CI}(-.59,-.07)$. Therefore, the results provided evidence for partial mediation in both directions for the Iranian Canadian claimant as compared to the claimant from Iran (see Figure 1). 


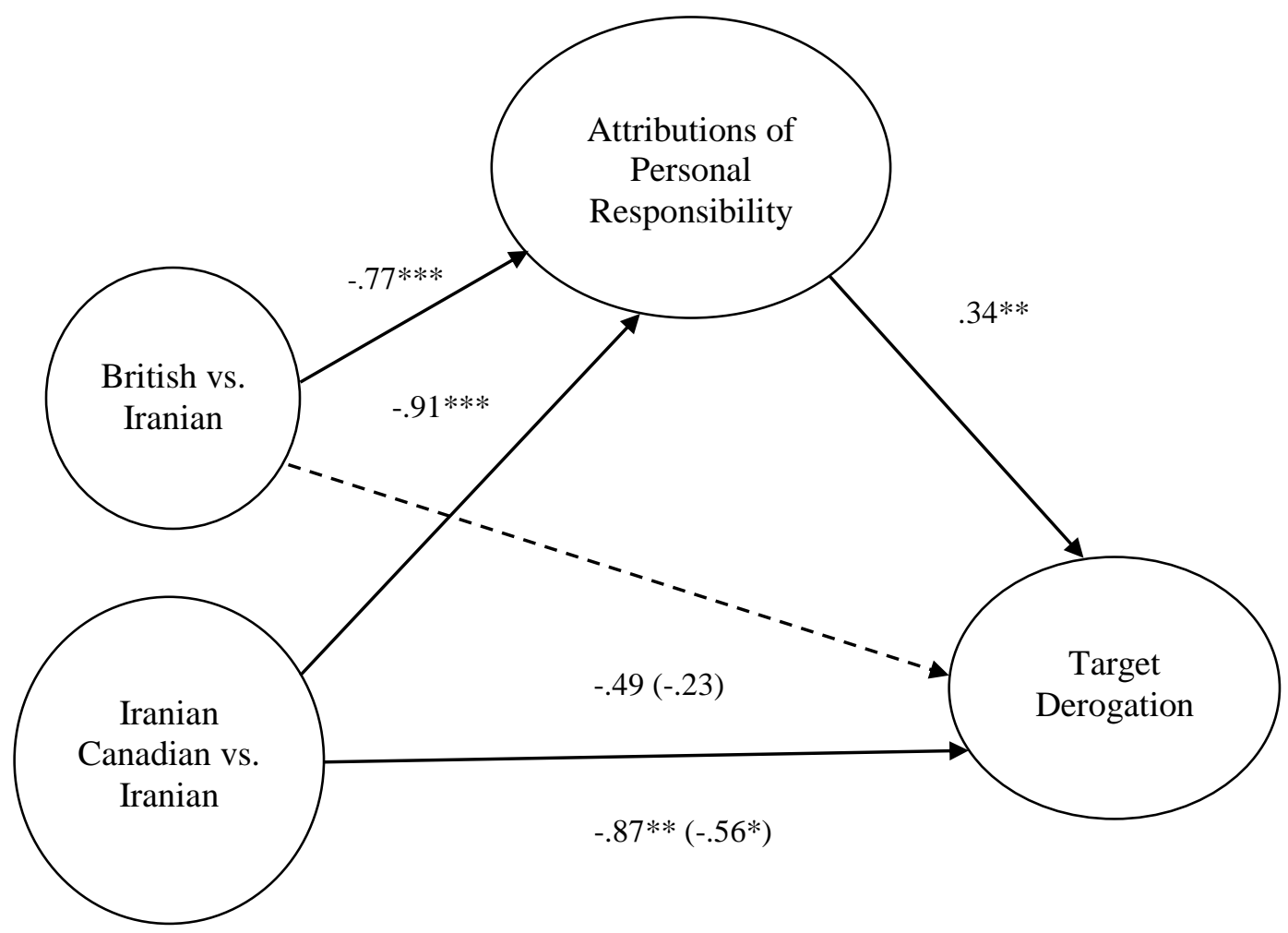

Figure 1: Mediational effects of country of origin on target derogation through attributions of personal responsibility

$* p<.05, * * p<.01, * * * p<.001$ 


\subsubsection{Outcome deservingness}

The direct effect of country of origin on outcome deservingness was significant for the Iranian Canadian claimant, $\beta=-.90, S E=.29, t(75)=-3.07, p=.003$. However, the direct

effect was not significant for the British claimant, $\beta=-.58, S E=.30, t(75)=-1.91, p=$ .060 ; for this reason, it was not further investigated.

Next, Iranian Canadian as a country of origin significantly predicted the mediator (perceived responsibility), $\beta=-.91, S E=.25, t(75)=-3.58, p=.0006$. In turn, the mediator (attributions of personal responsibility) positively predicted outcome deservingness, $\beta=.70, S E=.11, t(74)=6.53, p=.0001$. With the inclusion of attributions of personal responsibility in the model, the effect of country of origin on outcome deservingness became non-significant, $\beta=-.27, S E=.25, t(74)=-1.04, n s$. The indirect effect of attributions of personal responsibility was strongly significant, $\beta=-.64$, $S E=.20,95 \%$ CI $(-1.08,-.29)$.

Testing the association in the opposite direction revealed that with the inclusion of outcome deservingness in the model, the effect of country of origin on attributions of personal responsibility remained significant, $\beta=-.44, S E=.22, t(74)=-2.03, p=.046$. The indirect effect was significant, $\beta=-.47, S E=.18,95 \% \mathrm{CI}(-.86,-.16)$. Therefore, the results supported the direct mediation model wherein attributions of personal responsibility explained the effect of country of origin on outcome deservingness for the Iranian Canadian claimant as compared to the claimant from Iran (see Figure 2). 


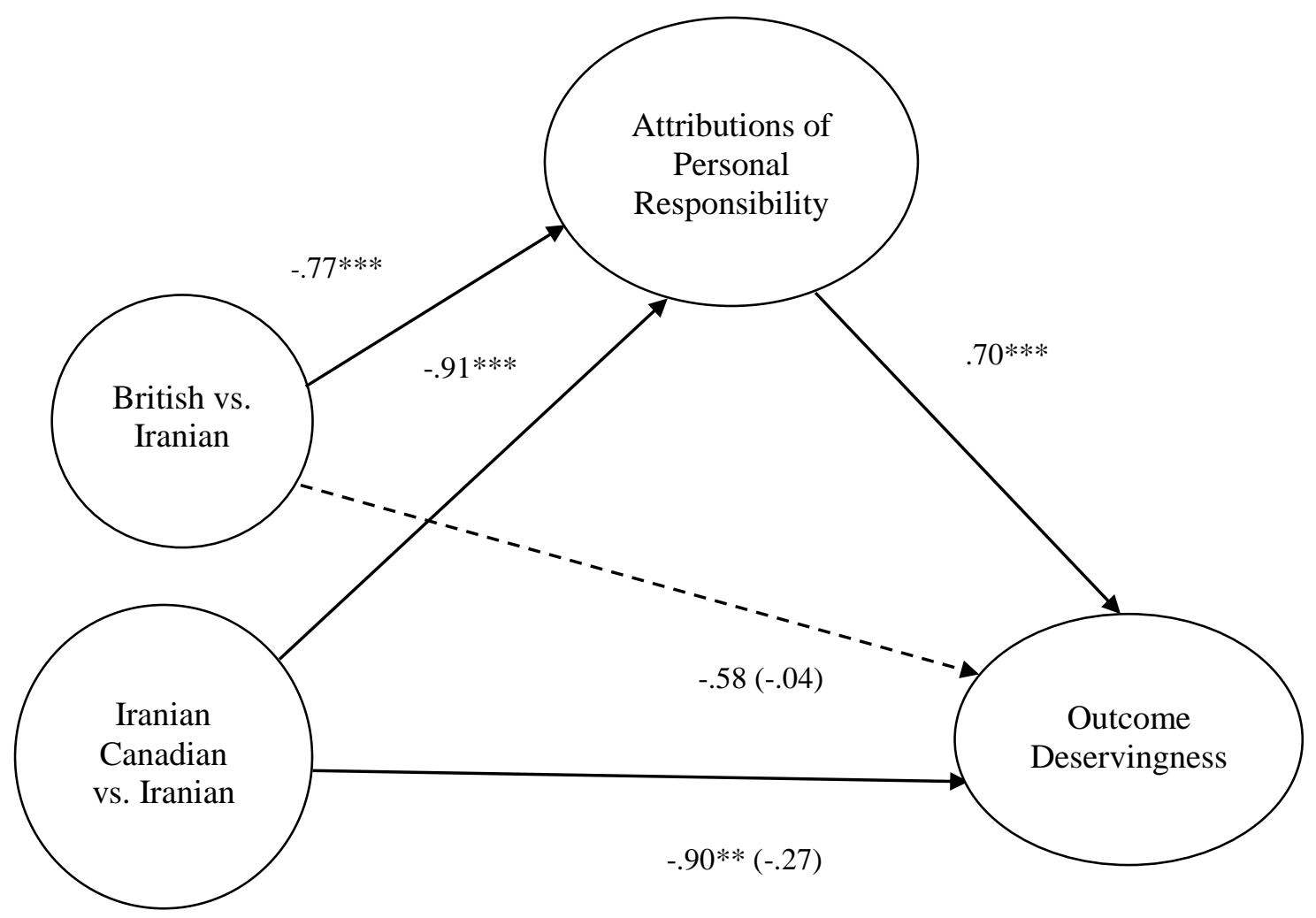

Figure 2: Mediational effects of country of origin on outcome deservingness through attributions of personal responsibility.

$* p<.05, * * p<.01, * * * p<.001$ 


\subsubsection{3}

\subsubsection{Support of government policy}

Attributions of personal responsibility did not mediate the relationship between the country of origin and support of government policy, due to a non-significant association between the proposed mediator (perceived responsibility) and the outcome (support of government policy), $\beta=-.27, S E=.23, t(75)=-1.19, n s$.

\subsection{Discussion}

Study 1 examined the effects of country of origin on attitudes toward discrimination claimants and behavioural intentions. The JSM (Crandall \& Eshleman, 2003) and previous research on attributions and attitudes toward individuals who claim discrimination (Hewstone, 1990; Kaiser, Dyrenforth, \& Hagiwara, 2006; Kaiser \& Miller, 2001, 2003) suggested that situational ambiguity, attributions of personal responsibility, and perceived difference in values might help to release prejudice and discriminatory tendencies toward certain out-groups. As these studies were conducted in the US, they often focused on African Americans as an out-group of interest.

Taking into account the Canadian context, Study 1 focused on discrimination claimants who were either from a presumably similar culture (Britain), dissimilar culture (Iran) or were born and raised in Canada (Iranian Canadian). As expected, participants perceived the ethnic background of the Iranian and the Iranian Canadian as either Arab or East Indian. In the case of the immigrant from Britain, participants selected a wider range of ethnicities, including White and Latin American. Moreover, in their comments at the end of the study, participants indicated that the article was inconclusive and vague, and it was hard to draw conclusions based on the content. Therefore, the article served its purpose well.

It was expected that the claimant from a dissimilar culture (Iran) would elicit more negative attitudes would be perceived as less discriminated against, more deserving of termination, personally responsible for the outcome, derogated more, and elicit less 
support for a government policy to protect immigrant victims of discrimination than the claimant from Britain or the Iranian-Canadian. The results partially supported this hypothesis. Indeed, the claimant from Iran was perceived as less discriminated against, derogated more, and more deserving of job termination than the second generation Iranian Canadian immigrant, and more personally responsible for the situation than the second generation Iranian Canadian immigrant and British immigrant. However, contrary to hypothesis, the reactions to the Iranian and British immigrants often did not differ significantly. One possible reason is that both Iranians and British were perceived as holding different values than Canadians, and the majority of participants perceived the ethnic background of the claimant from Britain as Arab or East Indian. Consequently, although he immigrated from Britain, in many cases he may have elicited negative attitudes similar to the claimant from Iran based on his ethnic background. Furthermore, as predicted, the claimant from Iran was also perceived as more personally responsible for the outcome than the second-generation Iranian Canadian and the claimant from Britain. He also elicited less support for government policies than the British claimant.

In line with the second hypothesis, Study 1 demonstrated that the relations between claimant's country of origin and target derogation and outcome deservingness may be explained by attributions of personal responsibility. Although in the case of target derogation there was evidence of partial mediation and the effects seem to be bidirectional, the results conceptually fit the previously proposed model wherein personal responsibility for the situation is an important mediator of other effects. Therefore, these results are in line with the JSM and research on the role of personal responsibility in attitudes toward discrimination claimants (Kaiser, Dyrenforth, \& Hagiwara, 2006; Kaiser \& Miller, 2001, 2003), in that attributions of responsibility may have served as a justification for prejudice against the claimant from Iran, as he was seen as more personally responsible for termination, and therefore these attributions might have been used as an explanation for why he indeed deserved to be terminated from the job and derogated. There was no evidence of attributions of personal responsibility mediating the relationship between claimant's country of origin and support of government policy to protect immigrant victims of discrimination. 


\section{Chapter 3}

\section{Study 2}

Study 2 explored other possible explanations of negative attitudes toward the claimant from Iran. Specifically, it examined whether perceived similarity with the claimant of discrimination would play a role in attitudes toward discrimination claimants. Finally, Study 2 assessed the role of individual differences, namely motivation to control prejudiced reactions.

It was expected that:

1. There would be a main effect of country of origin on perceptions of the discrimination claimant. An immigrant from Iran would be derogated more, and perceived as more personally responsible and deserving the treatment than an immigrant from Britain or a second generation Iranian Canadian immigrant.

2. Perceptions of discrimination in the situation, perceptions of similarity, and attribution of personal responsibility would mediate the effect of country of origin on attitudes toward the discrimination claimant. Specifically, perceptions of discrimination in the situation, perceptions of similarity, and attributions of personal responsibility would account for the relation between the immigrant's country of origin and target derogation and outcome deservingness. In other words, a claimant who was perceived as less discriminated against, less similar, and more personally responsible for the negative outcome would be more derogated and seen as more deserving of the outcome.

3. The main effect of country of origin on target derogation, attributions of personal responsibility, and outcome deservingness would be moderated by motivation to control prejudiced reactions (MCPR), such that participants low in MCPR would demonstrate more negative attitudes toward an immigrant 
from Iran than an immigrant from Britain or a second generation Iranian Canadian immigrant.

\subsection{Method}

\subsubsection{Participants}

Prior to data collection, the study was approved by the University of Western Ontario, Department of Psychology Research Ethics Board. A sample of Canadian-born undergraduates $(N=72)$ was invited through the online sign-up system and on-campus advertisements to take part in a laboratory study looking at media perceptions. Participants ranged in age from 17 to 27 years $(M=18.56, S D=1.41) ; 62.5 \%$ were females. The majority of participants (76.4\%) were from Europe or North America, $20.8 \%$ of participants were from Asia, $1.4 \%$ (1 participant) was of mixed JamaicanCanadian background, and 1 participant did not report his or her region of origin. Participants were randomly assigned to one of three experimental conditions, manipulating the country of the claimant's origin: Britain $(N=24)$, $\operatorname{Iran}(N=23)$, or a second-generation immigrant from Iran $(N=25)$. The main outcomes were analyzed using a one-way ANOVA between-subjects design. Participants received 1\% credit toward their final grade or entered a draw with one in 10 chances to win a $\$ 15$ gift card for the study lasting approximately 45 minutes.

\subsubsection{Materials and Procedure}

Participants were recruited to participate in a study on Media perceptions. During the school year, the study was conducted in a lab setting where participants read the same manipulation article as in Study 1 and then filled out questionnaires using an online survey tool. During the summer months, the data were collected online, wherein all materials, including consent forms, manipulation article, and debriefing form were uploaded as part of an online survey. Additional dependent measures pertaining to potential mediators (perceptions of similarity) and individual differences in motivation to control prejudiced reactions were included in this second study. Upon completion of the study, participants were fully debriefed. 


\subsubsection{Measures}

As in Study 1, participants filled out measures assessing perceptions of discrimination in the situation (2 items, Cronbach's $\alpha=.91$ ), target derogation (Kaiser \& Miller, 2001, 2003; Cronbach's $\alpha=.83$ ), outcome deservingness (Cronbach's $\alpha=.80$ ), and personal responsibility (Kaiser, Dyrenforth, \& Hagiwara, 2006; Cronbach's $\alpha=.80$ ). In addition, the following measures were added to the study:

\subsubsection{Perceptions of similarity}

Participants completed a three-item scale (Kaiser, Dyrenforth, Hagiwara, 2006) to assess perceptions of similarities between themselves and the trainee: "I am similar to the trainee (Sam Barzun)", “The trainee and I share common values”, “The trainee and I have similar personalities”. Responses ranged from strongly disagree (1) to strongly agree (7). Mean scores were calculated, with higher numbers representing higher perceptions of similarity (Cronbach's $\alpha=.70$ ).

\subsubsection{Motivation to control prejudice}

Motivation to control prejudice was assessed with a 17-item Motivation to Control Prejudiced Reactions scale (Dunton \& Fazio, 1997), e.g., "When speaking to a person from a disadvantaged group, it's important to me that he/she not think I'm prejudiced", with response options from strongly disagree (1) to strongly agree (7). The scale consisted of two subscales: concern with acting prejudiced (13 items) and restraint to avoid dispute (4 items). The first subscale was of particular interest for the current research and thus was used in further analyses. One item was reverse-coded. Mean scores for the first subscale were calculated $(M=5.02, S D=.90)$, with higher scores indicating a higher motivation to control prejudice (Cronbach's $\alpha=.74)^{3}$.

\footnotetext{
3 The Motivation to Control Prejudiced Reactions scale was not influenced by the manipulation.
} 


\subsection{Results}

\subsubsection{Gender effects}

Participants' gender did not affect any dependent measures and thus was not included in the description of results.

\subsubsection{Perceptions of claimant's ethnic background}

Table 4 presents the frequencies of the claimant's perceived ethnic background as a function of condition. When the claimant was from Britain, he was perceived as being from Europe or North America and also as Arab or Middle Eastern, with one case of perceived Latin American background. In the Iranian condition, in most of the cases he was perceived as of Arab or Middle Eastern background, with less European/North American and other perceived backgrounds. Finally, the background of the Iranian Canadian claimant was predominantly Arab or Middle Eastern.

To ascertain whether the difference in the perceived ethnic background as a function of country of origin was present, a Likelihood Ratio test was utilized instead of a Pearson chi-square test due to a small sample size. It indicated that indeed there was a significant association between the perceived ethnic background of the claimant and his

country of origin as indicated in the article, $X^{2}(4)=24.90, p<.001$, Cramer's $v=.405$. A follow-up post-hoc test revealed that when participants were reading about the immigrant from Britain, he was perceived as being of the European/North American background more frequently than would be expected by chance, $z=3.4$. Furthermore, in the case of the second-generation Iranian Canadian, he was perceived as being of the European/North American background less frequently than would be expected by chance, $z(72)=-2.1, p<.05$. There were no other differences in the perceptions of the claimant's ethnic background. 
Table 4

Frequencies of Perceptions of Claimant's Ethnic Background as a Function of Country of Origin

\begin{tabular}{|c|c|c|c|}
\hline Condition & Ethnic Background & Count & Percent \\
\hline \multirow[t]{3}{*}{ Britain } & Arab, Middle Eastern & 10 & 41.7 \\
\hline & European, North American & 11 & 45.8 \\
\hline & Latin American, Other & 3 & 12.5 \\
\hline \multirow[t]{4}{*}{ Iran } & Arab, Middle Eastern & 18 & 78.3 \\
\hline & European, North American & 1 & 4.3 \\
\hline & Other & 3 & 13.0 \\
\hline & Did not report & 1 & 4.3 \\
\hline \multirow[t]{2}{*}{ Iranian Canadian } & Arab, Middle Eastern & 23 & 92.0 \\
\hline & Other & 2 & 8.0 \\
\hline
\end{tabular}




\subsubsection{Correlations between the outcome variables}

Table 5 presents Pearson's bivariate correlations between the outcome variables. The main outcomes- perceptions of discrimination, target derogation, outcome deservingness, attributions of personal responsibility, and perceived similarity - were moderately to strongly related to each other. Perceptions of discrimination were negatively associated with other outcomes, except perceived similarity. 
Table 5

Bivariate Correlations Between Outcome Variables $(N=72)$

Dependent Variable

1

2

34

1 Perceptions of Discrimination

2. Target Derogation

$-.23$

3. Outcome Deservingness

$-.55^{* * *}$

$.31^{* *}$

4. Personal Responsibility

$-.57^{* * *}$

$.51^{* * *}$

$.71^{* * * *}$

5. Perceived Similarity

$.34^{* *}$

$-.26^{*}$

$-.16$

$-.31^{* *}$

Note. $* p<.05, * * p<.01, * * * p<.001$. 


\subsubsection{Manipulation check}

A one-way between-subjects ANOVA was conducted on the question regarding whether the trainee blamed the termination of his employment on discrimination. As seen in Table 4, there were no differences between experimental conditions.

\subsubsection{Perceptions of discrimination in the situation}

To examine the effect of condition on perceptions of discrimination, a one-way between-subjects ANOVA was conducted on perception of discrimination questions. As seen in Table 6, the claimant from Iran was perceived as less discriminated against than the second-generation Iranian-Canadian. The British claimant consistently fell between the ratings for the claimant from Iran and the Iranian Canadian so that he did not differ from either.

\subsubsection{Perceived similarity in values}

As in Study 1, perceptions of value similarity between Canadians and British and Iranians, were compared using a one-sample t-tests wherein the values for $\operatorname{British}(M=$ $5.47, S D=1.20)$ and Iranians $(M=2.60, S D=1.13)$ were contrasted to the maximum score (7). The results were similar to Study 1, in that both British, $t(71)=-10.82, p<$ .001 , and Iranians, $t(71)=-32.94, p<.001$, were perceived as holding different values than Canadians. The difference in perceptions of value difference between British and Iranians was also significant, $t(71)=16.79, p<.001$. Once again, these results demonstrated a perceived value difference between Canadians, British, and Iranians, with higher perceptions of difference for Iranians.

\subsubsection{Main outcome variables}

To determine the effect of condition on target derogation, outcome deservingness, attributions of personal responsibility, and perceived similarity, one-way betweensubjects ANOVAs were conducted with the country of origin as a between-subjects factor. All main effects were statistically significant. Follow-up post-hoc analyses with 
Bonferroni correction for each of the dependent variables revealed that as expected, the claimant from Iran was derogated more, was perceived as more deserving of job termination, and was seen as more personally responsible for the situation than the claimant from Britain, with the second generation Iranian Canadian immigrant often falling in between the two (see Table 6). Participants perceived the immigrant from Iran as less similar compared to the Iranian Canadian claimant, with no differences between Iranian and British immigrants (see Table 6). Thus, the results supported Hypothesis 1 in that the claimant from Iran elicited more negative attitudes than the British claimant in terms of attributions of personal responsibility, target derogation and outcome deservingness. At the same time, no support was found for more favourable attitudes toward the second generation Iranian Canadian claimant, except perceived similarity. 
Table 6

Descriptive Statistics (M, SD), F-tests, and $\eta^{2}$ of the Main Outcome Variables

\begin{tabular}{|c|c|c|c|c|c|}
\hline \multirow[t]{3}{*}{ Dependent Variable } & \multicolumn{3}{|c|}{ Country of Origin } & \multirow{3}{*}{$F$} & \multirow{3}{*}{$\eta^{2}$} \\
\hline & Britain & Iran & Iranian Canadian & & \\
\hline & $(M, S D)$ & $(M, S D)$ & $(M, S D)$ & & \\
\hline \multirow[t]{2}{*}{ Manipulation Check } & $6.21_{\mathrm{ab}}$ & $6.09_{\mathrm{ab}}$ & $5.60_{\mathrm{ab}}$ & 0.95 & .027 \\
\hline & $(1.14)$ & $(1.44)$ & $(2.14)$ & & \\
\hline \multirow[t]{2}{*}{ Perceived Discrimination } & $3.54 \mathrm{a}$ & $2.72_{b}$ & $3.84 \mathrm{ab}$ & $4.48 *$ & .115 \\
\hline & $(1.38)$ & $(1.35)$ & $(1.28)$ & & \\
\hline \multirow[t]{2}{*}{ Target Derogation } & $3.42_{\mathrm{a}}$ & $4.28 \mathrm{~b}$ & $4.01_{\mathrm{ab}}$ & $5.05 * *$ & .128 \\
\hline & $(1.05)$ & $(.86)$ & $(.92)$ & & \\
\hline \multirow[t]{2}{*}{ Outcome Deservingness } & $3.35 \mathrm{a}$ & $4.10_{\mathrm{b}}$ & $3.69_{\mathrm{ab}}$ & $4.23 *$ & .109 \\
\hline & $(.88)$ & $(.92)$ & $(.87)$ & & \\
\hline \multirow[t]{2}{*}{ Personal Responsibility } & $4.07 \mathrm{a}$ & $4.93 b$ & $4.38 \mathrm{ab}$ & $5.60 * *$ & .140 \\
\hline & $(.85)$ & $(.87)$ & $(.94)$ & & \\
\hline \multirow[t]{2}{*}{ Perceived Similarity } & $2.49_{\mathrm{ab}}$ & $1.93_{\mathrm{a}}$ & $2.63_{b}$ & $4.32 *$ & .111 \\
\hline & $(1.03)$ & $(.69)$ & $(.84)$ & & \\
\hline
\end{tabular}

Note. Scores ranged from 1 to 7, with higher scores indicating higher endorsement of scales' items. * $p<.05, * * p<.01, * * * p<.001$. 


\subsubsection{Mediational analysis}

To test the second hypothesis, a series of mediational analyses using bootstrapping procedures (Hayes, 2009; Preacher \& Hayes, 2004) was performed to assess whether attributions of personal responsibility and perceived discrimination would explain the effect of country of origin on target derogation and outcome deservingness.

For these analyses, the claimant from Iran was used as a reference category, as the main target of hypotheses. Thus, in the analyses, British and Iranian Canadian claimants were compared to the claimant from Iran.

It was expected that the proposed mediators would account for the relation between country of origin and target derogation and outcome deservingness such that the effect of country of origin would become non-significant after controlling for the effects of the mediating variables. In addition, to support the mediation models, reverse mediation models, wherein the mediator and dependent variable were switched, were also analyzed.

\subsubsection{Target derogation}

\subsection{Attributions of personal responsibility}

As seen in Figure 1, the direct effect of country of origin on target derogation was significant for the British claimant, $\beta=-.86, S E=.28, t(69)=-3.09, p=.003$, meaning that British claimant was derogated less than the Iranian claimant. The direct effect for the Iranian Canadian claimant was non-significant, $\beta=-.26, S E=.28, t(69)=-.95$, $n s$; for this reason, it was not further investigated.

Next, country of origin (Britain) significantly predicted the mediator (attributions of personal responsibility), $\beta=-.86, S E=.26, t(69)=-3.31, p=.0015$. In turn, the mediator (attributions of personal responsibility) positively predicted target derogation, $\beta$ $=.48, S E=.12, t(68)=4.16, p=.0001$. In this last step, with the inclusion of attributions of personal responsibility in the model, the effect of country of origin (Britain) on target derogation became non-significant, $\beta=-.44, S E=.27, t(68)=-1.65, n s$. Finally, the 
indirect effect of attributions of personal responsibility was significant, $\beta=-.41, S E=.16$, $95 \%$ CI $(-.77,-.15)$.

To test whether the opposite association was also evident, the mediator (attributions of personal responsibility) and the dependent variable (target derogation) were switched, so that target derogation served as a mediator between the country of origin and attributions of personal responsibility. In this case, with the inclusion of target derogation in the model, the effect of country of origin (Britain) on attributions of personal responsibility remained significant, $\beta=-.50, S E=.23, t(68)=-2.00, p=.050$. At the same time, the indirect effect was significant, $\beta=-.36, S E=.16,95 \% \mathrm{CI}(-.75$, .11 ), as the $95 \%$ confidence intervals did not include zero. Thus, the results indicate that for the claimant from Britain, attributions of personal responsibility mediated the effect of country of origin on target derogation. 


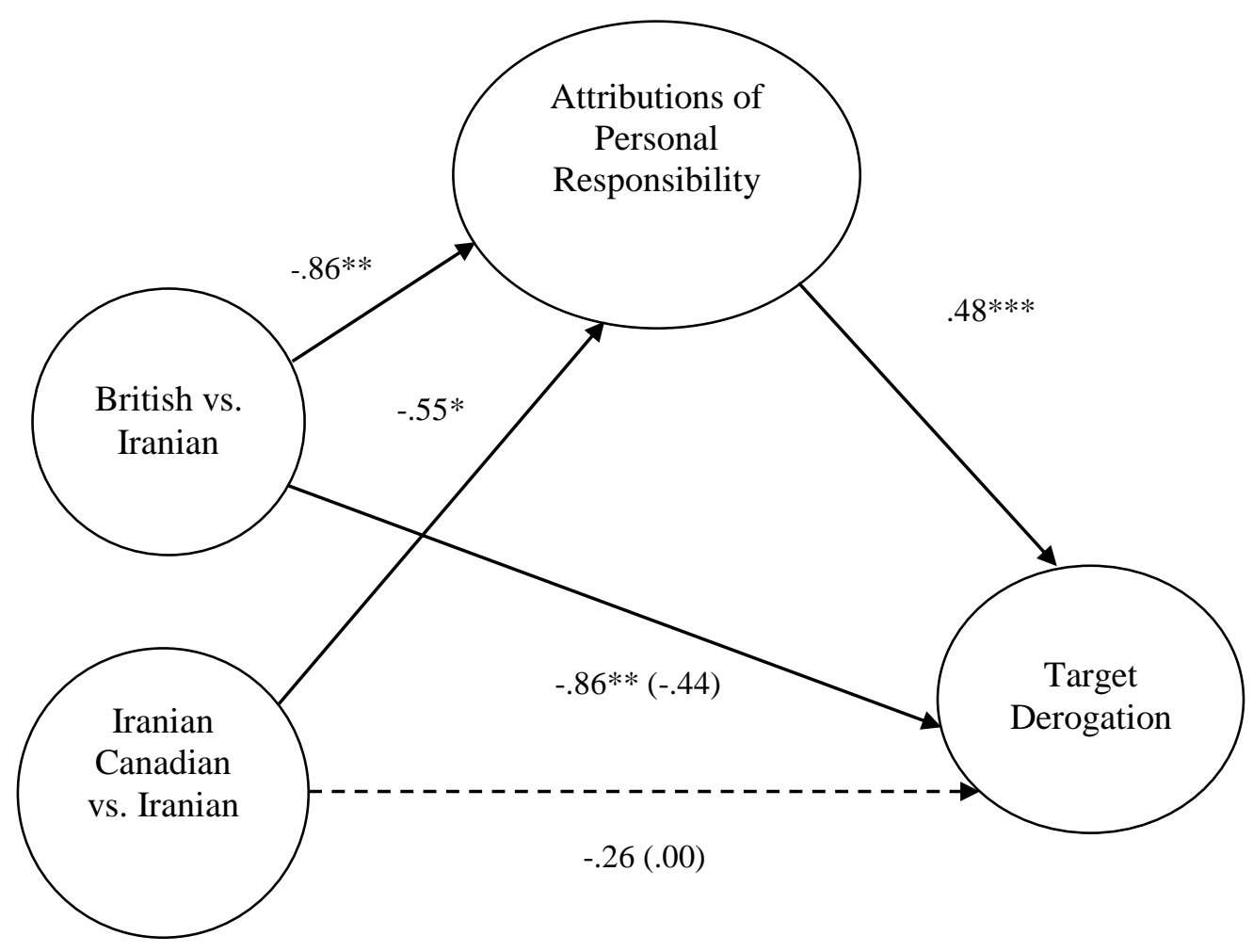

Figure 3: Mediational effects of country of origin on target derogation through attributions of personal responsibility

$* p<.05, * * p<.01, * * * p<.001$ 


\subsection{Perceived discrimination}

The direct effect of country of origin on target derogation was the same as in the case with attributions of personal responsibility used as a mediator. Once again, it was significant for the British claimant, but non-significant for the Iranian Canadian claimant.

Britain as a country of origin significantly predicted the mediator (perceived discrimination), $\beta=.82, S E=.39, t(69)=2.11, p=.038$. However, the mediator did not predict target derogation, $\beta=-.14, S E=.08, t(68)=-1.59, n s$. In this last step, with the inclusion of perceived discrimination in the model, the effect of country of origin (Britain) on target derogation remained significant, $\beta=-.75, S E=.28, t(68)=-2.63, p=$ .010. The indirect effect of perceived discrimination was non-significant, $\beta=-.11, S E=$ $.09,95 \%$ CI $(-.36, .01)$, as it included zero. These results indicate that perceived discrimination did not mediate the effect of country of origin on target derogation. For this reason, the reverse mediation model was not tested.

\subsection{Perceived similarity}

As previously described, the direct effect of country of origin on target derogation was significant for the British claimant and non-significant for the Iranian Canadian claimant. Britain as a country of origin predicted perceptions of similarity, $\beta=.56, S E=.25, t(69)$ $=2.21, p=.030$. However, the mediator did not predict target derogation, $\beta=-.24, S E=$ $.13, t(68)=-1.82, n s$. In this last step, with the inclusion of perceived similarity in the model, the effect of country of origin (Britain) on target derogation remained significant, $\beta=-.73, S E=.28, t(68)=-2.57, p=.013$. The indirect effect of perceived similarity was non-significant, $\beta=-.13, S E=.10,95 \% \mathrm{CI}(-.41, .00)$, as it included zero. Hence, the results did not support a model where perceived similarity mediated the effect of country of origin on target derogation. 


\subsubsection{Outcome deservingness}

\subsection{Attributions of personal responsibility}

As shown in Figure 4, as in the case with target derogation, the direct effect of country of origin on outcome deservingness was significant for the British claimant, $\beta=-.75, S E=$ $.26, t(69)=-2.90, p=.0049$. However, similar to target derogation, the direct effect was not significant for the Iranian Canadian claimant, $\beta=-.41, S E=.26, t(69)=-1.59, n s$; for this reason, it was not further investigated.

At the next step, Britain as a country of origin significantly predicted the mediator (perceived responsibility), $\beta=-.86, S E=.26, t(69)=-3.31, p=.0015$. In turn, the mediator (attributions of personal responsibility) positively predicted outcome deservingness, $\beta=.67, S E=.09, t(68)=7.37, p<.0001$. With the inclusion of attributions of personal responsibility in the model, the effect of country of origin on outcome deservingness became non-significant, $\beta=-.18, S E=.21, t(68)=-.87, n s$.

Finally, the indirect effect of attributions of personal responsibility was significant for the British claimant, $\beta=-.57, S E=.17,95 \% \mathrm{CI}(-.94,-.26)$.

Testing the association in the opposite direction revealed that with the inclusion of outcome deservingness in the model, the effect of country of origin on attributions of personal responsibility became non-significant for the British claimant, $\beta=-.35, S E=$ $.21, t(68)=-1.72, n s$. The indirect effect was significant, $\beta=-.50, S E=.18,95 \% \mathrm{CI}(-.89$, -.16). Thus, the results suggest bidirectional mediation effects regarding attributions of personal responsibility as a mediator. 


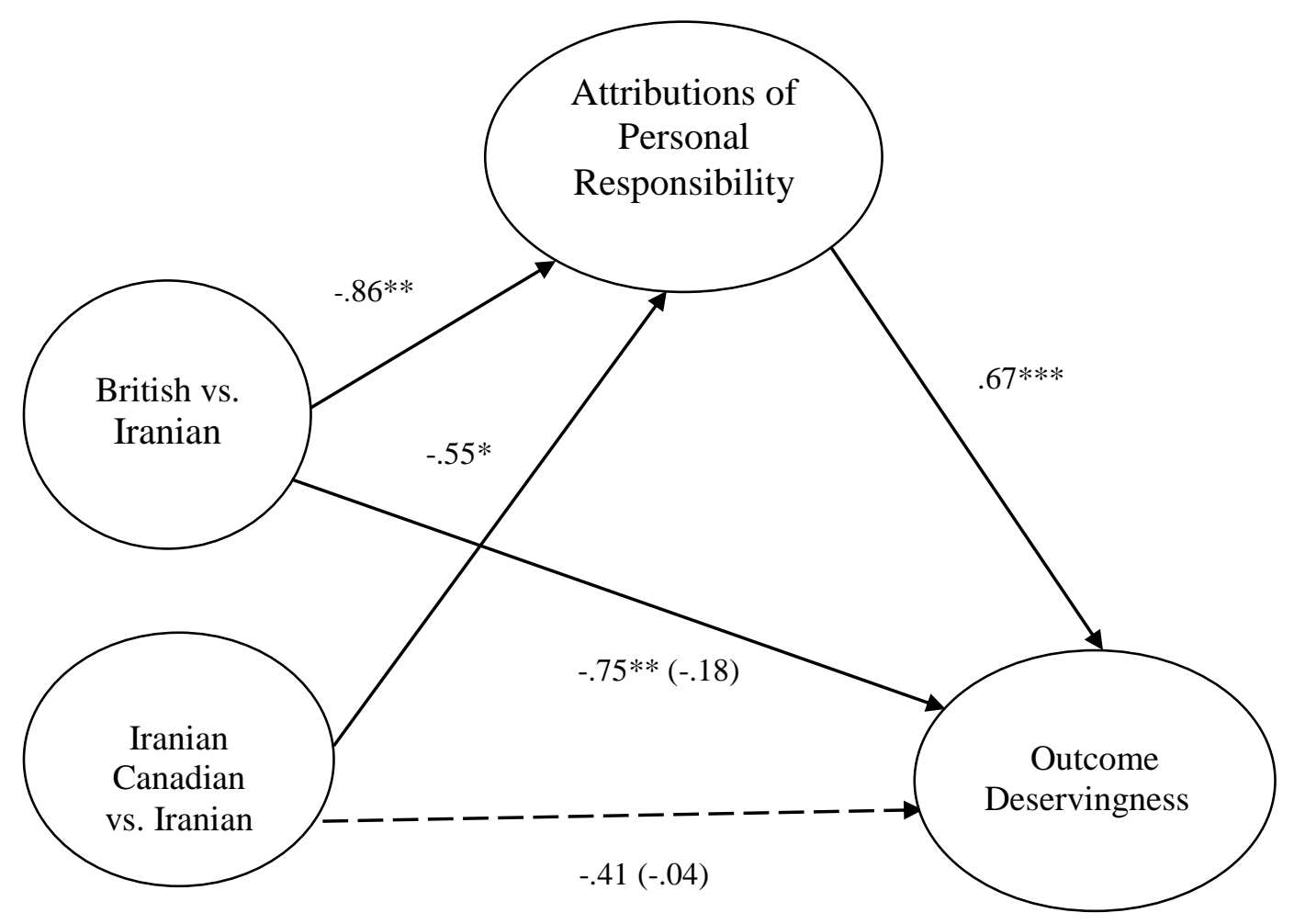

Figure 4: Mediational effects of country of origin on outcome deservingness through attributions of personal responsibility

$* p<.05, * * p<.01, * * * p<.001$ 


\subsection{Perceived discrimination}

As seen in Figure 5, the direct effect of country of origin on outcome deservingness was the same as in the case with attributions of personal responsibility used as a mediator: significant for the British claimant, but non-significant for the Iranian Canadian claimant.

At the next step, Britain as a country of origin significantly predicted the mediator (perceived discrimination). In turn, the mediator negatively predicted outcome deservingness, $\beta=-.35, S E=.07, t(68)=-5.17, p<.0001$. With the inclusion of perceived discrimination in the model, the effect of country of origin on outcome deservingness remained significant, $\beta=-.46, S E=.23, t(68)=-2.02, p=.047$. Finally, the indirect effect of attributions of personal responsibility was significant for the British claimant, $\beta=-.29, S E=.15,95 \% \mathrm{CI}(-.63,-.02)$.

Testing the association in the opposite direction revealed that with the inclusion of outcome deservingness in the model, the effect of country of origin on perceived discrimination became non-significant for the British claimant, $\beta=.22, S E=.35, t(68)=$ $.63, n s$. The indirect effect was significant, $\beta=.60, S E=.23,95 \% \mathrm{CI}(.20,1.13)$. In other words, there was stronger support of the reverse mediation model wherein outcome deservingness mediated the effect of country of origin on perceived discrimination. 


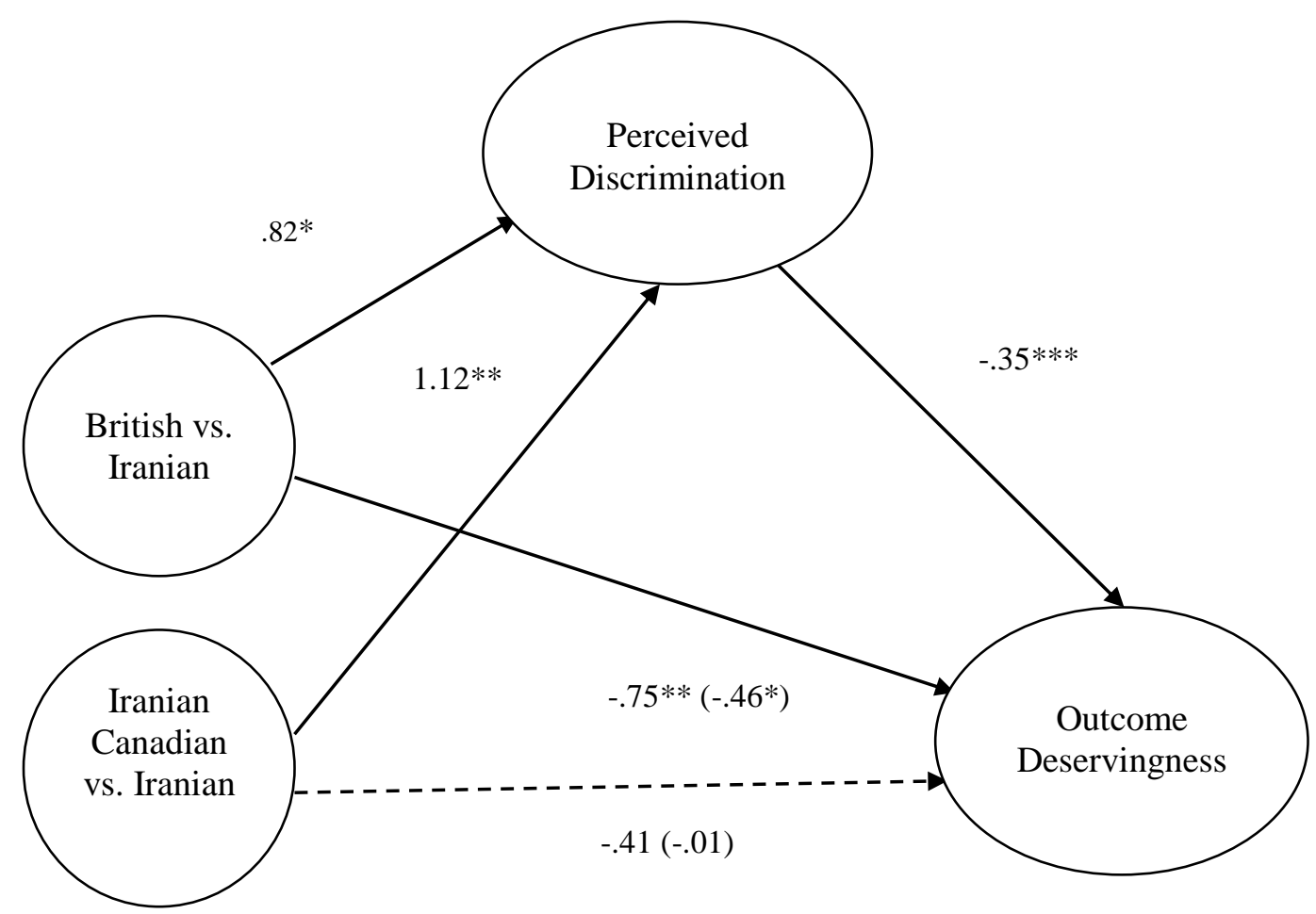

Figure 5: Mediational effects of country of origin on outcome deservingness through perceived discrimination

$* p<.05, * * p<.01, * * * p<.001$ 


\subsection{Perceived similarity}

As outlined above, the direct effect of country of origin (Britain) on outcome deservingness and proposed mediator (perceived similarity) was significant. At the next step the mediator did not predict outcome deservingness, $\beta=-.09, S E=.12, t(68)=-.70$, $n s$. Furthermore, with the inclusion of perceived similarity in the model, the effect of country of origin on outcome deservingness remained significant, $\beta=-.71, S E=.27$, $t(68)=-2.62, p=.011$. Finally, the indirect effect of perceived similarity was nonsignificant for the British claimant, $\beta=-.05, S E=.08,95 \% \mathrm{CI}(-.28, .06)$. Thus, perceived similarity did not mediate the effect of country of origin (Britain) on outcome deservingness.

\subsubsection{Summary of mediated effects}

To sum up, there was partial support for the second hypothesis, as attributions of personal responsibility mediated the effect of country of origin (Britain) on target derogation.

However, perceived discrimination and perceived similarity to the claimant did not act as mediators. In the case of outcome deservingness, there was evidence in both directions regarding attributions of personal responsibility as a mediator. In addition, there was stronger support for the reverse mediation model wherein outcome deservingness explained the effect of country of origin on perceived discrimination. Perceived similarity did not play a mediating role.

\subsubsection{Moderated effects}

To test the third hypothesis regarding the moderated effects, the concern with acting prejudiced subscale was used as moderator in hierarchical regression models. The claimant's country of origin was dummy coded so that British and second-generation Iranian Canadian were compared to the Iranian condition which served as a control. The concern with acting prejudiced was centered before running multiple linear regression models. In these models, at the first step, the country of origin predicted the main outcomes: perceived discrimination, target derogation, outcome deservingness, attributions of personal responsibility, and perceived similarity. The second step included 
main effects and two-way interactions between the concern with acting prejudiced and the dummy-coded country of origin. The two-way interactions between the concern with acting prejudiced and the country of origin were not significant in the case of target derogation, attributions of personal responsibility, and perceived similarity, meaning concern with acting prejudiced did not moderate the effect of the condition on these outcomes. For this reason, these outcomes are not discussed further here.

\subsubsection{Perceived discrimination}

The first multiple regression model which included the main effects of the country of origin and concern with acting prejudiced was significant, $R^{2}=.18, F(3,68)=4.98, p$ $=.004$. At the second step, the two-way interactions between the country of origin and the moderator contributed significantly to the model, $R^{2}$ change $=.07, F(2,66)=3.17, p$ $=.048$.

Simple effects analysis revealed that for individuals who were high in concern with acting prejudiced (+ 1SD) there were no significant differences between British and Iranian claimants, $\beta=.14, t(66)=.76, n s$, and Iranian Canadian and Iranian claimants, $\beta$ $=.04, t(66)=.19, n s$. However, individuals who were lower in concern with acting prejudiced (-1SD), perceived the Iranian Canadian claimant as being more discriminated against than the Iranian claimant, $\beta=.61, t(66)=3.65, p=.001$. No differences were

found between the British and Iranian claimants, $\beta=.21, t(66)=1.15, n s$. These findings partially support the hypothesis, in that individuals who were less concerned with acting prejudiced expressed more positive attitudes toward the Iranian Canadian than Iranian claimant. At the same time, concern with acting prejudiced did not moderate the relationship between the country of origin and perceptions of discrimination when contrasting the claimants from Britain and Iran (see Figure 6). 


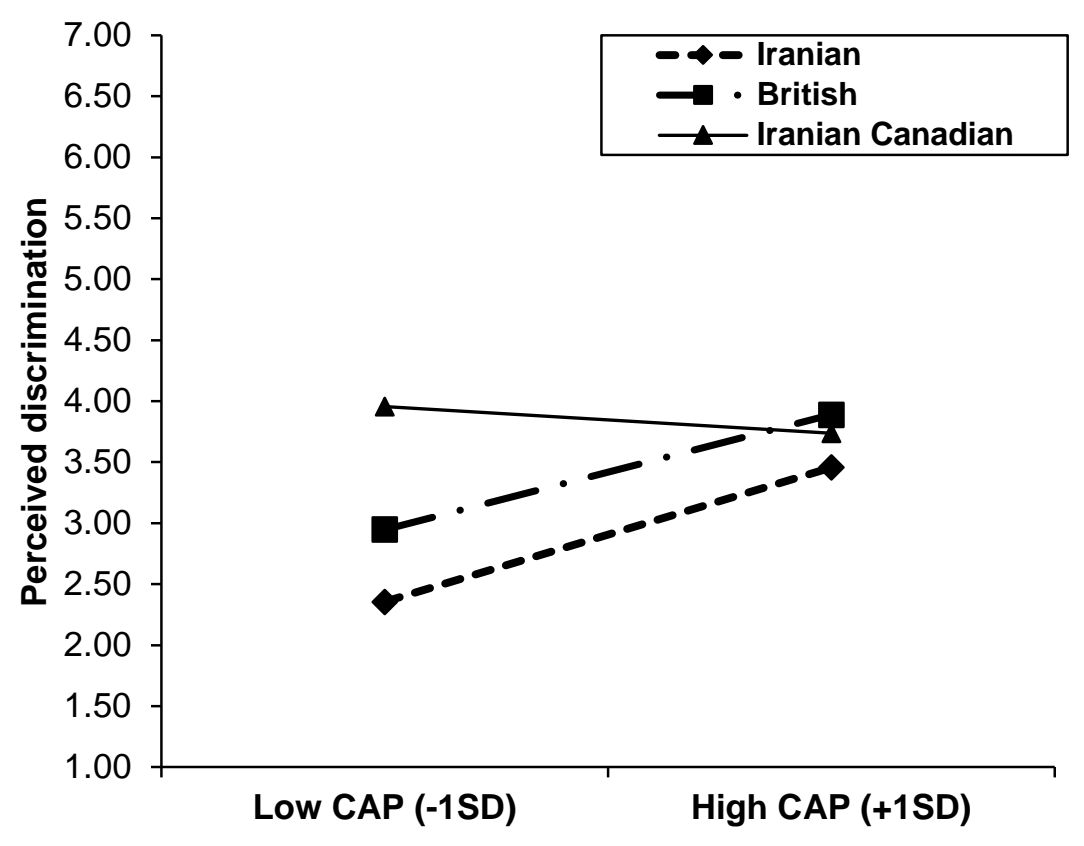

Figure 6: Mean perceived discrimination in individuals higher and lower in concern with acting prejudiced depending on the claimant's country of origin 


\subsubsection{Outcome deservingness}

The first multiple regression model which included the main effects of the country of origin and concern with acting prejudiced was significant, $R^{2}=.11, F(3,68)=2.78, p$ $=.047$. An addition of the two-way interactions between the country of origin and the moderator at the second step revealed a significant change in the $R^{2}=.11, F(2,66)=$ $4.41, p=.016$. Figure 2 depicts these significant interactions.

Analysis of simple effects revealed that for individuals who were high in concern with acting prejudiced (+ 1SD) there were no significant differences between claimants from Britain and Iran, $\beta=-.08, t(66)=-.41, n s$, and Iranian Canadian and Iranian claimants, $\beta=.21, t(66)=1.09, n s$. At the same time, as predicted, individuals who were lower in concern with acting prejudiced (-1SD), perceived the claimant from Britain as less deserving of the outcome than the claimant from Iran, $\beta=-.60, t(66)=-3.21, p=$ .002. In addition, they also perceived the Iranian Canadian claimant as less deserving of the outcome than the Iranian claimant, $\beta=-.53, t(66)=-3.08, p=.003$. Thus, individuals who were less concerned with acting prejudiced expressed their negative attitudes toward the Iranian claimant more readily than individuals who cared more about acting prejudiced (see Figure 7). 


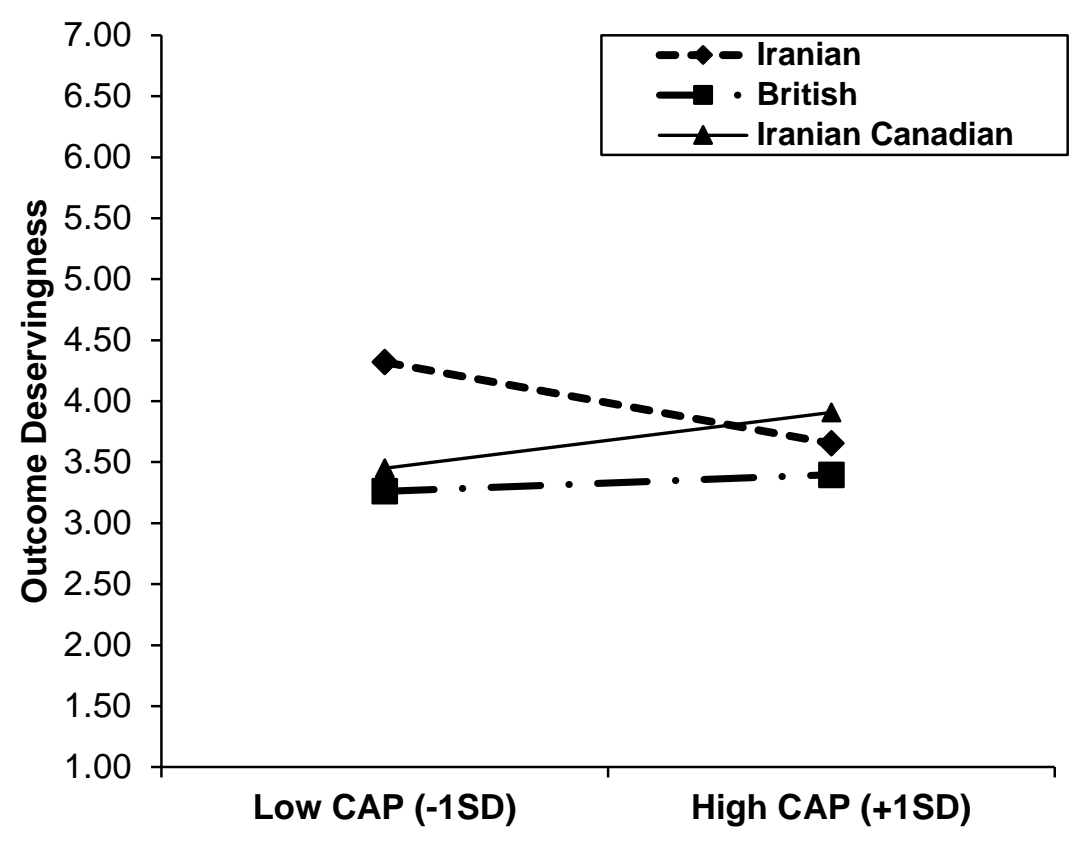

Figure 7: Mean outcome deservingness in individuals higher and lower in concern with acting prejudiced depending on the claimant's country of origin 


\subsection{Discussion}

Study 2 partially replicated findings from Study 1 and also explored the role of other possible mediators and moderators in the outcomes of interest. As in Study 1, the results of Study 2 were in line with the JSM (Crandall \& Eshleman, 2003) and previous research on attributions and attitudes toward individuals who claim discrimination (Hewstone, 1990; Kaiser, Dyrenforth, \& Hagiwara, 2006; Kaiser \& Miller, 2001, 2003). Moreover, the design of this study allowed assessing the interplay of justification and suppression components of the JSM framework.

To be consistent in the study methodology, participants read an identical manipulation articles, with minor changes in dates. After that, they responded to questions pertaining to the main outcomes. In addition, as I wanted to further investigate their perceptions of similarity to the discrimination claimant, I included the measure specifically designed to assess such perceptions. At the end of the study, participants provided responses to the individual difference measure on motivation to control prejudiced reactions and demographic items.

The results of Study 2 were in the predicted direction but somewhat different from Study 1. First, I expected that the discrimination claimant from Iran would elicit more negative attitudes than the claimants from Britain and the second generation Iranian Canadian. Specifically, an immigrant from Iran was expected to be derogated more, and perceived as more personally responsible and deserving the job termination than the immigrant from Britain or a second generation Iranian Canadian immigrant. The results were in line with predictions in terms of more positive attitudes toward the claimant from Britain than Iran. At the same time, contrary to hypothesis and Study 1 results, the reactions to the Iranian and Iranian Canadian claimants did not differ significantly. Therefore, the Iranian Canadian claimant elicited attitudes that were more ambivalent, as his outcome scores were in between those of British and Iranian claimants. These results may be explained by perceived ethnic background of the claimant: less than half of participants perceived the ethnic background of the claimant from Britain as Arab, with the rest perceived him as being of European, North American, or Latin American 
background. At the same time, almost all participants perceived the Iranian Canadian claimant as Arab.

Importantly, Study 2 included an individual difference measure of the motivation to control prejudiced reactions (MCPR). Study 2 looked at the concern with acting prejudiced subscale of MCPR as a potential moderator that might explain the relationship between the country of origin and main outcomes. In particular, it was expected that participants who scored low on the concern with acting prejudiced subscale would express their prejudicial attitudes toward the Iranian claimant more readily, as opposed to the claimants from Britain and the second generation Iranian Canadian. No differences were expected in participants with high concern with acting prejudiced scores, as they are more likely to successfully suppress their prejudiced reactions, due to either internal or external motivations. Therefore, for highly motivated participants, all claimants regardless of their country of origin and ethnic background would be perceived similarly in terms of perceptions of discrimination, target derogation, outcome deservingness, and attributions of personal responsibility. The results of moderation analyses confirmed these predictions for two outcome measures- perceived discrimination and outcome deservingness. As predicted, participants who scored low on the concern with acting prejudiced subscale perceived the second generation Iranian Canadian claimant as more discriminated against compared to the claimant from Iran. Moreover, both British and the second generation Iranian Canadian claimant were perceived as less deserving of the job termination by participants who were less concerned with acting prejudiced.

These findings complement the results from hypothesis 1 testing and therefore make the overall pattern of results more clear. That is, participants in Study 2 readily expressed more negative attitudes toward the claimant from Iran and more positive attitudes toward the British claimant because such attitudes could be justified more easily. In contrast, it was evidently harder to justify why the Iranian claimant should had been treated worse than the second generation Iranian Canadian as the attitudes toward the latter were more ambivalent. Despite this, a subset of participants who were less concerned with acting prejudiced inhibited their prejudicial attitudes less and thus were 
able to justify and express more positive attitudes toward the second generation Iranian Canadian claimant.

What is more, Study 2 allowed looking at perceptions of similarity between participants and the claimant more specifically, in terms of general similarity, similar values and personalities (Kaiser, Dyrenforth, Hagiwara, 2006). Based on these results, the Iranian Canadian claimant was perceived as more similar than Iranian, although responses to this measure were below the mean, meaning an overall low perceived similarity.

Study 2 also attempted to explore why discrimination claimants from Britain, Iran, and Iranian born in Canada were perceived differently. In line with the second hypothesis, the effect of country of origin on target derogation was explained by attributions of personal responsibility. The claimant from Iran was derogated more because he was perceived as more personally responsible for the outcome, as opposed to the claimant from Britain. That is, participants justified negative attitudes toward the claimant from Iran by making an internal attribution - blaming him (being late, missing work) and thus assigning him the responsibility for his actions. In the case of outcome deservingness, there was evidence of bidirectional mediation, such that attributions of personal responsibility mediated the effect of country of origin on outcome deservingness, but also outcome deservingness mediated the effect of country of origin on attributions of personal responsibility. One of the explanations might be that perceived responsibility and outcome deservingness are closely related concepts and the results suggest that they are mutually reinforcing.

Interestingly, although I expected that the claimant from Iran would be perceived as more deserving of job termination because he was perceived as less discriminated against, the reverse mediation model found more support. In other words, he was perceived as less discriminated against than the claimant from Britain because he deserved the termination.

Finally, I expected that perceived similarity would explain the difference between the Iranian and British claimants in terms of target derogation and outcome 
deservingness. This prediction was based on research by Kaiser, Dyrenforth, and Hagiwara (2006) who found that perceptions of dissimilarity mediated relationships between system-justifying beliefs (meritocracy) and target derogation. Study 2 explored whether perceived similarity could also explain target derogation and outcome deservingness in terms of who claims discrimination. That is, perceived dissimilarity was expected to release prejudice toward the Iranian claimant. This was not the case, however, as perceived similarity did not mediate the effect of country of origin on target derogation and outcome deservingness. This finding is not surprising, given that participants perceived the immigrant from Iran as less similar to themselves, compared to the Iranian Canadian claimant. At the same time, there was no difference in perceived similarity between Iranian and British immigrants, although they were different in other outcomes (target derogation, outcome deservingness). 


\section{Chapter 4}

\section{Study 3}

Studies 1 and 2 were designed to maximize situational ambiguity to allow participants to express genuine prejudice if they had such tendencies. Study 3 explored how the inclusion of other factors that might justify and thus release prejudice or potentially suppress it would affect the results.

In addition to the country of origin, Study 3 manipulated a source of attributions for discrimination. To do so, in addition to situational ambiguity, Study 3 added two other explanations for the discrimination claimant's contract termination - one considered to be internal to the claimant and the other external.

The internal attribution was related to the individual's abilities and behaviour, with the claimant described as struggling with the program requirements from the start and not able to meet them on a third evaluation. . In this case, I expected no country differences, in line with previous findings on no discrimination when a candidate's qualifications are obviously weak (e.g., Dovidio \& Gaertner, 2000).

In the external attribution condition, the source of attribution was external to the claimant, in that the article attributed the termination to the program director, indicating that the director stated that the candidate was terminated because of his culture, and that the program director had done this before. In this case, I expected one of two outcomes. I expected either no country differences as the situation was not ambiguous and the responsibility was external to the claimant, or that highlighting bias might make participants bend over backwards not to appear biased and they would thus rate the claimant from Iran especially favourably.

To explore the effect of both factors, participants were randomly assigned to one of nine experimental conditions, which were a combination of the country of origin (Iran, Iranian Canadian, Britain) and type of attribution provided for the termination (the job 
termination had no clear explanation: ambiguous situation; the job termination was clearly due to the claimant's inability to meet the program requirements: internal; or the job termination was clearly due to the program director's biases against people of certain cultural backgrounds: external (see Appendix H).

It was expected that:

1. There would be a two-way interaction between the country of origin and attribution type, so that in the ambiguous attribution condition, the claimant from Iran would elicit more negative attitudes than the claimant from Britain or the Iranian Canadian claimant, thereby replicating the results of Studies 1 and 2. No differences between countries of origin were expected in the internal attribution condition, and in the external attribution condition there would either be no differences between countries of origin or the Iranian applicant would be perceived most favorably.

2. Attribution of personal responsibility would mediate the effect of condition on attitudes toward the discrimination claimant. Specifically, attributions of personal responsibility would account for the joint effect of the attribution type and country of origin on target derogation and outcome deservingness. In other words, in the ambiguous condition, the claimant from Iran would be more derogated and seen as more deserving of the outcome because of being more personally responsible for the negative outcome. Depending on the findings for the external attribution condition, personal responsibility might also play a role in this condition.

3. Concern with acting prejudiced (CAP) would moderate the predicted effects of country of origin in the ambiguous and external attribution conditions. In the ambiguous condition, it was expected that, as demonstrated in Study 2, only participants who were lower in CAP would demonstrate more negative attitudes toward the immigrant from Iran than the Iranian Canadian and British claimants. In the external attribution condition, if it was found that participants 
bent over backwards to not show bias against the Iranian claimant, this would be especially the case for those higher in CAP.

\subsection{Method}

\subsubsection{Participants and design}

The study was approved by the University of Western Ontario Research Ethics Board. A sample of Canadian-born first-year undergraduates $(N=231)$ was invited through the online sign-up system to take part in a laboratory study looking at media perceptions. Participants ranged in age from 17 to 60 years $(M=18.52, S D=2.97) ; 68.4 \%$ were female. The majority of participants, $67.5 \%$ were of White ethnic background, $22.5 \%$ of participants were from Asia, 2.2\% were Black, and $1.3 \%$ were of mixed ethnic background. Participants were randomly assigned to one of nine experimental conditions: ambiguous attribution + Iranian $(N=24)$, internal attribution + Iranian $(N=22)$, external attribution + Iranian $(N=25)$, ambiguous attribution +Iranian Canadian $(N=23)$, internal attribution + Iranian Canadian $(N=24)$, external attribution + Iranian Canadian $(N=33)$, ambiguous attribution + British $(N=31)$, internal attribution + British $(N=$ $24)$, external attribution + British $(N=25)$. The main outcomes were analyzed using a two-way ANOVA between-subjects design. Participants received 1 research credit toward their final grade in introductory psychology for the study lasting approximately 45 minutes.

\subsubsection{Materials and procedure}

Participants were recruited to participate in a study on Media perceptions. The study was conducted in a laboratory setting where participants read a letter of information and then signed an informed consent (Appendix F). After that, they read one of the nine manipulation articles. The ambiguous articles were identical to those used in Studies 1 and 2 . The internal and external articles varied attribution type by adding specific text. In the internal attribution condition, the trainee described how he struggled with the program requirements from the start, and then was not able to meet them at the third evaluation (see Appendix H). In the external attribution condition, the article cited the 
program director`s negative comments about the trainee's culture as a reason for his contract termination and indicated that the program director had terminated a previous trainee for a similar reason.

After reading one of the articles, participants filled out the same dependent measures as in Study 2, as well as completing measures of emotional reactions (Appendix $\mathrm{G})$ and the motivation to control prejudiced reactions individual difference measure. Upon completion of the study, participants were fully debriefed.

\subsubsection{Measures}

As in Study 2, participants filled out measures assessing perceptions of discrimination in the situation ( 2 items, Cronbach's $\alpha=.88$ ), target derogation (6 items; Kaiser $\&$ Miller, 2001, 2003; Cronbach's $\alpha=.85$ ), outcome deservingness ( 3 items; Cronbach's $\alpha=$ .90 ), perceptions of similarity to the claimant ( 3 items; Kaiser, Dyrenforth, \& Hagiwara, 2006; Cronbach's $\alpha=.80$ ), and personal responsibility (5 items; Kaiser, Dyrenforth, \& Hagiwara, 2006; Cronbach's $\alpha=.87$ ).

In addition, the following measure was added to the study:

Emotional reactions to the claimant were assessed with the Emotional Response Questionnaire (modified from Dovidio, ten Vergert, Stewart, Gaertner, Johnson, Esses, Riek, \& Pearson, 2004). Participants were asked to indicate how much each adjective described how they felt (or how they would expect to feel) about the trainee at the moment. The questionnaire included 26 emotional responses, ranging from negative (e.g., distressed, angered, annoyed, agitated, threatened) to positive (e.g., soft-hearted, touched, empathic, sympathetic). Responses ranged from not at all (1) to extremely (7).

A principal components analysis with Varimax rotation was conducted on the 26 emotional responses in order to reduce their number. Based on a scree test and eigenvalues greater than 1 (Stevens, 2002), three components were identified, explaining $65.1 \%$ of the variance. Based on factor loadings of .45 or higher, the first factor reflected anger, including angered, bothered, outraged, agitated, upset, disgusted, distressed, 
irritated, annoyed, disturbed, troubled, alarmed, contemptuous (Cronbach's $\alpha=.95$ ). The second factor represented empathy, including sympathetic, trusting, soft-hearted, tender, touched, concerned, empathic (Cronbach's $\alpha=.87$ ). The third factor comprised threat/anxiety, namely threatened, grieved, diffident, fearful, anxious (Cronbach's $\alpha=$ .88). Mean scores were calculated on each scale, with higher numbers representing higher emotional reactions to the claimant.

Finally, the study included the same measure of motivation to control prejudice (Dunton \& Fazio, 1997) as in Study 2. From the latter, the concern with acting prejudiced subscale was of particular interest for the current research and thus was used in the analyses that follow (11 items, Cronbach's $\alpha=.75$ ). A three-way between subjects ANOVA was performed on the CAP score to determine whether it was affected by the manipulations (country of origin or attribution type) as well as gender. The analysis revealed a significant gender $\mathrm{x}$ country of origin interaction, $F(2,213)=12.83, p<$ $.0001, \eta^{2}=.107$. As part of this interaction, female participants reported higher concern with acting prejudiced after they read the article about the claimant from Iran than about the other two claimants. For this reason, the CAP measure was excluded from further analyses as a moderator.

\subsection{Results}

\subsubsection{Gender effects}

Participants' gender did not moderate any of the effects reported below, and thus was not included in the description of results that follows.

\subsubsection{Perceptions of claimant's ethnic background}

Table 7 presents the frequencies of the claimant's perceived ethnic background as a function of country of origin condition. The claimant from Britain was perceived as being of a White background significantly more often than the two other claimants. In addition, he was perceived as being of West Asian (e.g., Iranian, Armenian, Afghani) background less frequently. No other differences in perceptions of ethnic background emerged. A 
Likelihood Ratio test indicated that there was a strong significant association between the perceived ethnic background of the claimant and his country of origin as specified in the article, $X^{2}(12)=104.84, p<.0001$, Cramer's $v=.456$. The association between the attribution type and claimant's perceived ethnic background was not significant, $X^{2}(12)=$ 7.51, $n s$, Cramer's $v=.122$. 
Table 7

Frequencies and Percentages of Perceptions of Claimant's Ethnic Background as a Function of Country of Origin

\begin{tabular}{|c|c|c|c|}
\hline \multirow[t]{2}{*}{ Ethnic Background } & \multicolumn{3}{|c|}{ Country of Origin } \\
\hline & Iran & Iranian Canadian & Britain \\
\hline \multirow[t]{2}{*}{ White } & $1_{\mathrm{a}}$ & $0_{\mathrm{a}}$ & $32_{b}$ \\
\hline & $(1.4 \%)$ & $(0 \%)$ & $(40.0 \%)$ \\
\hline \multirow[t]{2}{*}{ South Asian } & $4 a$ & $1_{\mathrm{a}}$ & $5 \mathrm{a}$ \\
\hline & $(5.6 \%)$ & $(1.3 \%)$ & $(6.3)$ \\
\hline \multirow[t]{2}{*}{ Latin American } & $1_{\mathrm{a}}$ & $1_{\mathrm{a}}$ & $7 \mathrm{a}$ \\
\hline & $(1.4 \%)$ & $(1.3 \%)$ & $(8.8 \%)$ \\
\hline \multirow[t]{2}{*}{ Southeast Asian } & $0_{\mathrm{a}}$ & $1_{\mathrm{a}}$ & $0_{\mathrm{a}}$ \\
\hline & $(0 \%)$ & $(1.3 \%)$ & $(0 \% 0$ \\
\hline \multirow[t]{2}{*}{ Arab } & $9 \mathrm{a}$ & $12 \mathrm{a}$ & $14_{a}$ \\
\hline & $(12.7 \%)$ & $(15.0 \%)$ & $(17.5 \%)$ \\
\hline \multirow[t]{2}{*}{ West Asian } & $56_{a}$ & $65_{\mathrm{a}}$ & $21_{b}$ \\
\hline & $(78.9 \%)$ & $(81.3 \%)$ & $(26.3 \%)$ \\
\hline \multirow[t]{2}{*}{ Other } & $0_{\mathrm{a}}$ & $0_{\mathrm{a}}$ & $1_{\mathrm{a}}$ \\
\hline & $(0 \%)$ & $(0 \%)$ & $(1.3 \%)$ \\
\hline
\end{tabular}

Note. Each subscript letter denotes a subset of country categories whose column proportions do not differ significantly from each other at the .05 level. 


\subsubsection{Perceived similarity in values}

As in Studies 1 and 2, perception of value similarity between Canadians and British and Iranians was compared using a one-sample t-test wherein the values for British $(M=$ $5.71, S D=1.12)$ and Iranians $(M=3.11, S D=1.19)$ were contrasted to the maximum score (7). The results were similar to Studies 1 and 2, as both British, $t(230)=-7.47, p<$ .001 , and Iranians, $t(229)=-49.63, p<.001$, were perceived as holding different values than Canadians. Based on the results of a paired-sample t-test, the difference in perceptions of value difference between British and Iranians was also significant, $t$ (229) $=25.70, p<.001$. Once again, these results demonstrated a perceived value difference between Canadians, British, and Iranians, with higher perceptions of difference for Iranians.

\subsubsection{Correlations between the outcome variables}

Table 8 presents Pearson's bivariate correlations between the outcome variables. The main outcomes- target derogation, outcome deservingness, attributions of personal responsibility, and perceived similarity- were moderately to strongly related to each other. Perceptions of discrimination were associated with emotional reactions more strongly than with the main outcomes. Emotional reactions were positively and moderately to strongly correlated with each other. 
Table 8

Bivariate Correlations Between Outcome Variables $(N=231)$

\begin{tabular}{|c|c|c|c|c|c|c|c|}
\hline Dependent Variable & 1 & 2 & 3 & 4 & 5 & 6 & 7 \\
\hline 1 Perceptions of Discrimination & - & & & & & & \\
\hline 2. Target Derogation & $-.19^{* *}$ & - & & & & & \\
\hline 3. Outcome Deservingness & $-.14^{*}$ & $.59^{* * *}$ & - & & & & \\
\hline 4. Personal Responsibility & $-.17^{*}$ & $.60^{* * *}$ & $.76^{* * *}$ & - & & & \\
\hline 5. Perceived Similarity & $.26^{* * *}$ & $-.27^{* * *}$ & $-.37^{* * *}$ & $-.40^{* * * *}$ & - & & \\
\hline 6. Anger & $.31^{* * *}$ & -.07 & -.12 & -.08 & $.19^{* *}$ & - & \\
\hline 7. Empathy & $.55^{* * *}$ & -.04 & -.09 & -.13 & $.19^{* *}$ & $.43^{* * *}$ & - \\
\hline 8. Threat/Anxiety & $.33^{* * * *}$ & -.05 & -.07 & -.08 & $.15^{*}$ & $.80^{* * *}$ & $.50^{* * *}$ \\
\hline
\end{tabular}

$* p<.05, * * p<.01, * * * p<.001$ 


\subsubsection{Effects of attribution type and country of origin on the dependent variables}

To determine the effect of attribution type and country of origin on the dependent variables, 3 × 3 between-subjects ANOVAs were conducted with attribution type and country of origin as between-subjects factors. The two-way interactions were significant in the case of target derogation, outcome deservingness, attributions of personal responsibility, and perceived similarity. At the same time, they were not significant in the case of blaming the termination on discrimination, perceptions of discrimination, and emotional reactions. To follow-up significant interactions, the data were examined separately within attribution conditions, thus focusing on within-attribution differences between countries of origin.

\subsubsection{Target derogation}

The two-way interaction between attribution type and country of origin on target derogation was significant, $F(4,222)=2.84, p=.025, \eta^{2}=.049$. To follow-up the significant interaction, the differences between countries of origin were compared within each attribution type. The country of claimants' origin did not affect target derogation in the ambiguous attribution condition, $F(2,75)=1.12, n s, \eta^{2}=.029$, and in the external attribution condition, $F(2,80)=2.07, n s, \eta^{2}=.049$. However, the difference between countries was significant in the internal attribution condition, $F(2,67)=3.96, p=.024$, $\eta^{2}=.106$. Post-hoc analyses with Bonferroni correction indicated that, in the internal attribution condition, the claimant from Britain $(M=4.40, S D=.91)$ was derogated more than the Iranian claimant $(M=3.55, S D=1.06), p=.045$, and Iranian Canadian claimant $(M=3.62, S D=1.24)$; the latter difference was marginally significant at $p=.064$ (see Figure 8). 


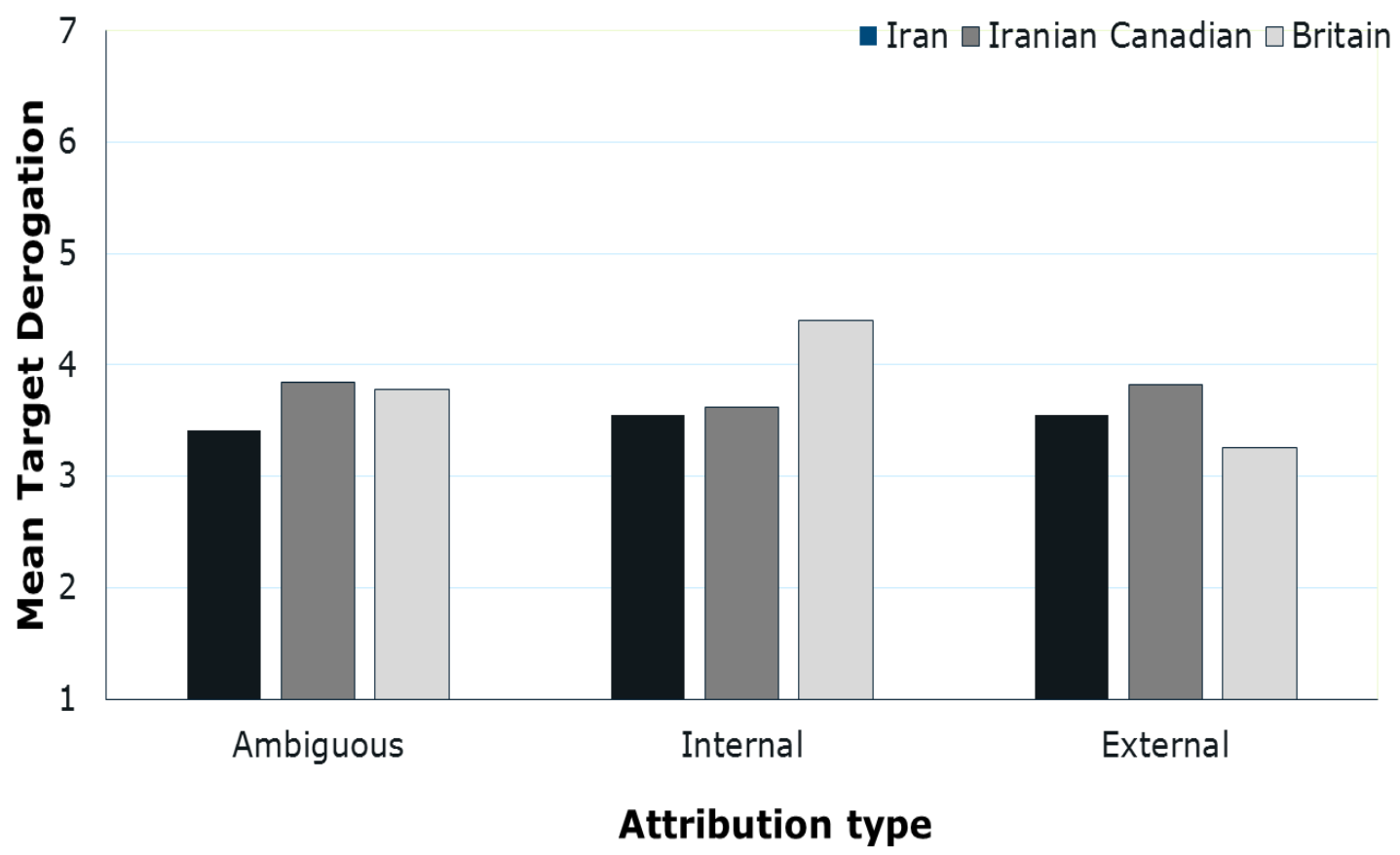

Figure 8: Mean target derogation depending on the attribution type and claimant's country of origin 


\subsubsection{Outcome deservingness}

The two-way interaction between attribution type and country of origin on outcome deservingness was significant, $F(4,222)=14.61, p<.0001, \eta^{2}=.208$.

When looking at the differences between countries of origin within each attribution type, the claimant's country of origin did not affect outcome deservingness in the ambiguous attribution condition, $F(2,75)=.35, n s, \eta^{2}=.009$. Similar to the results for target derogation, the difference between countries was significant in the internal attribution condition, $F(2,67)=27.97, p<.0001, \eta^{2}=.455$. Post-hoc analyses with Bonferroni correction indicated that in the internal attribution condition, the claimant from Britain $(M=5.21, S D=1.14)$ was perceived as more deserving of contract termination than the Iranian claimant $(M=3.02, S D=1.44), p<.0001$, and Iranian Canadian claimant $(M=2.90, S D=1.21), p<.0001$. The difference between the Iranian and Iranian Canadian claimants was not significant.

In addition, the effect of country was significant in the external attribution condition, $F(2,80)=4.71, p=.012, \eta^{2}=.105$. Here the difference was in the opposite direction: the Iranian Canadian claimant $(M=4.24, S D=1.25)$ was perceived as more deserving of contract termination than the claimant from Britain $(M=3.32, S D=.83), p$ $=.009$. The difference between the Iranian $(M=3.77, S D=1.25)$ and Iranian Canadian was non-significant, as well as the difference between the Iranian and British claimants (See Figure 9). 


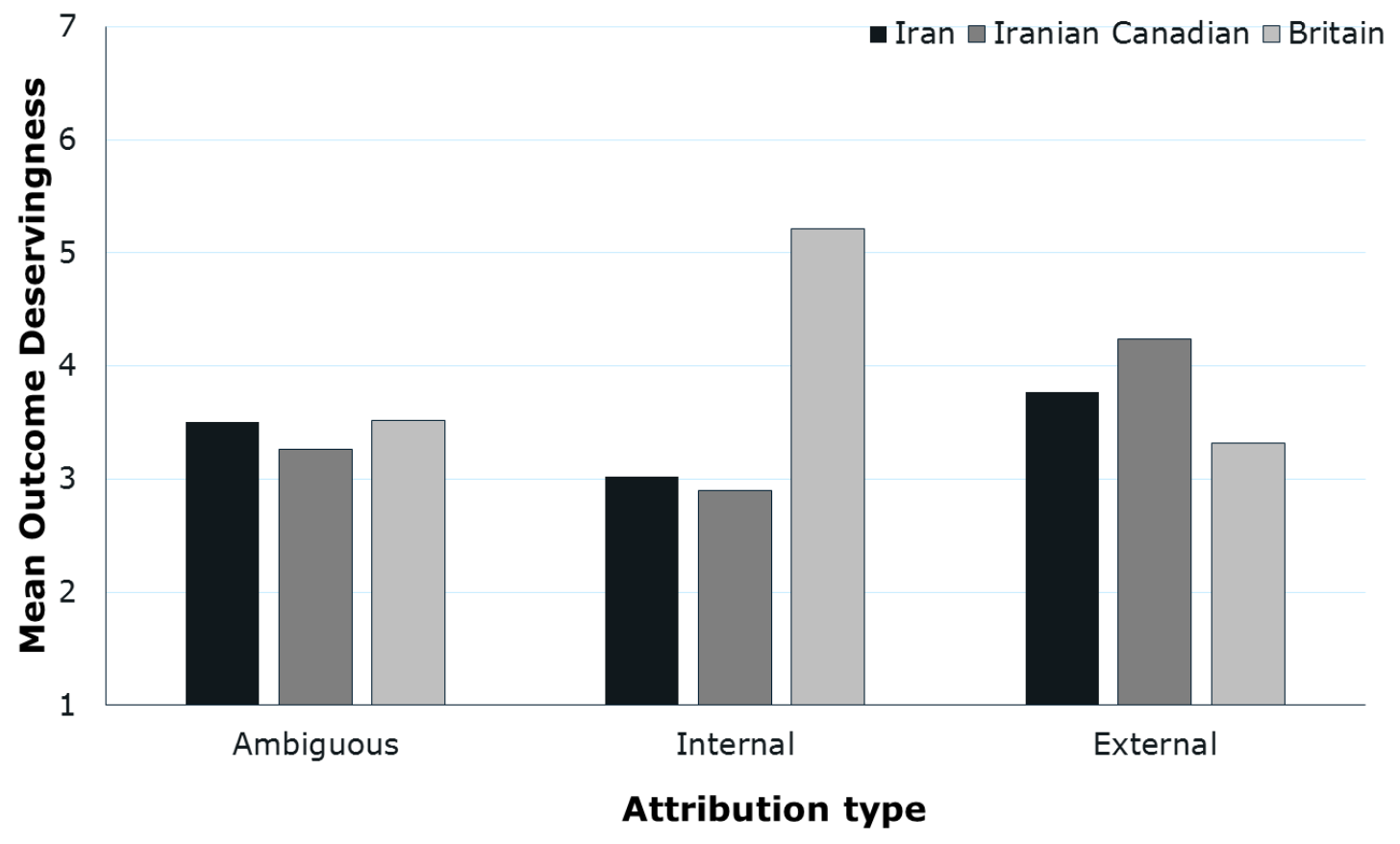

Figure 9: Mean outcome deservingness depending on the attribution type and claimant's country of origin. 


\subsubsection{Attributions of personal responsibility}

The results for attributions of personal responsibility were similar to outcome deservingness. The two-way interaction between attribution type and country of origin on attributions of personal responsibility was significant, $F(4,222)=9.65, p<.0001, \eta^{2}=$ .148 ,

To follow-up the two-way interaction, the differences between countries of origin were evaluated within each attribution type. No differences between countries of claimants' origin were revealed in the ambiguous attribution condition, $F(2,75)=.87$, $n s, \eta^{2}=.023$. Once again, the difference between countries was significant in the internal attribution condition, $F(2,67)=17.98, p<.0001, \eta^{2}=.349$. Post-hoc analyses with Bonferroni correction indicated that the claimant from Britain $(M=5.28, S D=.97)$ was perceived as more personally responsible for the negative outcome than the Iranian claimant $(M=3.68, S D=1.19), p<.0001$, and Iranian Canadian claimant $(M=3.47, S D$ $=1.25), p<.0001$. The difference between the Iranian and Iranian claimants was not significant.

In addition, the effect of country was significant in the external attribution condition, $F(2,80)=4.05, p=.021, \eta^{2}=.092$. As for outcome deservingness, the Iranian Canadian claimant $(M=4.61, S D=1.20)$ was perceived as more responsible for the termination than the claimant from Britain $(M=3.78, S D=.97), p=.020$. The difference between the Iranian $(M=4.40, S D=1.12)$ and Iranian Canadian, and the difference between the Iranian and British claimants were not significant (See Figure 10). 


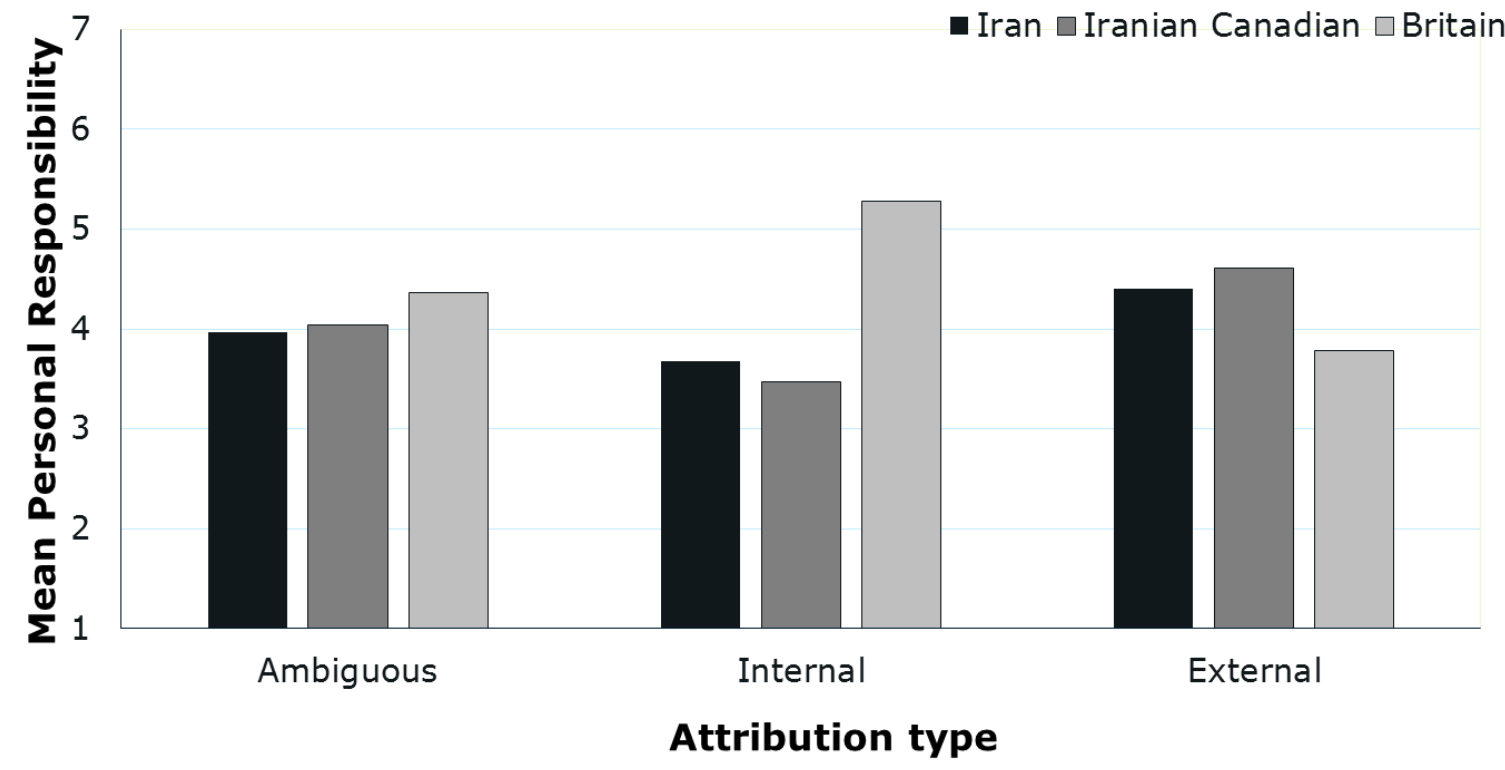

Figure 10: Mean personal responsibility depending on the attribution type and claimant's country of origin 


\subsubsection{Perceived similarity}

The two-way interaction between attribution and country of origin on perceived similarity was significant, $F(4,221)=3.08, p=.017, \eta^{2}=.053$.

To follow-up the significant interaction, the differences between countries of origin were evaluated within each attribution type. No differences were revealed in the ambiguous attribution condition, $F(2,75)=1.21, n s, \eta^{2}=.031$, and external attribution condition, $F(2,79)=.90, n s, \eta^{2}=.022$. The difference between countries was significant in the internal attribution condition, $F(2,67)=9.47, p<.0001, \eta^{2}=.220$, where participants perceived the Iranian Canadian claimant $(M=2.94, S D=1.08)$ as more similar to themselves than the claimant from $\operatorname{Iran}(M=2.29, S D=.91), p=.048$, and the British claimant $(M=1.82, S D=.65), p<.0001$. The difference between the Iranian and British claimants was not significant (see Figure 11). 


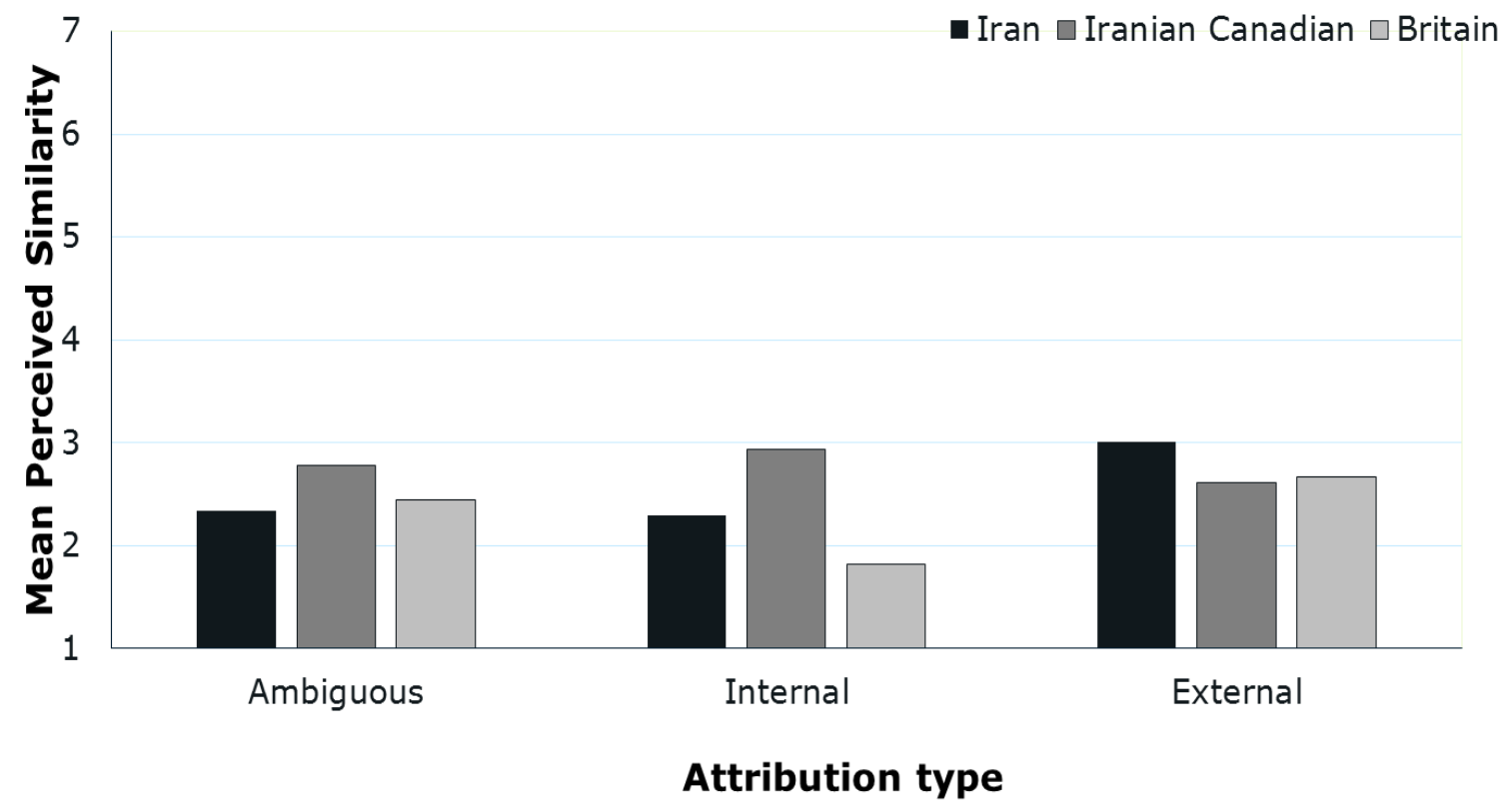

Figure 11: Mean perceived similarity depending on the attribution type and claimant's country of origin. 


\subsubsection{Blaming the termination on discrimination}

The two-way interaction between the country of origin and attribution type was not significant, $F(4,222)=.29, n s, \eta^{2}=.005$ for the variable of whether the claimant blamed his termination on discrimination. The main effect of attribution type was also not significant, $F(2,222)=1.69, n s, \eta^{2}=.015$. The main effect of country of origin was significant, $F(2,222)=7.38, p=.001, \eta^{2}=.062$. Follow-up post-hoc analyses with Bonferroni correction revealed that the claimant from Iran $(M=6.66, S D=.58)$ was perceived as having blamed his termination on discrimination more than the claimant from Britain $(M=6.19, S D=.93), p=.001$. The Iranian Canadian claimant $(M=6.50$, $S D=.76), p=.035$ was also perceived as having blamed his termination on discrimination more than the British claimant. The difference between the Iranian and Iranian Canadian claimants was not significant.

\subsubsection{Perceptions of discrimination in the situation}

The two-way interaction between country of origin and attribution type was not significant, $F(4,222)=.60, n s, \eta^{2}=.011$. The main effect of country was also not significant, $F(2,222)=1.33, n s, \eta^{2}=.012$. The main effect of attribution was strongly significant, $F(2,222)=78.21, p<.0001, \eta^{2}=.413$. Follow-up post-hoc analyses with Bonferroni correction revealed that the ambiguous $(M=3.67, S D=1.48)$ and external $(M$ $=5.13, S D=1.13$ ) attribution conditions led to perceptions of the claimant as more discriminated against as compared to the internal attribution condition $(M=2.49, S D=$ $1.29), p<.0001$. The difference between the ambiguous and external attributions was also significant, $p<.0001$, in that in the external attribution condition the claimant, was perceived as more discriminated against than in the ambiguous attribution condition.

\subsubsection{Emotional reactions}

In the case of anger, the two-way interaction between the country of origin and attribution type was not significant, $F(4,222)=.32, n s, \eta^{2}=.006$. The main effect of country was also not significant, $F(2,222)=2.45, n s, \eta^{2}=.022$, as well as the main effect of attribution type, $F(2,222)=2.65, p=.073, \eta^{2}=.023$. 
The two-way interaction between country of origin and attribution type on empathy was not significant, $F(4,222)=.80, n s, \eta^{2}=.014$. The main effect of country was also not significant, $F(2,222)=1.41, n s, \eta^{2}=.013$. The main effect of attribution was significant, $F(2,222)=11.76, p<.0001, \eta^{2}=.096$. Follow-up post-hoc analyses with Bonferroni correction revealed that the external $(M=3.71, S D=1.05)$ attribution elicited higher empathy than the internal $(M=2.80, S D=1.21), p<.0001$, and ambiguous $(M=3.22, S D=1.16), p=.021$ attributions. The difference between the ambiguous and internal attributions was not significant $(p=.080)$.

The two-way interaction between country of origin and attribution type on threat/anxiety was not significant, $F(4,222)=.17, n s, \eta^{2}=.003$. The main effect of attribution type was also not significant, $F(2,222)=2.09, n s, \eta^{2}=.019$. The main effect of country was marginally significant, $F(2,222)=2.99, p=.053, \eta^{2}=.026$. Follow-up post-hoc analyses with Bonferroni correction revealed that the Iranian Canadian claimant $(M=2.53, S D=1.40)$ elicited more anxiety than the claimant from Britain $(M=2.04, S D$ $=1.02), p=.046$. No other differences were found.

\subsubsection{Summary of interaction and main effects}

To sum up, the two-way interactions between the country of origin and attribution type were significant for many of the main outcome variables. In particular, attributions of personal responsibility, target derogation and outcome deservingness depended on the claimant's country of origin and whether the reason for his contract termination was described as more internal, external or ambiguous. However, unexpectedly, in the internal attribution condition the claimant from Britain was perceived more negatively than the claimant from Iran and the Iranian Canadian. At the same time, participants perceived both British and Iranian claimants as less similar to themselves, and the Iranian Canadian claimant as more similar, in the internal attribution condition. Interestingly, the pattern was different in the external attribution condition: the Iranian Canadian claimant was perceived as more deserving of the job termination and more responsible for it than the claimant from Britain. 
Two types of main effects were evident: the effect of country and the effect of attribution type. In terms of the country effects, Iranian and Iranian Canadian claimants were perceived as more blaming their employment termination on discrimination than the claimant from Britain, and the Iranian Canadian claimant elicited more threat/anxiety than the claimant from Britain. In the case of the main effect of attribution type, regardless of the country of origin, the claimant was perceived as more discriminated against in the ambiguous and external attribution as compared to the internal attribution condition, and in the external than ambiguous attribution condition. The external attribution condition also led to higher empathy as compared to the internal and ambiguous conditions.

\subsubsection{Mediational analysis}

To test the second hypothesis, a series of mediational analyses using bootstrapping procedures (Hayes, 2009; Preacher \& Hayes, 2004) was performed to assess whether attributions of personal responsibility would explain the joint effect of country of origin and attribution type. To do so, given the significant interaction effects on the main outcome variables, the differences between countries were examined within attribution types. This approach provided an opportunity to explain the differences between countries revealed in the internal and external attribution conditions.

For these analyses, the claimant from Britain was used as a reference category, as the differences emerged between the British and the other two claimants. Thus, in the analyses, Iranian and Iranian Canadian claimants were compared to the claimant from Britain. Separate analyses were performed for each attribution type.

\subsubsection{Target derogation}

As seen in Figure 12, within the internal attribution condition, the direct effect of country of origin on target derogation was significant for Iranian Canadian vs. British claimant, $\beta$ $=-.78, S E=.33, t(67)=-2.36, p=.021$, as well as the direct effect for Iranian vs. British claimant, $\beta=-.85, S E=.34, t(67)=-2.50, p=.015$, meaning that both Iranian Canadian and Iranian claimants were derogated less than the British claimant. 
Next, Iranian Canadian as a country of origin significantly predicted the mediator (perceived responsibility), $\beta=-1.82, S E=.33, t(67)=-5.51, p<.0001$. The same effect was significant in the case of Iranian, $\beta=-1.60, S E=.34, t(67)=-4.75, p<.0001$.

In turn, the mediator (attributions of personal responsibility) positively predicted target derogation, $\beta=.55, S E=.10, t(66)=5.25, p<.0001$. In this last step, with the inclusion of attributions of personal responsibility in the model the effect of country of origin on target derogation became non-significant, $\beta=.21, S E=.34, t(66)=.62$, $n s$ for the Iranian Canadian claimant, and $\beta=.03, S E=.33, t(66)=.09, n s$ for the Iranian claimant. Finally, the indirect effect of attributions of personal responsibility was significant for both the Iranian Canadian, $\beta=-1.00, S E=.25,95 \% \mathrm{CI}(-1.57,-.57)$, and Iranian claimants, $\beta=-.88, S E=.23,95 \% \mathrm{CI}(-1.39,-.49)$.

To test whether the opposite association was true, the mediator (attributions of personal responsibility) and the dependent variable (target derogation) were switched, so that target derogation served as a mediator between the country of origin and attributions of personal responsibility. In this case, with the inclusion of target derogation in the model the effect of country of origin on attributions of personal responsibility stayed significant, $\beta=-1.40, S E=.29, t(80)=-4.81, p<.0001$, for the Iranian Canadian claimant, and $\beta=-1.14, S E=.30, t(80)=-3.84, p=.0003$, for the Iranian claimant. At the same time, the indirect effects were significant, $\beta=-.42, S E=.19,95 \% \mathrm{CI}(-.87,-$ $.08)$, for the Iranian Canadian, and $\beta=-.46, S E=.19,95 \% \mathrm{CI}(-.89,-.14)$ for the Iranian claimant, as $95 \%$ confidence intervals did not include zero.

In the external attribution condition, the direct effect of country of origin on target derogation was significant for the Iranian Canadian claimant, $\beta=.56, S E=.28$, $t(80)=2.03, p=.046$. However, the direct effect was not significant for the Iranian claimant, $\beta=.29, S E=.30, t(80)=97, n s$; for this reason, it was not further investigated.

At the next step, Iranian Canadian as a country of origin significantly predicted the mediator (perceived responsibility), $\beta=.82, S E=.29, t(80)=2.79, p=.007$. In turn, the mediator (attributions of personal responsibility) positively predicted target derogation, $\beta=.37, S E=.10, t(80)=3.79, p=.0003$. With the inclusion of attributions 
of personal responsibility in the model, the effect of country of origin on target derogation became not significant, $\beta=.26, S E=.27, t(80)=.97, n s$. Finally, the indirect effect of attributions of personal responsibility was significant for the Iranian Canadian, $\beta$ $=.30, S E=.14,95 \%$ CI $(.09, .65)($ see Figure 13$)$.

To test whether the opposite association was also evident, the mediator (attributions of personal responsibility) and the dependent variable (target derogation) were switched, so that target derogation served as a mediator between the country of origin and attributions of personal responsibility. As in the case with the internal attribution condition, with the inclusion of target derogation in the model, the effect of country of origin on attributions of personal responsibility stayed significant for the Iranian Canadian claimant, $\beta=.59, S E=.28, t(80)=2.10, p=.039$. The indirect effects was significant for the Iranian Canadian, $\beta=.24, S E=.14,95 \%$ CI $(.03, .57)$.

In sum, the results suggest that attributions of personal responsibility mediated the effect of country of origin on target derogation in the internal and external attribution conditions. In the internal attribution condition, the British claimant was derogated more than the Iranian Canadian and Iranian claimants because he was perceived as more personally responsible for his contract termination. In the external attribution condition, the Iranian Canadian claimant was derogated more than the British claimant because participants attributed to him more personal responsibility. 
Internal attribution

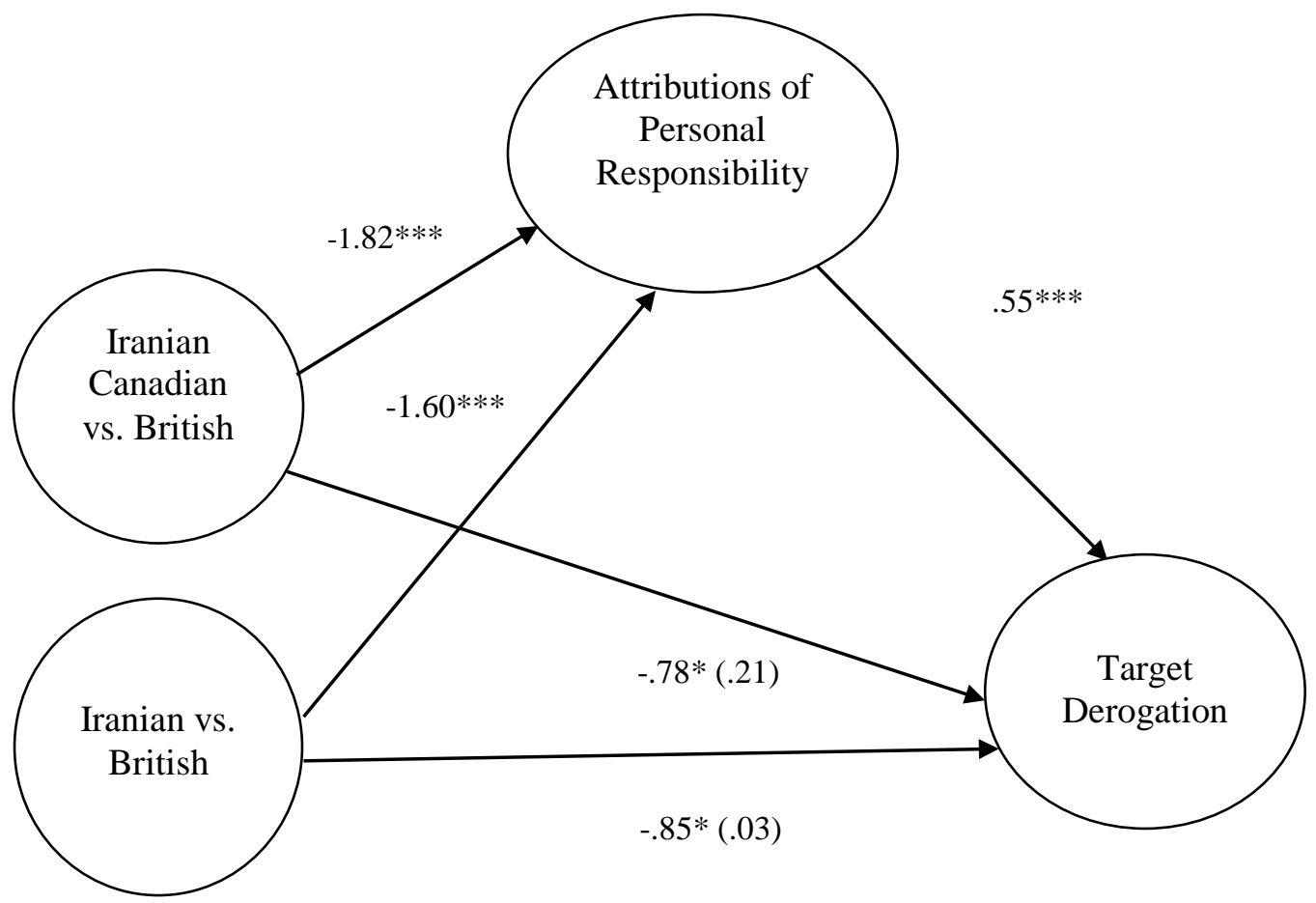

Figure 12: Mediational effects of country of origin on target derogation through attributions of personal responsibility in the internal attribution condition.

$* p<.05, * * p<.01, * * * p<.001$ 
External attribution

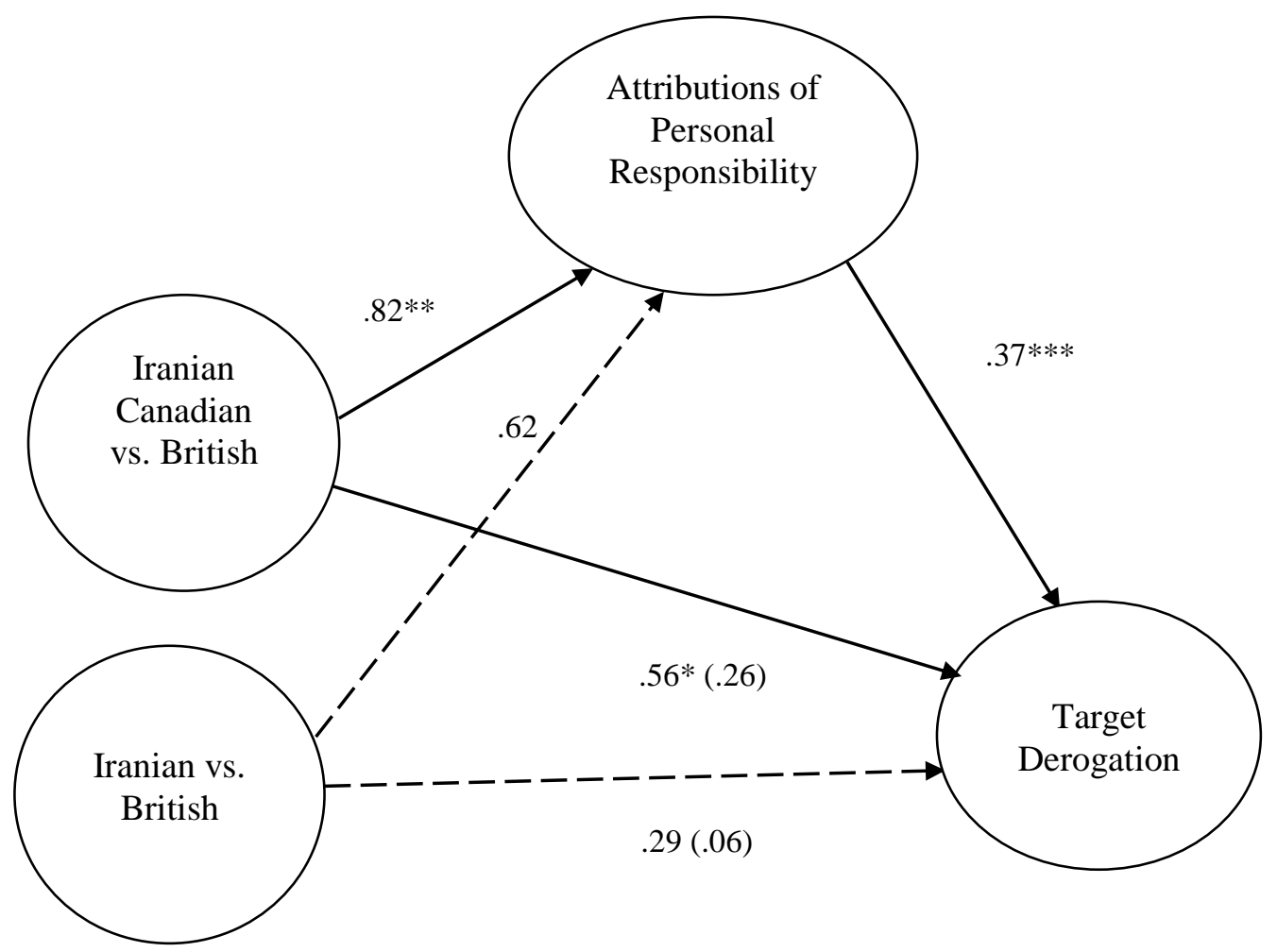

Figure 13: Mediational effects of country of origin on target derogation through attributions of personal responsibility in the external attribution condition

$* p<.05, * * p<.01, * * * p<.001$ 


\subsubsection{Outcome deservingness}

In the internal attribution condition, the direct effect of country of origin on outcome deservingness was significant for the Iranian Canadian claimant, $\beta=-2.31, S E=.35$, $t(67)=-6.67, p<.0001$, as well as for the Iranian claimant, $\beta=-2.19, S E=.35, t(67)=-$ $6.21, p<.0001$.

Next, as in the case with target derogation, Iranian Canadian as a country of origin significantly predicted the mediator (perceived responsibility), $\beta=-1.82, S E=.33, t(67)$ $=-5.51, p<.0001$. The same effect was significant in the case of the Iranian claimant, $\beta$ $=-1.60, S E=.34, t(67)=-4.75, p<.0001$.

In turn, the mediator (attributions of personal responsibility) positively predicted outcome deservingness, $\beta=.63, S E=.10, t(66)=6.14, p<.0001$. With the inclusion of attributions of personal responsibility in the model, the effect of country of origin on outcome deservingness decreased but stayed significant, $\beta=-1.16, S E=.33, t(66)=-$ $3.46, p=.001$ for the Iranian Canadian claimant, and $\beta=-1.18, S E=.33, t(66)=-3.60$, $p=.0006$ for the Iranian claimant (see Figure 14). Finally, the indirect effect of attributions of personal responsibility was significant for both the Iranian Canadian, $\beta=$ $1.15, S E=.28,95 \% \mathrm{CI}(-1.77,-.68)$, and Iranian claimants, $\beta=-1.02, S E=.27,95 \% \mathrm{CI}$ $(-1.60,-.56)$.

To test whether the opposite association was also evident, the mediator and the dependent variable were switched. In this case, with the inclusion of outcome deservingness in the model, the effect of country of origin on attributions of personal responsibility became non-significant, $\beta=-.49, S E=.34, t(66)=-1.44, n s$, for the Iranian Canadian claimant, and $\beta=-.34, S E=.34, t(66)=-1.00, n s$, for the Iranian claimant. The indirect effects were significant, $\beta=-1.33, S E=.27,95 \% \mathrm{CI}(-1.90,-.84)$, for the Iranian Canadian, and $\beta=-1.26, S E=.28,95 \% \mathrm{CI}(-1.90,-.78)$ for the Iranian claimants.

In the external attribution condition, as shown in Figure 15, the direct effect of country of origin on outcome deservingness was significant for the Iranian Canadian claimant, $\beta=.92, S E=.30, t(80)=3.06, p=.003$. However, similar to target derogation, 
the direct effect was not significant for the Iranian claimant, $\beta=.45, S E=.32, t(80)=$ $1.41, n s$; for this reason, it was not further investigated.

At the next step, Iranian Canadian as a country of origin significantly predicted the mediator (perceived responsibility), $\beta=.82, S E=.29, t(80)=2.79, p=.007$. In turn, the mediator (attributions of personal responsibility) positively predicted outcome deservingness, $\beta=.74, S E=.08, t(80)=9.27, p<.0001$. With the inclusion of attributions of personal responsibility in the model, the effect of country of origin on outcome deservingness became non-significant, $\beta=.31, S E=.22, t(79)=1.43, n s$. Finally, the indirect effect of attributions of personal responsibility was significant for the Iranian Canadian claimant, $\beta=.61, S E=.23,95 \% \mathrm{CI}(.19,1.11)$.

Testing the association in the opposite direction revealed that with the inclusion of outcome deservingness in the model, the effect of country of origin on attributions of personal responsibility was not significant for the Iranian Canadian claimant, $\beta=.17, S E$ $=.22, t(79)=.80, n s$. The indirect effect was significant for the Iranian Canadian, $\beta=.65$, $S E=.23,95 \%$ CI $(.26,1.15)$.

In sum, the results suggested that in the internal attribution condition, the reverse model wherein outcome deservingness mediated the effect of country of origin on attributions of personal responsibility found stronger statistical support than the opposite mediation. This finding was not in line with Hypothesis 2. Thus, in the internal attribution condition, participants attributed more personal responsibility for termination because they perceived the claimant as more deserving of the outcome. In the external attribution condition, there was evidence of mediation in both directions for the Iranian Canadian claimant. 
Internal attribution

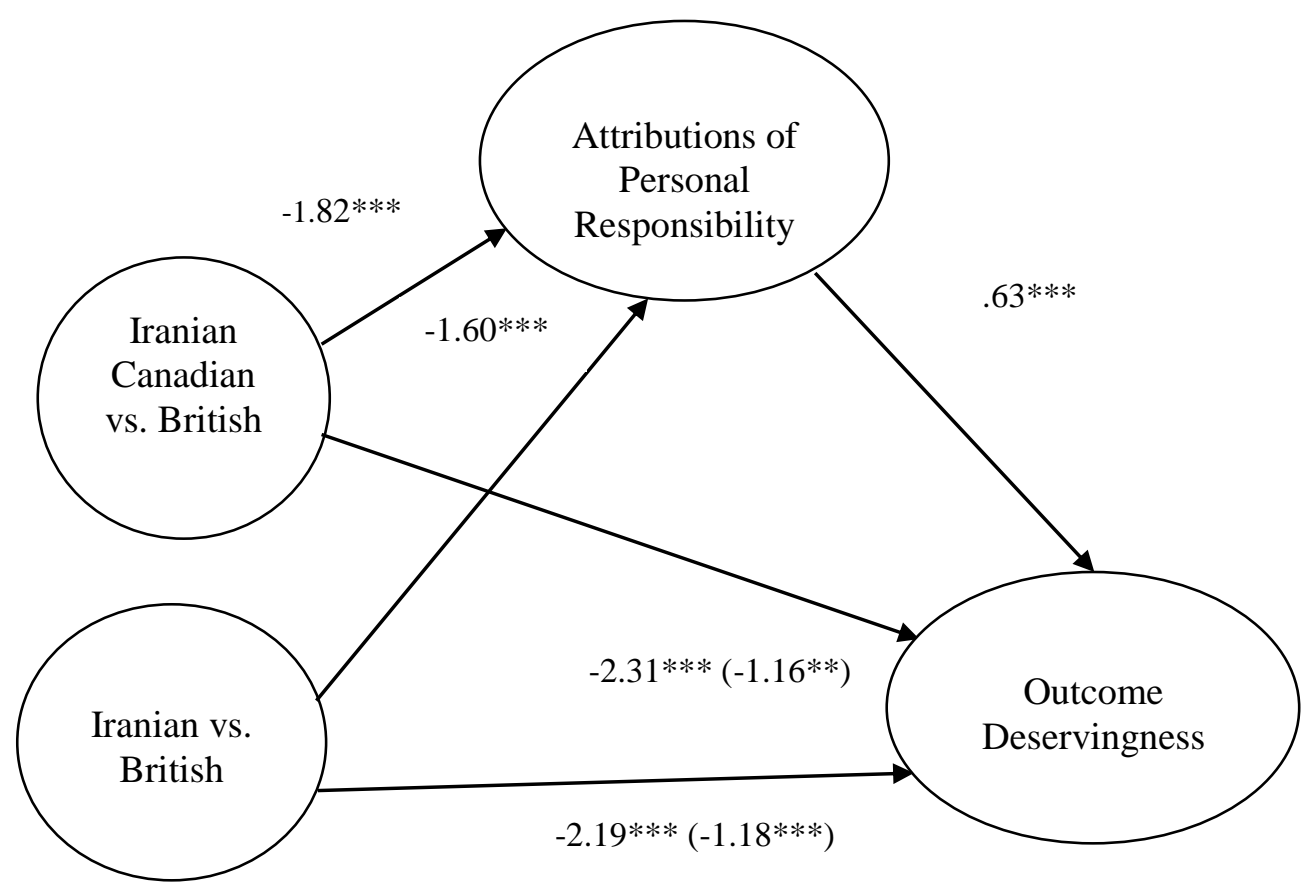

Figure 14: Mediational effects of country of origin on outcome deservingness through attributions of personal responsibility in the internal attribution condition

$* p<.05, * * p<.01, * * * p<.001$ 
External attribution

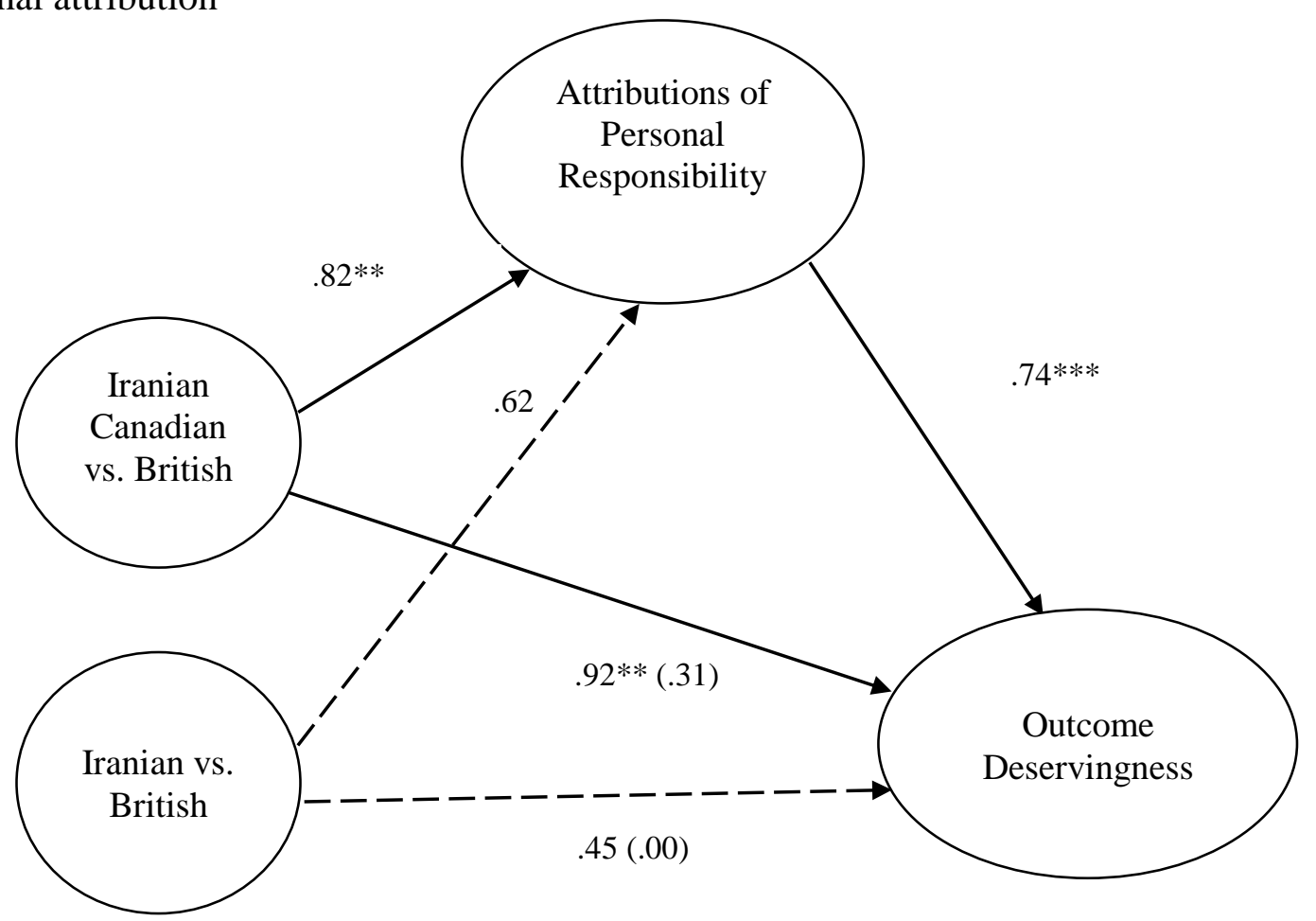

Figure 15: Mediational effects of country of origin on outcome deservingness through attributions of personal responsibility in the external attribution condition

$* p<.05, * * p<.01, * * * p<.001$ 


\subsubsection{Auxiliary analyses}

An additional mediation analysis was performed to further examine the effect of attribution condition on empathy. Specifically, perceptions of discrimination in the situation were used as a conceptually fitting mediator. The attribution variable was dummy coded: the internal condition served as a control condition, as the main difference in both cases of perceived discrimination and empathy emerged between the ambiguous and internal and external and internal conditions. The first variable compared the ambiguous attribution to the internal, and the second one - external to internal attributions.

The direct effect of attribution type on empathy was significant for ambiguous vs. internal attribution conditions, $\beta=.42, S E=.19, t(227)=2.23, p=.027$, as well as for external vs. internal condition, $\beta=.91, S E=.18, t(227)=4.91, p<.0001$.

Next, the ambiguous attribution strongly predicted the mediator (perceptions of discrimination), $\beta=1.19, S E=.21, t(227)=5.53, p<.0001$. The same was true for the external attribution, $\beta=2.65, S E=.21, t(227)=12.51, p<.0001$.

In turn, the mediator positively predicted empathy, $\beta=.42, S E=.05, t(226)=$ $8.16, p<.0001$. With the inclusion of the mediator in the model, the effect of attribution type on empathy became non-significant, $\beta=-.08, S E=.18, t(226)=-.43, n s$, for the ambiguous attribution, and $\beta=-.19, S E=.21, t(226)=-.92, n s$, for the external condition (see Figure 11). Finally, the indirect effect of attributions of personal responsibility was significant for both the ambiguous, $\beta=.49, S E=.11,95 \% \mathrm{CI}(.30, .72)$, and external attributions, $\beta=1.10, S E=.15,95 \% \mathrm{CI}(.82,1.41)$.

To test whether the opposite association was also evident, the mediator and the dependent variable were switched. In this case, with the inclusion of empathy in the model, the effect of attribution type on perceptions of discrimination stayed significant, $\beta$ $=.99, S E=.19, t(226)=5.02, p<.0001$, for the ambiguous attribution, and $\beta=2.15, S E$ $=.20, t(226)=10.98, p<.0001$, for the external attribution conditions. 
The indirect effects through empathy were significant, $\beta=.23, S E=.11,95 \% \mathrm{CI}$ $(.03, .48)$, for the ambiguous attribution, and $\beta=.49, S E=.12,95 \% \mathrm{CI}(.28, .76)$ for the external attribution, although in the first case the effect was weak because the lower confidence interval was close to zero.

To sum up, the results provided strong support for the first model depicted in Figure 16, wherein perceptions of discrimination explained the effect of attribution type on empathy. The reverse model did not provide evidence for empathy as a mediator. Based on these results, participants reported higher empathy in the ambiguous and external attribution conditions because they perceived the claimant as being more discriminated against. These effects were independent of the country of origin. 


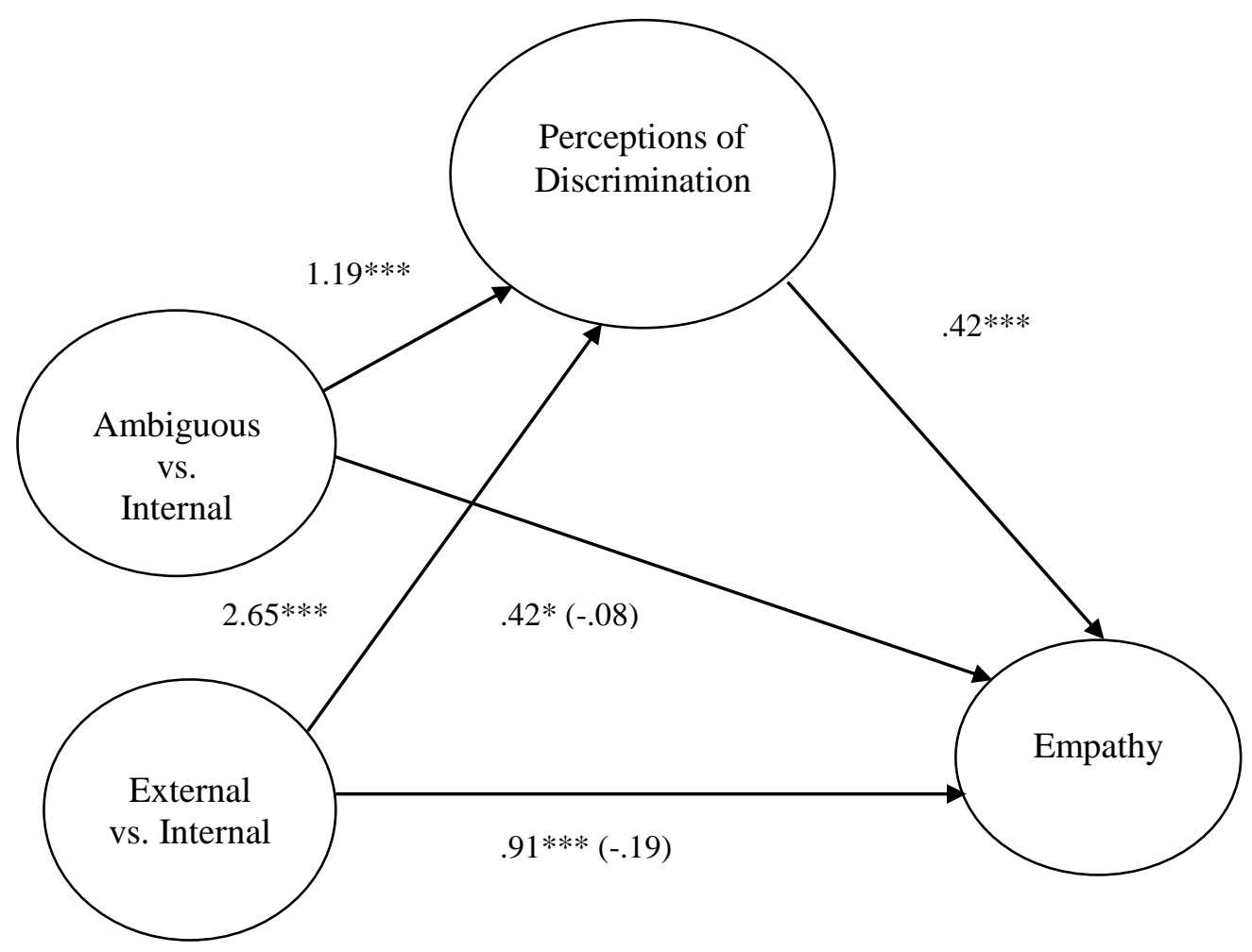

Figure 16: Mediational effects of attribution type on empathy through perceptions

\section{of discrimination}

$* p<.05, * * p<.01, * * * p<.001$ 


\subsection{Discussion}

Study 3 examined attitudes toward discrimination claimants from the same countries of origin as Studies 1 and 2 - once again the claimant from a dissimilar culture (Iran) was compared to the one from a similar culture (Britain), and the Iranian Canadian claimant who was born and raised in the same country as participants in the study. In addition, Study 3 varied three types of attributions for the claimant's contract termination: ambiguous, internal and external. Therefore, it was expected that reactions to the claimant would depend on both country of origin and attribution type.

As part of the first hypothesis regarding the two-way interaction between the country of origin and attribution type, it was expected that in the ambiguous attribution condition, participants would readily express genuine prejudice if they had such tendencies initially. In other words, in this condition, I expected to replicate the results of Studies 1 and 2, with more negative attitudes toward the Iranian claimant. Contrary to expectation, the outcome variables (target derogation, outcome deservingness, attributions of personal responsibility, perceived similarity, perceptions of discrimination) did not depend on the country of origin. Therefore, it seems that in this study, situational ambiguity was not sufficient to release participants' pre-existing prejudice toward the Iranian claimant. This fits with the finding that overall, participants reported higher motivation to suppress prejudice against the Iranian claimant, and women were especially inclined to do so.

Next, in the internal attribution condition, the claimant was described as struggling with the program requirements from the start of the training program, in addition to being late and missing the program on several occasions. This situation was less ambiguous and provided a clearer explanation for the contract termination, such that the claimant was a bad candidate for this position, as he was not able to perform in order to meet the program requirements. This is also supported by the fact that in the internal attribution condition, the claimant was perceived as less discriminated against than in the other two conditions, and elicited less empathy. Because of the situational non-ambiguity in the internal attribution condition, no differences between countries of origin were 
expected. However, unexpectedly, the claimant from Britain was perceived more negatively than the claimant from Iran and the Iranian Canadian: he was derogated more than the claimant from Iran, perceived as more deserving of the contract termination, and as more personally responsible for the situation than the Iranian and Iranian Canadian claimants. At the same time, participants perceived the British claimant as less similar to themselves. These results are in line with research on the "black sheep effect" (Marques \& Paez, 1994; Marques, Abrams, \& Serôdio, 2001; Garcia et al., 2005). The effect refers to more extreme reactions to in-group members than to comparable outgroup members based on performance. Thus, the black sheep effect would predict more favourable judgements of successful in-group members and more unfavourable judgements of unsuccessful in-group members as compared to similarly performing out-group members (Marques \& Paez, 1994). According to the black sheep effect, in-group members get derogated more than out-group members when they possess socially undesirable characteristics or behaviours, in order to distance oneself and one's group from these group members and preserve a positive social identity (Marques \& Paez, 1994; Hutchison, Abrams, Gutierrez, \& Viki, 2008; Pinto, Marques, Levine, \& Abrams, 2010). From this perspective, the British claimant could be an easy target for derogation: given that the majority of participants identified their ethnic background as White and perceived this claimant's background as predominantly White, they might have perceived him as part of their in-group. Therefore, his underperformance in the program was clearly perceived as a deviation from the group norm, thus reflecting negatively on the in-group. As a result, he got derogated more than the claimant from Iran, and perceived as more deserving of the outcome and more personally responsible than the Iranian and Iranian Canadian claimants. In line with the black sheep effect explanation, the British claimant was seen as potentially reflecting on White Canadians and thus was pushed away and seen as less similar to participants.

At the same time, not surprisingly, they perceived the Iranian claimant as different and the Iranian Canadian claimant as more similar to themselves. In line with these findings, Garcia and colleagues (2005) reported that in-group (same gender) targets who attributed their failing grade to discrimination rather than answer quality were evaluated more negatively compared to an out-group (opposite gender) target. 
Interestingly, in the external attribution condition, where the program director provided negative comments about the claimant's culture as a reason for his contract termination, I expected no differences in attitudes toward the claimant based on the country of origin or evidence of reverse discrimination in which the Iranian claimant would be rated more favourably than the British and Iranian Canadian claimants. However, the Iranian Canadian claimant was perceived as more deserving of job termination and more responsible for it than the claimant from Britain. Thus, the Iranian Canadian claimant elicited more prejudice than the claimant from Britain. In other words, participants found enough grounds to justify prejudice toward the Iranian Canadian claimant.

Once again, they suppressed their prejudice toward the claimant from Iran, which resulted in relatively lower scores. However, these scores were not low enough to get interpreted as an evidence of overcorrection or reverse discrimination because the Iranian claimant fell in between the Iranian Canadian and British claimants.

According to the JSM, as part of covering justification, when another individual can be held responsible for discrimination, it can help to release prejudice (Crandall \& Eshleman, 2003). In this case, participants recognized the fact that the claimant was indeed more discriminated against in the external attribution condition than in the internal and ambiguous attribution conditions, and felt sorry for him. However, the fact that the program director discriminated against the claimant but also cited the claimant's culture as a reason for contract termination may have made it seen that the Iranian Canadian who had experience with Canadian culture, was somewhat responsible for the discrimination. In turn, this provided enough grounds for the justification of prejudice, as prejudice toward the claimant was not participants' fault anymore. Moreover, Iranian and Iranian Canadian claimants were perceived more negatively- as more blaming their employment termination on discrimination than the claimant from Britain, and the Iranian Canadian claimant elicited more threat and anxiety than the claimant from Britain. Therefore, both Iranian and Iranian Canadian claimants could have been suitable targets in terms of prejudice expression. However, as was previously mentioned, participants 
suppressed prejudice toward the Iranian claimant. Thus, they picked the Iranian Canadian claimant as an easy target.

These findings are also in line with research on business justifications for discrimination provided by an authority figure which releases pre-existing prejudice. For instance, previous research found that the availability of justifying instructions to not hire visible minority job candidates led to discrimination against qualified Black applicants by participants who scored high in modern racism (Brief, Dietz, Cohen, Pugh, \& Vaslow, 2000). Similarly, in another study, subtly prejudiced participants who were instructed to maintain a homogeneous workforce, chose fewer foreign applicants for a job interview (Petersen \& Dietz, 2005). In the current study, the business justification may have released prejudice against the Iranian claimant, but it seems to be suppressed for the claimant from Iran but not the Iranian Canadian claimant.

On the other hand, given that the Iranian Canadian was born and raised in Canada, participants might think he should know how to act and should act more in line with the Canadian work ethic. In this case, the fact that the program director blamed his termination on his culture suggests that he did not follow Canadian work culture enough, even though he should know how to behave. This could then be interpreted as suggesting that prejudice per se did not play a role, but instead that the finding was based on expectations for individuals born and raised in Canada.

The second hypothesis predicted that in the ambiguous attribution condition, the claimant from Iran would be more derogated and seen as more deserving of the outcome because of being more personally responsible for the negative outcome. The mediation results did not support this particular hypothesis, due to higher suppression of prejudice against the Iranian claimant, and an absence of differences between countries of origin in the ambiguous attribution condition.

The proposed mediator (attributions of personal responsibility) explained the differences in target derogation between countries of origin in the internal and external attribution conditions. Specifically, in the internal attribution condition, the British claimant was derogated more than Iranian Canadian and Iranian claimants because he 
was perceived as more personally responsible for his contract termination. Once again, these findings are in line with Garcia and colleagues' (2005) findings that by claiming discrimination, the in-group target avoided responsibility for the outcome, which in turn mediated the relationship between attribution type and dislike of this target.

Interestingly, the reverse mediation model wherein outcome deservingness mediated the effect of country of origin on attributions of personal responsibility found stronger statistical support than the hypothesized one. In other words, the British claimant was perceived as more deserving of the job termination, which in turn led to higher attributions of personal responsibility for the outcome, as opposed to the other two claimants. The British claimant deviated from the group norm because he demonstrated inability to meet program requirements and subsequent underperformance. Therefore, as a bad candidate, he was judged as indeed deserving the termination, and thus he is personally responsible for his fate.

In the external attribution condition, the Iranian Canadian claimant who was picked as the discrimination target was derogated more and perceived as more deserving of contract termination than the British claimant because participants attributed to him more personal responsibility. Once again, these findings are in line with the JSM and Kaiser and Miller's (2001) findings.

Additional analyses were performed to explain why participants reported higher empathy in the external attribution condition. On the one hand, the JSM views empathy as a suppressor of pre-existing prejudice. Therefore, participants should have suppressed their prejudice and not differentiated between the claimants based on the country of origin. However, this was not the case, given higher expressions of prejudice against the Iranian Canadian as compared to the British claimant. Clearly, prejudice was released due to the availability of a justification - an authority figure who discriminated against the claimant. What is more, the association between emotional reactions, including empathy, and the main outcomes were not significant. It means that empathy did not play a suppressor role in prejudice against the Iranian Canadian claimant. Instead, empathy was positively related to perceptions of discrimination and other emotional reactions (anger 
and threat/anxiety). Indeed, the mediation analyses provided substantial evidence that participants experienced empathy because the claimant (regardless of his country of origin) got discriminated against. These findings correspond to previous research on targets of discrimination which demonstrated that reading a story of discrimination elicited empathy in participants, but still did not diminish prejudice against obese individuals (Teachman, Gapinski, Brownell et al., 2003).

Finally, I expected to replicate the findings of Study 2 regarding the moderated effects. It was expected that the interaction between the attribution type and country of origin would be moderated by concern with acting prejudiced, such that participants who scored low on the concern with acting prejudiced subscale of the MCPR would express their prejudicial attitudes toward the Iranian claimant more readily, as opposed to the claimants from Britain and the Iranian Canadian. However, the concern with acting prejudiced scale was affected by the manipulations and thus could not be used as a moderator with these variables.

Overall, Study 3 findings were partially in line with Studies 1 and 2. Although in the ambiguous attribution condition there were no differences in any outcomes between the countries of origin, other interesting differences emerged in two other conditions which were not investigated previously. First, in the internal attribution condition, there was evidence of the "black sheep effect", as the British claimant elicited more negative attitudes compared to the other two claimants, partially due to higher attributions of personal responsibility. In the external attribution condition, the pattern was the opposite: the Iranian Canadian claimant elicited more negative attitudes than the claimant from Britain, which again might be explained by higher attributions of personal responsibility. 


\section{Chapter 5}

\section{General Discussion}

This dissertation consists of three studies. Previous research provided evidence regarding more negative perceptions of complaints about discrimination compared to other explanations of negative outcomes, such as poor answer quality, difficulty of a test (Kaiser, Dyrenforth, \& Hagiwara, 2006; Kaiser \& Miller, 2001, 2003), or making an internal attribution (Garcia et al., 2005). In other words, previous studies evaluated responses to a variety of types of attributions: internal, external, as opposed to discrimination. Going one step further, instead of varying types of attributions, the present dissertation evaluated reactions to the same attribution - claiming discriminationdepending on who made such claims and in what circumstances.

Based on the JSM, the first study examined perceptions of an immigrant from a similar culture (Britain), dissimilar culture (Iran), and a second generation Iranian Canadian who claimed employment discrimination in terms of attitudes, attributions of personal responsibility, and behavioural intentions. Study 2 extended the first study by exploring perceptions of discrimination and perceptions of similarity with the claimant as potential mediators. It also evaluated the interplay between justification and suppression factors in the release of prejudice against the Iranian claimant. In addition to the country of origin, Study 3 manipulated a source of attributions for discrimination to further investigate the role of other explanations for the claimant's contract termination - one considered to be internal to the claimant and the other external.

\subsection{Country and generation effects}

All three studies provided evidence of different attitudes toward discrimination claimants based on their country of origin. Based on the evidence of negative attitudes toward and existing employment discrimination toward certain immigrant groups, it was expected that members of immigrant out-groups that are perceived as more dissimilar to Canadians would elicit more prejudice even when they try to voice complaints about unfair 
treatment, especially when a situation is ambiguous and can be interpreted against them in a socially acceptable way.

In line with the JSM and other research on attitudes toward discrimination claimants (Kaiser, Dyrenforth, \& Hagiwara, 2006; Kaiser \& Miller, 2001, 2003), the claimant from Iran elicited more negative attitudes than the Iranian Canadian (Study 1) and British (Study 2) claimants. The JSM views situational ambiguity as a justification factor for the release of genuine prejudice because an ambiguous situation provides room for interpretation and cover up of prejudice. Indeed, the manipulation articles included a photo of the claimant which was not very clear, thus requiring that participants rely on other information to figure out the claimant's ethnic background. As a result, they determined his ethnic background on the basis of his country of origin as stated in the article- mainly Arab and Middle Eastern if he was Iranian or Iranian Canadian, and more White if he was from Britain. Likewise, the article itself was ambiguous in nature in Studies 1 and 2, so that participants could rely on their prejudicial attitudes toward the Iranian claimant if they had them initially. This situational ambiguity manipulation indeed helped to release prejudice toward the Iranian claimant: participants perceived him as less discriminated against, more deserving of termination, more personally responsible and derogated him more. While in the first study the main difference emerged between the Iranian and Iranian Canadian claimants, in the second study it was between the Iranian and British claimants. However, in the second study, participants who were less concerned with acting prejudiced reported more negative attitudes toward the claimant from Iran as compared to the Iranian Canadian claimant. Therefore, the moderated effects were in line with the findings from Study 1.

In the third study, the same pattern was expected in the ambiguous condition. However, no differences in attitudes toward the claimant depending on his country of origin emerged. Further investigation suggests that participants suppressed their prejudice toward the claimant from Iran. This finding explained why the claimant from Iran was evaluated similarly to the other two claimants. Thus, Studies 2 and 3 provided evidence of an interplay between justification and suppression factors in the release of pre-existing prejudice. 
What is more, this dissertation explored attitudes toward the second generation claimant who was born in Canada but his parents immigrated from Iran. Importantly, although such children are raised in the Canadian mainstream culture, in certain immigrant groups second-generation immigrants also face biases and experience employment discrimination, even worse than their parents (Hou \& Coulombe, 2010; Skuterud, 2010). On the other hand, because they were raised in Canada, they might be seen as members of the in-group, which might lead to more positive attitudes and lower discriminatory tendencies, compared to the first-generation immigrants of a culturally dissimilar background. In this light, the findings of Study 2 regarding higher perceived similarity to the Iranian Canadian claimant as compared to the Iranian claimant may mean that he was more likely to be seen as an in-group member. Moreover, not surprisingly, the more participants perceived the claimant as similar to themselves, the more they perceived him as being more discriminated against, derogated him less and attributed less personal responsibility for the outcome. Study 3 in the internal attribution condition also provided support of higher perceived similarity to the Iranian Canadian as compared to the Iranian and British claimants.

However, the findings in the external attribution condition in Study 3 were in line with the first statement regarding more negative attitudes toward the Iranian Canadian claimant, as he was perceived as more deserving of the job termination and more responsible for it than the British claimant. These findings provide evidence of more ambivalent attitudes toward the Iranian Canadian claimant, which can go in either direction depending on the availability of other justification factors.

\subsection{Attribution type effects}

In addition to situational ambiguity, Study 3 evaluated effects of internal and external attributions for the claimant's contract termination. Variations in the attribution type allowed me to see whether the effect of country of origin stayed the same as in the previous two studies. 
Interestingly, in the internal attribution condition, when situational ambiguity was low and the claimant was described as a poor candidate for the position, there was evidence of the black sheep effect (Marques \& Paez, 1994; Marques, Abrams, \& Serôdio, 2001; Garcia et al., 2005). In particular, the claimant from Britain was perceived more negatively than the claimant from Iran and the Iranian Canadian: he was derogated more than the claimant from Iran, perceived as more deserving of the contract termination, and as more personally responsible for the situation than the Iranian and Iranian Canadian claimants. At the same time, participants perceived the British claimant as less similar to themselves. Therefore, as an underperformer, and a complainer about discrimination, he deviated from the group norm, and thus was pushed away. The "black sheep effect" was not evident in Studies 1 and 2 because it was specific to the internal attribution condition under conditions of low situational ambiguity and the description of the claimant as a weak candidate for the position.

The pattern was different in the external attribution condition: the Iranian Canadian claimant was perceived as more deserving of job termination and more responsible for it than the claimant from Britain, with the claimant from Iran falling in between the two other claimants. In this case, participants acknowledged the fact of discrimination and felt sorry for the claimant. However, they picked the Iranian Canadian claimant as an easy target for prejudice expression and as in other conditions suppressed prejudice toward the Iranian claimant. Thus, the Iranian Canadian claimant elicited more prejudice than the claimant from Britain because they found enough grounds to justify their prejudice. Specifically, the fact that the program director discriminated against the claimant and he was raised in Canada and thus was somewhat responsible for the discrimination, and thus prejudice toward the claimant was not participants' fault anymore.

On the other hand, the fact that the program director blamed his termination on his culture suggests that he did not follow Canadian work culture enough, even though he should know how to behave. In this case, the findings may be due not to prejudice per se, but to overall expectations for individuals born and raised in Canada. 


\subsection{Explanatory variables}

To explain the findings of these studies, I expected that the relations between claimant's country of origin and target derogation and outcome deservingness might be explained by attributions of personal responsibility. In the JSM, attributions of responsibility serve as a justification for prejudice. Indeed, in all three studies, attributions of personal responsibility explained the effect of country or origin on target derogation. In Studies 1 and 2 the claimant from Iran was derogated more in part because he was seen as more responsible for the outcome. The same applied to Study 3, as in the internal and external attribution conditions, the claimant was derogated more (British in the internal condition and Iranian Canadian in the external condition) because participants attributed to him higher personal responsibility for the job termination.

The models with outcome deservingness as an outcome were not so consistent with prediction, and depended on the study. Specifically, in Study 1 where the Iranian claimant was perceived as more deserving of the job termination than the Iranian Canadian claimant, perceived responsibility indeed explained this effect. Study 2, where the Iranian claimant was perceived as more deserving of the outcome than the British claimant, provided evidence of mediation in both directions. Consequently, not only attributions of personal responsibility could explain why the Iranian claimant was seen as more deserving of the outcome, but also he might be seen as more responsible because he was deserving in the first place. The JSM views deservingness of the outcome as another justification that can release suppressed prejudice (Crandall and Eshleman, 2003). This particular justification is related to the belief that the world is just and therefore only those who violate norms get punished, whereas those who are worthy get rewarded. Similar results occurred in the internal attribution condition in Study 3, and in the external condition there was support of bidirectional mediation.

On the same note, Study 2 provided strong evidence that outcome deservingness mediated the effect of country on perceived discrimination, in that the claimant from Iran was perceived as less discriminated against than the British claimant because he deserved the termination. 
All together, these findings provide support of attributions of personal responsibility as a justification for target derogation, and outcome deservingness as a justification of perceived responsibility and perceived discrimination. Finally, perceived similarity to the claimant did not explain any effects in Studies 2 and 3, which means that although participants viewed the Iranian claimant and British (in Study 3, internal attribution) as different from themselves, this perceived difference did not mediate effects on negative treatment. Instead, attributions of responsibility and outcome deservingness mediated the expression of their prejudice to the unfavourable claimants.

In some cases, obtained mean scores on dependent measures were below a midpoint. However, the studies in this dissertation were focused on processes rather than absolute levels of variable measurement. Therefore, they looked at higher and lower scores on the dependent measures, rather than absolute indications of target derogation, outcome deservingness and so on.

\subsection{Implications}

\subsubsection{Theoretical implications}

This dissertation was based on the Justification- Suppression Model of Prejudice (Crandall \& Eshleman, 2003). It evaluated justification and suppression factors that may play a role in the expression of prejudice toward discrimination claimants. Although most of the results fit with the model, a few findings needed additional explanations.

For instance, in the situation in which the claimant had clearly weak qualifications, the JSM would predict that due to the absence of situational ambiguity, there would be no difference between discrimination claimants based on their country of origin. Contrary to this prediction, there was evidence of the 'black sheep effect' (Marques \& Paez, 1994; Hutchison, Abrams, Gutierrez, \& Viki, 2008; Pinto, Marques, Levine, \& Abrams, 2010), in which the British claimant elicited more negative attitudes and was perceived as less similar than the Iranian Canadian claimant. 
Furthermore, in addition to attributions of personal responsibility, outcome deservingness also played a role as a justification factor. What is more, it explained the effect of country of origin on attributions of personal responsibility. Therefore, these two justifications may be used interchangeably, or one may cause another. Although the JSM mentions judgements of deservingness (Crandall \& Eshleman, 2003), they are seen as a part of a belief system - belief in a just world- which also plays a role in release of prejudice.

Moreover, the JSM views empathy as a suppressor of prejudice because it makes people reconsider the appropriateness of prejudice and promotes tolerance, thus resulting in more favourable out-group attitudes. Based on these propositions, one would expect empathy to suppress prejudice in the external and ambiguous attribution conditions in Study 3. Not in line with this prediction, empathy was not or was weakly related to attitudinal outcomes. Despite higher empathy, participants evaluated negatively the Iranian Canadian claimant in the external attribution condition. Therefore, the effects of empathy and expression of prejudice toward discrimination claimants may be independent.

In sum, in combination with other models, the JSM explains well the results of this dissertation. It is especially useful to examine the interplay between suppression and justification factors in the release of prejudice.

\subsubsection{Practical implications}

A number of federal and provincial policies prohibit any form of discrimination. For instance, the Ontario Human Rights Code promotes equal rights and opportunities and prohibits employment discrimination based on the grounds of race, ethnic origin, place of origin, and other characteristics (Human Rights Code, R.S.O. 1990). Moreover, to increase accessibility to the human rights system in Ontario, since 2008 discrimination claimants can get free legal asistance and get their case reviewed by the Human Rights Tribunal free of charge (Pinto, 2012). 
Despite these policies, certain immigrant groups still experience discrimination at every step of employment: from hiring to wage gaps, promotions, and being first to be laid off. Skilled immigrants in Canada are more likely than non-immigrants to be unemployed, underemployed, and underpaid (Lo et al., 2010; Reitz, 2013). In Ontario, the pattern is similar, with wage gaps especially evident between racialized (visible minority) immigrant women and non-racialized men (Block, 2010).

Even though minority immigrants experience more employment discrimination, oftentimes they do not officially complain about their experiences or open a legal case. This dissertation explored Canadians perceotions of immigrants claiming discrimination, in order to understand factors that contribute to biased perceptions of such claims. This can inform government and private sector emloyers' policies to encourage discrimination claims and review them more objectively.

Based on my doctoral dissertation research, I argue that there are several issues that still need to be addressed to reduce biases in reviewing discrimination claims and encourage report of employment discrimination. First, my research suggests that situational ambiguity in the presentation of a discrimination case may provide room for the expression of bias toward immigrants, especially if they come from dissimilar cultures. In some cases, it may be applied to second-generation immigrant minorities who were raised in Canada. Therefore, reducing situational ambiguity by obtaining more information about the claimant and his case may help to view the case more objectively.

Furthermore, non-discrimination policies might be effective for those officials and employers who are highly motivated to not discriminate against certain minorities. That is, they are less inclined to discriminate in the first place, and the policy regarding equal treatment of all employees and bias correction may serve for them as a reminder that they should not discriminate. On the other hand, my research suggests that employers who are less motivated to suppress their biases will still express these biases, but in a way that is more subtle and thus harder to prove and take legal action against. This can explain why despite the existence of these policies, immigrants still struggle to obtain jobs, especially 
those that match their qualifications, and reluctant to share their discrimination experiences.

To counteract these biases and to reduce the chances that employers are not familiar with the Human Rights Code and its policies, the government may implement workshops and campaigns for employers to educate them about employees' rights and employer's responsibilities in terms of providing a healthy non-discriminatory work environment. As part of these workshops, it will be important to educate employers regarding the consequences of their discriminatory actions such as loss of economic and non-economic benefits, reputational and momentary costs. Employers have to be educated about hard-to-detect biases and how to avoid them in their decision making.

The next suggestion is to increase monetary and reputational costs for companies that violate the Human Rights Code in cases of proven discrimination. In addition, their reputation as those who practice discrimination should be available to the public, which in turn may result in turning away some customers (and thus result in economic losses). The public should be made aware of ethical behaviour and taking corporate responsibility by companies that support human rights and provide equal treatment to employees. In terms of benefits, low discrimination increases trust of employees to the company and management and this in turn improves commitment of employees (Kim, Lee, Lee, \& Kim, 2010).

Finally, new employees should attend orientation workshops where a third member (ideally from the government) will provide full information to employees regarding their rights, signs of overt and subtle discrimination, and where to file a claim, thus increasing their confidence in the human rights system.

In sum, these changes may result in reductions of ambiguity in reviewing discrimination cases, better awareness of subtle biases, and higher motivation to suppress those biases, which should encourage minorities to claim employment discrimination when appropriate and get their cases reviewed objectively. 


\subsection{Limitations and future directions}

This dissertation has a number of limitations that may be addressed in future work to clarify the pattern of findings. First, in all three studies, participant samples comprised university-aged undergraduates, which raises a question of the generalizability of results to the general Canadian population. Given that university students tend to be especially likely to suppress their prejudices, we might expect that research with a general population of participants would demonstrate more evidence of prejudice and discrimination. Next, a laboratory intervention was used in all three studies; although an effort was made to present the manipulation articles in a believable format, participants might be still aware that it is not a real-world situation. Their intergroup perceptions and behaviours in real life situations may thus differ. For instance, in some cases individuals may have enough time and resources to suppress their prejudice, even in ambiguous situations. On the other hand, as prejudice suppression depends on social norms and personal standards (Crandall \& Eshleman, 2003), it might be expressed more readily if the norms are more permissive. At the same time, as biases are still widespread in discrimination case reviews (Al-Waqfi \& Jain, 2008), it might be the case that the effect of country of origin would be magnified in real-world situations.

In line with the previous limitation, a number of situational and individual difference variables that have not been included in the present study may also affect the pattern of results. For instance, prejudice in case of the claimant from a dissimilar culture (Iran) may be also explained by perceptions of differences in religion. It is possible that the claimant from Iran is perceived as being Muslim. This in turn may raise concerns about differences in religious beliefs and associated threat appraisals. Follow-up studies may ask participants about their perceptions of applicants' religious affiliation and their own affiliation to see if differences in religious affiliation contribute to prejudice.

Moreover, this dissertation does not take into account individual difference variables related to expression of prejudice and discrimination, except motivation to control prejudice. For instance, among these variables are the strength of in-group identity (social identity; Cameron, 2004), person's social dominance orientation (Pratto, 
Sidanius, Stallworth, \& Malle, 1994), belief in a just world (Lerner, 1980), religious fundamentalism (Altemeyer, \& Hunsberger, 2004) and others. For example, belief in a just world (BJW) is an important individual difference variable that influences attitudinal outcomes and judgements of deservingness (Lerner, 1980; Hafer \& Begue, 2005). It refers to the belief that the world is just place and therefore individuals should deserve their outcomes. From this point of view, inclusion of the BJW scale might help to explain why outcome deservingness mediated the effect of country of origin on perceived responsibility and perceived discrimination in Studies 2 and 3. This tendency may be more evident in a subset of participants with higher BJW, similar to other studies in this area (Galen, \& Miller, 2011; Halabi, Statman, \& Dovidio, 2015).

Finally, as the results of this dissertation contribute to a better understanding of the job-related problems faced by immigrants of different cultural backgrounds, future research should test strategies for reducing the negative impact of cultural dissimilarity on perceptions of discrimination claims. For instance, it will be of interest to determine $t$ whether awareness of the biases faced by immigrants from dissimilar cultures reduces the effects, and whether proposed policy changes that increase motivation to control prejudice can be used to counteract these biases.

\subsection{Conclusion}

The present dissertation evaluated Canadians' perceptions of employment discrimination claims by culturally similar (Britain), dissimilar (Iran), or a second generation immigrant claimant from a dissimilar culture (Iranian Canadian). It found that ambiguity in the case description resulted in negative bias against the claimant from Iran, unless participant suppressed their prejudice toward the claimant. Furthermore, when the claimant was clearly unskilled for the job, there was an evidence of a "black sheep effect"- more negative attitudes toward the British claimant. Finally, in the situation with an authority figure responsible for discrimination, the second generation Iranian Canadian elicited more negativity. These effects may be explained by attributions of personal responsibility and judgements of outcome deservingness. The results of this research contribute to a better understanding of the problems faced by immigrants of different cultural 
backgrounds who claim work-related discrimination. This will contribute to recent attempts to reduce the underemployment and unemployment of skilled immigrants in Canada, and ensure that their claims of employment discrimination get reviewed objectively. 


\section{References}

Ajzen, I., \& Fishbein, M. (2005). The influence of attitudes on behavior. In D.

Albarracín, B. T. Johnson, \& M. P. Zanna (Eds.), The handbook of attitudes (pp. 173-221). Mahwah, NJ: Erlbaum.

Al-Waqfi, M., \& Jain, H. C. (2008). Racial inequality in employment in Canada: empirical analysis and emerging trends. Canadian Public Administration, 51, 429-453.

Altemeyer, B., \& Hunsberger, B. (2004). Research: A revised religious fundamentalism scale: The short and sweet of it. The International Journal for the Psychology of Religion, 14(1), 47-54.

Block, S. (2010). Ontario's Growing Gap: The Role of Race and Gender. Canadian Centre for Policy Alternatives.

Booth, A. L., Leigh, A., \& Varganova, E. (2012). Does ethnic discrimination vary across minority groups? Evidence from a field experiment. Oxford Bulletin of Economics and Statistics, 74, 547-573.

Brief, A. P., Dietz, J., Cohen, R. R., Pugh, S. D., \& Vaslow, J. B. (2000). Just doing business: Modern racism and obedience to authority as explanations for employment discrimination. Organizational Behavior and Human Decision Processes, 81(1), 72-97.

Cameron, J. E. (2004). A three-factor model of social identity. Self and Identity, 3, 239262.

Citizenship and Immigration Canada (2013). Annual report to parliament on immigration, 2013. Retrieved Apr. 30, 2014 from http://www.cic.gc.ca/english/resources/publications/annual-report-2013/index.asp

Citizenship and Immigration Canada (2013). Facts and figures 2012: Immigration overview - Permanent and temporary residents. Retrieved Apr. 30, 2014 from http://www.cic.gc.ca/english/pdf/research-stats/facts2012.pdf

Crandall, C. S., Eshleman, A., \& O'Brien, L. (2002). Social norms and the expression and suppression of prejudice: the struggle for internalization. Journal of personality and social psychology, 82, 359-78. 
Crandall, C. S., \& Eshleman, A. (2003). A justification-suppression model of the expression and experience of prejudice. Psychological Bulletin, 129, 414-46.

Crocker, J., \& Major, B. (1989). Social stigma and self-esteem: The self-protective properties of stigma. Psychological Review, 96, 608-30.

Creese, G., \& Wiebe, B. (2012). 'Survival employment': Gender and deskilling among african immigrants in Canada. International Migration, 50(5), 56-76.

Cunningham, E., \& Platow, M. J. (2007). On helping lower status out-groups: The nature of the help and the stability of the intergroup status hierarchy. Asian Journal of Social Psychology, 10, 258-64.

Dipboye, R. L., \& Collella, A. (2005). An introduction. In R. L. Dipboye \& A. Colella (Eds.), Discrimination at work: The psychological and organizational bases (pp. 1- 10). Mahwah, NJ: Lawrence Erlbaum Associates Publishers.

Dovidio, J. F., Esses, V. M. (2001). Immigrants and immigration: Advancing the psychological perspective. Journal of Social Issues, 57, 378-87.

Dovidio, J. F., \& Gaertner, S. L. (1998). On the nature of contemporary prejudice: The causes, consequences, and challenges of aversive racism. In J. Eberhardt \& S.T. Fiske (Eds.), Confronting racism: The problem and the response (pp. 3-32). Newbury Park, CA: Sage

Dovidio, J. F., \& Gaertner, S. L. (2000). Aversive racism and selection decisions: 1989 and 1999. Psychological Science, 11, 319-23.

Dovidio, J. F., \& Gaertner, S. L. (2004). Aversive racism. In M. P. Zanna (Ed.), Advances in experimental social psychology (pp. 1 - 52). San Diego, CA: Academic Press.

Dovidio, J. F., \& Hebl, M. R. (2005). Discrimination at the level of the individual: Cognitive and affective factors. In R. L. Dipboye \& A. Colella (Eds.), Discrimination at work: The psychological and organizational bases (pp. 1135). Mahwah, NJ: Erlbaum.

Dovidio, J. F., Gaertner, S. L., Kawakami, K., \& Hodson, G. (2002). Why can't we just get along? Interpersonal biases and interracial distrust. Cultural Diversity and Ethnicity Minority Psychology, 8, 88-102. 
Dovidio, J. F., Gaertner, S. L., Validzic, A., Matoka, K., Johnson, B., \& Frazier, S. (1997). Extending the benefits of recategorization: Evaluations, self-disclosure and helping. Journal of Experimental Social Psychology, 33, 401-420.

Dunton, B. C., \& Fazio, R. H. (1997). An individual difference measure of motivation to control prejudiced reactions. Personality and Social Psychology Bulletin, 23, 31626.

Esses, V. M., Dietz, J., Bennett-Abuayyash, C., \& Joshi, C. (2007). Prejudice in the workplace The role of bias against visible minorities in the devaluation of immigrants' foreign-acquired qualifications and credentials. Canadian Issues/Thèmes Canadiens, Spring, 114-118.

Esses, V. M., Dietz, J., \& Bhardwaj, A. (2006). The role of prejudice in the discounting of immigrant skills. In R. Mahalingam (Ed.), Cultural psychology of immigrants (pp.113-130). Mahwah, NJ: Lawrence Erlbaum Associates Publishers.

Fazio, R. H., \& Dunton, B. C. (1997). Categorization by race: The impact of automatic and controlled components of racial prejudice. Journal of experimental social psychology, 33, 451-70.

Feagin, J. R., \& Sikes, M. P. (1994). Living with racism: The Black middle-class experience. Boston: Beacon.

Gaertner, S. L., \& Dovidio, J. F. (1986). The aversive form of racism. Academic Press. Galarneau, D., \& Morisette, R. (2004). Immigrants: Settling for less? Analytical paper. Perspectives on Labour and Income, 5(6), 5-16. Ottawa: Statistics Canada. Catalogue no. 75-001-XIE. Retrieved Sept. 20, 2013 from http://www.statcan.gc.ca/pub/75001-X/10604/6921-eng.pdf

Galen, L. W., \& Miller, T. R. (2011). Perceived deservingness of outcomes as a function of religious fundamentalism and target responsibility. Journal of Applied Social Psychology, 41(9), 2144-2164.

Garcia, D. M., Horstman Reser, A., Amo, R., Redersdorff, S., \& Branscombe, N. R. (2005). Perceivers' responses to in-group and out-group members who blame a negative outcome on discrimination. Personality and Social Psychology Bulletin, 31, 769-80. 
Gilmore, J. (2009). The 2008 Canadian immigrant labour market: analysis of quality of employment. The Immigrant Labour Force Analysis Series. No. 5. Statistics Canada Catalogue no. 71-606-X. Retrieved May 52014 from: http://www.statcan.gc.ca/pub/71-606-x/71-606-x2009001-eng.pdf.

Goldman, B. M. (2001). Toward an understanding of employment discrimination claiming: An integration of organizational justice and social information processing theories. Personnel Psychology, 54(2), 361-386.

Hafer, C. L., \& Begue, L. (2005). Experimental research on just-world theory: problems, developments, and future challenges. Psychological bulletin, 131, 128-67.

Halabi, S., Dovidio, J. F., \& Nadler, A. (2008). When and how high status groups offer help: Effects of social dominance orientation and status threat. Political Psychology, 29, 841-58.

Halabi, S., Statman, Y., \& Dovidio, J. F. (2015). Attributions of responsibility and punishment for ingroup and outgroup members: The role of just world beliefs. Group Processes \& Intergroup Relations, 18(1), 104-115.

Haslett, B. B., \& Lipman, S. (1997). Micro inequalities: Up close and personal. In N. V. Benokraitis (Ed.), Subtle sexism: Current practice and prospects for change (pp. 34-53). Thousand Oaks, CA: Sage.

Hassan, H. D. (2007). Iran: Ethnic and Religious Minorities. Library of Congress Washington, DC Congressional Research Service. Retrieved on June 252015 from http://fas.org/sgp/crs/mideast/RL34021.pdf

Hayes, A. F. (2009). Beyond Baron and Kenny: Statistical mediation analysis in the new millennium. Communication monographs, 76(4), 408-420.

Hayes, A. F., \& Preacher, K. J. (2014). Statistical mediation analysis with a multicategorical independent variable. British Journal of Mathematical and Statistical Psychology, 67(3), 451-470.

Hegarty, P., \& Golden, A. M. (2008). Attributional beliefs about the controllability of stigmatized traits: Antecedents or justifications of prejudice? Journal of Applied Social Psychology, 38, 1023-44.

Heider, F. (1958). The Psychology of Interpersonal Relations. New York: Wiley. 
Henry, P. J., Reyna, C., \& Weiner, B. (2004). Hate welfare but help the poor: How the attributional content of stereotypes explains the paradox of reactions to the destitute in America. Journal of Applied Social Psychology, 34, 34-58.

Hewstone, M. (1990). The 'ultimate attribution error'? A review of the literature on intergroup causal attribution. European Journal of Social Psychology, 20, 311-35.

Hodson, G., Dovidio, J. F., \& Gaertner, S. L. (2002). Processes in racial discrimination: Differential weighting of conflicting information. Personality and Social Psychology Bulletin, 28, 460-71.

Hou, F., \& Coulombe, S. (2010). Earnings gaps for Canadian-born visible minorities in the public and private sectors. Canadian Public Policy, 36(1), 29-43.

Hoyle, R. H., \& Kenny, D. A. (1999). Statistical power and tests of mediation. In R. H. Hoyle (Ed.), Statistical strategies for small sample research. Newbury Park: Sage.

Human Rights Code. R.S.O. 1990, CHAPTER H.19. Retrieved May 8, 2015 from www.e-laws.gov.on.ca/Download/elaws_statutes_90h19_ev002.doc.

Hutchison, P., Abrams, D., Gutierrez, R., \& Viki, G. T. (2008). Getting rid of the bad ones: The relationship between group identification, deviant derogation, and identity maintenance. Journal of Experimental Social Psychology, 44(3), 874-881.

Jackson, L.M. \& Esses, V.M. (1997). Of scripture and ascription: The relation between religious fundamentalism and intergroup helping. Personality and Social Psychology Bulletin, 23, 893-906.

Jackson, L. M., \& Esses, V. M. (2000). Effects of perceived economic competition on people's willingness to help empower immigrants. Group Processes \& Intergroup Relations, 3, 419-35.

Kaiser, C. R., \& Major, B. (2006). A social psychological perspective on perceiving and reporting discrimination. Law and Social Inquiry, 36, 801-830.

Kaiser, C. R. \& Miller, C. T. (2003). Derogating the victim: The interpersonal consequences of blaming events on discrimination. Group Processes and Intergroup Relations, 6, 227-237. 
Kaiser, C. R., \& Miller, C. T. (2001). Stop complaining! The social costs of making attributions to discrimination. Personality and Social Psychology Bulletin, 27, 254-263.

Kaiser, C. R., Dyrenforth, P., \& Hagiwara, N. (2006). Why are attributions to discrimination interpersonally costly?: A test of status legitimizing and group justifying motivations. Personality and Social Psychology Bulletin, 32, 1523-36.

Lerner, M. J. (1980). The belief in a just world. Springer US.

Li, C., Gervais, G., \& Duval, A. (2006). The dynamics of overqualification: Canada's underemployed university graduates. Analysis in Brief. Ottawa: Statistics Canada. Catalogue no. 11-621-MIE-No.039. Retrieved Mar. 23, 2014 from http://www.statcan.gc.ca/pub/11-621-m/11-621-m2006039-eng.pdf.

Lo, L., Damsbaek, N., Phan, M., Kelly, P.F., Lemoine, M., Fang, T., Preston, V., \& Tufts, S. (2010). Place of Study of Highest Education: Are Degrees/Diplomas from Inside and Outside of Canada Valued Differently in the Labour Market? TIEDI Analytical Report 14 (December). Retrieved May 52014 from: www.yorku.ca/tiedi/pubreports14.html.

Major, B., Kaiser, C. R., \& McCoy, S. K. (2003). It's not my fault: When and why attributions to prejudice protect self-esteem. Personality and Social Psychology Bulletin, 29, 772-81.

Marques, J., Abrams, D., \& Serôdio, R. G. (2001). Being better by being right: subjective group dynamics and derogation of in-group deviants when generic norms are undermined. Journal of personality and social psychology, 81(3), 436.

Marques, J. M., \& Paez, D. (1994). The 'black sheep effect': Social categorization, rejection of ingroup deviates, and perception of group variability. European review of social psychology, 5(1), 37-68.

McConahay, J. B., Hardee, B. B., \& Batts, V. (1981). Has racism declined in America? It depends on who is asking and what is asked. Journal of conflict resolution, 25(4), 563-579.

Olson, M. A., \& Fazio, R. H. (2004). Trait inferences as a function of automatically activated racial attitudes and motivation to control prejudiced reactions. Basic and Applied Social Psychology, 26(1), 1-11. 
Oreopoulos, P. (2009). Why do skilled immigrants struggle in the labor market? A field experiment with six thousand resumes (No. w15036). National Bureau of Economic Research.

Ostrovsky, Y. (2008). Earnings inequality and earnings instability of immigrants in Canada. Research paper. Analytical Studies Branch Research Paper Series,309. Ottawa: Statistics Canada. Retrieved Dec.10, 2012 from http://www.statcan.gc.ca/pub/11f0019m/11f0019m2008309-eng.pdf.

Pearson, A. R., Dovidio, J. F., \& Gaertner, S. L. (2009). The nature of contemporary prejudice: Insights from aversive racism. Social and Personality Psychology Compass, 3, 314-38.

Petersen L.-E. \& Dietz J. (2005). Prejudice and enforcement of workforce homogeneity as explanations for employment discrimination. Journal of Applied Social Psychology, 35, 144-59.

Picot, G., Hou, F., \& Coulombe, S. (2007). Chronic low income and low-income dynamics among recent immigrants. Research paper. Analytical Studies Branch Research Paper Series, 294. Ottawa: Statistics Canada. Retrieved Nov. 1, 2013 from http://www.statcan.ca/english/research/11F0019MIE/11F0019MIE2007294.pdf

Pinto, A. (2012). Report of the Ontario Human Rights Review 2012. Ontario Ministry of the Attorney General. ISBN 978-1-4606-0150-1. Retrieved May 7, 2015 from http://www.attorneygeneral.jus.gov.on.ca/english/about/pubs/human_rights/Pinto _human_rights_report_2012-ENG.pdf.

Pinto, I. R., Marques, J. M., Levine, J. M., \& Abrams, D. (2010). Membership status and subjective group dynamics: Who triggers the black sheep effect?. Journal of personality and social psychology, 99, 107-19.

Plant, E. A., \& Devine, P. G. (1998). Internal and external motivation to respond without prejudice. Journal of Personality and Social Psychology, 75, 811-32.

Pratto, F., Sidanius, J., Stallworth, L. M., \& Malle, B. F. (1994). Social dominance orientation: A personality variable predicting social and political attitudes. Journal of personality and social psychology, 67(4), 741-63. 
Preacher, K. J., \& Hayes, A. F. (2004). SPSS and SAS procedures for estimating indirect effects in simple mediation models. Behavior Research Methods, Instruments, and Computers, 36, 717-731.

Reitz, J.G. (2013). Closing the gaps between skilled immigration and Canadian labour markets. In P. Triadafilopoulos (Ed.), Wanted and Welcome?: Policies for Highly Skilled Immigrants in Comparative Perspective (pp. 147-163). New York: Springer.

Reitz, J. G., Curtis, J., \& Elrick, J. (2014). Immigrant skill utilization: Trends and policy issues. Journal of International Migration and Integration, 15(1), 1-26.

Rudolph, U., Roesch, S., Greitemeyer, T., \& Weiner, B. (2004). A meta-analytic review of help giving and aggression from an attributional perspective: Contributions to a general theory of motivation. Cognition and Emotion, 18, 815-48.

Schwartz, S. H. (1994). Are there universal aspects in the structure and contents of human values?. Journal of social issues, 50(4), 19-45.

Skuterud, M. (2010). The visible minority earnings gap across generations of Canadians. Canadian Journal of Economics/Revue canadienne d'économique, 43, 860-81.

Statistics Canada (2015). CANSIM Table 282-0102 - Labour force survey estimates (LFS), by immigrant status, age group. Retrieved June 122015 from: http://www5.statcan.gc.ca/cansim/a26?lang=eng\&id=2820102.

Stephan, W. G., Renfro, C. L., Esses, V. M., Stephan, C. W., \& Martin, T. (2005). The effects of feeling threatened on attitudes toward immigrants. International Journal of Intercultural Relations, 29, 1-19.

Stevens, J.P. (2002). Applied multivariate statistics for the social sciences (4th Ed.). Mahwah, NJ: Lawrence Erlbaum Associates Publishers.

Stürmer, S., \& Snyder, M. (2010). Helping "us" versus “them": Towards a group-level theory of helping and altruism within and across group boundaries. In S. Stürmer \& M. Snyder (Eds.), The psychology of prosocial behavior: Group processes, intergroup relations, and helping (pp. 33-58). Oxford, UK: Wiley-Blackwell.

Syed, J. (2008). Employment prospects for skilled migrants: a relational perspective. Human Resource Management Review, 18(1), 28-45. 
Tajfel, H., \& Turner, J. C. (1979). An integrative theory of intergroup conflict. In W. G. Austin \& S. Worchel (Eds.), The social psychology of intergroup relations (pp. 33-47).

Tarrant, M., Dazeley, S., \& Cottom, T. (2009). Social categorization and empathy for outgroup members. British Journal of Social Psychology, 48, 427-46.

Turner, J. C., Hogg, M. A., Oakes, P. J., Reicher, S. D., \& Wetherell, M. S. (1987). Rediscovering the social group: A self-categorization theory. Oxford, UK: Blackwell.

Wicker, A. W. (1969). Attitudes versus actions: The relationship of verbal and overt behavioral responses to attitude objects. Journal of Social Issues, 25, 41-78.

Widner, D., \& Chicoine, S. (2011). It's all in the name: Employment discrimination against Arab Americans. Sociological Forum, 26, 806-23.

Yssaad, L. (2012). The Canadian Immigrant Labour Market. The Immigrant Labour Force Analysis Series. Statistics Canada, Ottawa. Retrieved May 52014 from http://www.statcan.gc.ca/pub/71-606-x/71-606-x2012006-eng.pdf. 


\section{Appendices}

Appendix A: Ethics Approvals for Studies 1-3

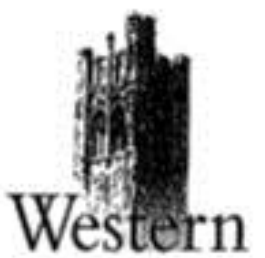

\section{Department of Psychology the Unversity of Westem Ontario Room 7418 social Sciences Contre. London ON Canada NBASC1 Toliephone}

Use of Human Subjects - Ethics Approval Notice

\begin{tabular}{|r|l|r|l|}
\hline Review Number & 101023 & Approval Dato & 101012 \\
\hline Principal Investigator & Vickie FuevNatalia Lapatima & End Dato & 116315 \\
\hline Protocol Thio & Media percoptions & & \\
\hline Sponsor & wa & & \\
\hline
\end{tabular}

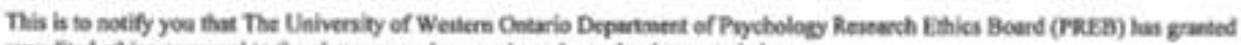
expolited ethics approval to the sbove named revearch thaty on the date soted abow.

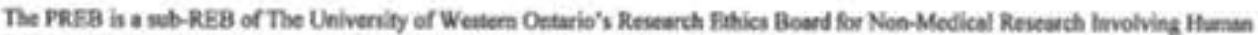

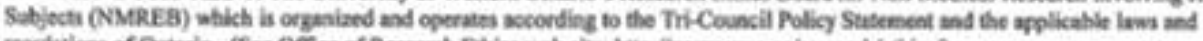

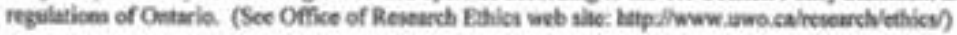

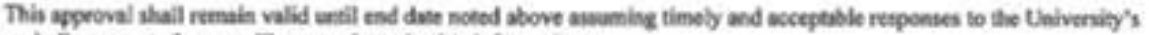
periodic requetsts for warveillance and monitoring information.

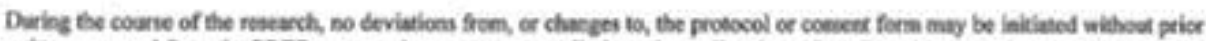

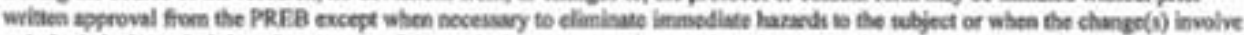

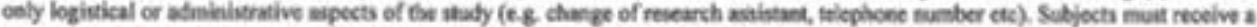
copy of the informationvocnuent docutorntation.

Inveritgatons must prongety aho repoet to the PREB:

a) changes increating the risk to the participanit(v) andor affecting significantly the coedest of the study.

b) all advene and unexperted experiencet or ewents bat ave bohs serioes and unexpected;

c) new information that may adversely affoct the asfety of the rabjects or the condoct of the sady.

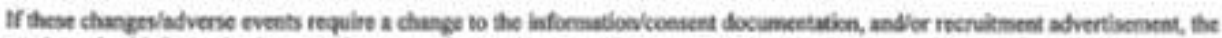
newly revived infornation/ceniest dextmentution, andier advertinement, nunt be sutmited to the PREB for approval.

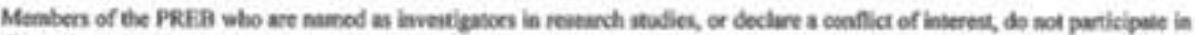
diacessice ipinted to, nor vobe cen, soch iludies when they are presented to dhe PRER.

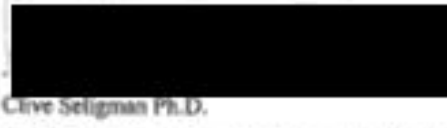

Chai, Pychology Expedited Restarch Ethics Bound (PRkB)

The other memben of the 2009-2010 Fres are: David Dasok, Bail Fither, Rilky Hinson and Sitve Lepker 
Department of Psychology The Univeraity of Western Ontarlo

Room 7418 Social Sclencos Centre, London, ON, Canada NEA SC1

Western

Telophone:

Use of Human Subjects - Ethics Approval Notice

\begin{tabular}{|r|l|r|l|}
\hline Review Number & 120405 & Approval Date & 120414 \\
\hline Principal Investigator & V. Eases & End Date & 130430 \\
\hline Protocol Tritle & Medis Perceptions-2 & \\
\hline Sponsor & $\mathrm{w} / \mathrm{a}$ & \\
\hline
\end{tabular}

This is to notify you that The Univerrity of Weetern Onterio Depertment of Pychology Rescwech EAtics Bowed (PREB) has granted expodited ethica approval to the above auned resestch stady an the dale noted above.

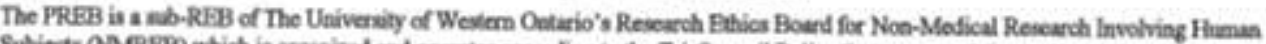

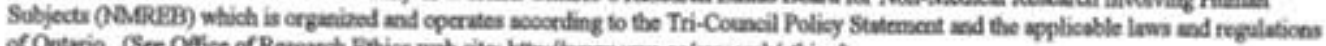

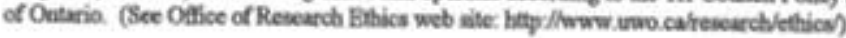

This appeoval shall remain valid until end date noted above stuming timely and scocptable responses to the Univerily's periodie requents for arveillenee and monitoring infommation.

During the oourse of the research, no deviaticns ffom, or changes ta, the protosol or coasent form may be initiated without prier written approval from the PREB exept when necessary to eliminute inmediate hartards to the wibjoct or when the chunge(s) imvolve caly

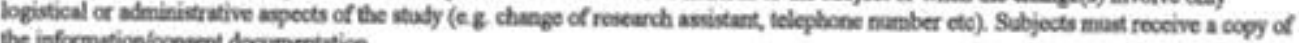
the informutionolocnecent documentution.

Investipators mast peongtly also report to the PREB:

a) changes incressing the risk to the purticipart(s) mdlor affecting significaetly the coedust of tho atudy:

b) All acturse and lesexpocted experiencess or events that are both serioas und unexpected,

c) new information that may advernely affect the safity of the mubjects or the condoct of the stoudy.

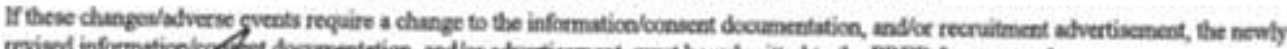

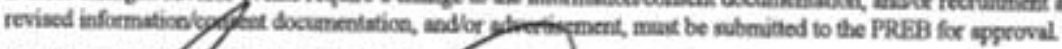

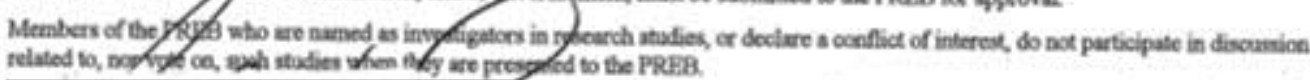

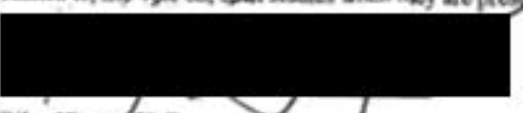

Riley Hinoced Ph.D

Acting Chair (in the absence of Cliv Scligman), Prychology Bxpedited Research Baics Bowed (PREB)

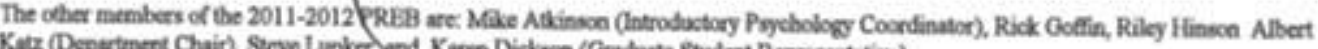
Katz (Depertment Chair), Steve Lupker, and Karm Dickson (Gridaste Student Regresentative) 
Principal Investigator: Poof. Vicki Kases

Department \& leatitutioes: Soclal Sciencethycholoky, Weatern Uniretsiny

NMREB Fle Namber 105745

Study Tilk: Modia Reresploes-3

Sponsor:

NMREB Initial Approval Date: Oetober 10, 2014

NMREB Expiry Date: Auguas 31, 2015

Docements Approved and/or Received for Information:

\begin{tabular}{|c|c|c|}
\hline Docunens Name & Cominents & Yenion Daite \\
\hline \multicolumn{3}{|l|}{ Recrnitment fleens } \\
\hline Revived Westem Univenity Protocol & Suhminioa with chaspes-FDF & 20140016 \\
\hline Inevinimeats & Raricipant questionnaire-pefl & 20141000 \\
\hline Other & Dobriefing pdr & $2014 / 1008$ \\
\hline Rerived Leter of hiformutioa \& Consent & LOA-paf & 20141008 \\
\hline Onet & Coessnt-pat & 20141008 \\
\hline
\end{tabular}

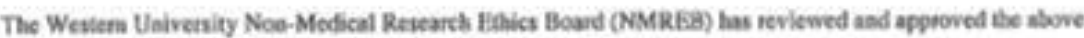
maned study, as of tho HSREB Intial Approval Date noted above.

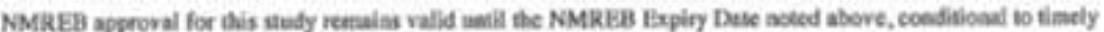
ubetision aed socepensce of HSFEB Continuing Eales Review.

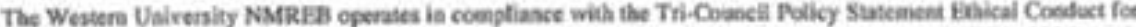

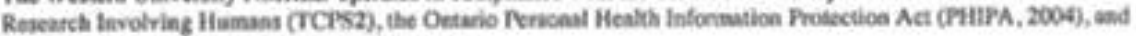
the applicable taws and regelations of Ontario.

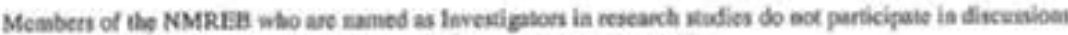

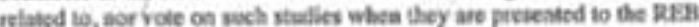

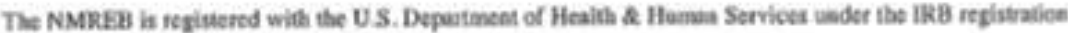

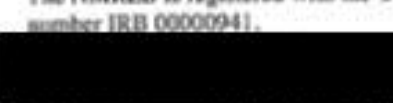

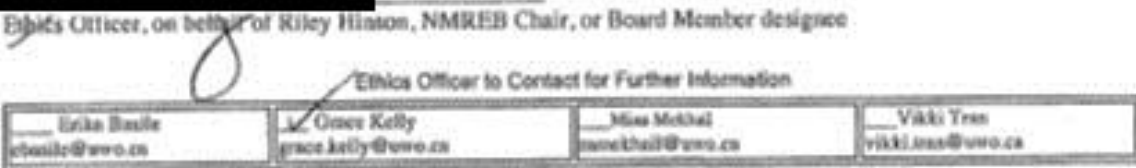

This is as effecial dociment. Plowe rebain the artginal in your flles. 
Appendix B: Studies 1 and 2

Letter of Information

Title: Media perceptions

Description: In this study, we will assess your reactions to a newspaper article randomly selected from a pool of articles of interest. After reading and evaluating this article, you will be asked to answer several questions about the article and about your attitudes more generally.

The data collected in this study will be kept confidential. Your informed consent form will be separated from your responses and kept in a separate and secured file by the research investigator who will keep this information confidential. The data will be used for research purposes only.

This study takes less than 60 minutes to complete. You will receive 1 credit for participation in this study.

Your participation in this study is entirely voluntary. At any point during the study you have the right to not complete certain questions or to withdraw without penalty.

There are no known risks associated with participation in this study.

You will receive additional written feedback at the end of the session and have a chance to ask questions about the study. 


\section{Consent Form}

I have read the Letter of Information, have had the nature of the study explained to me and I agree to participate. All questions have been answered to my satisfaction.

Full Name (please print):

Participant Signature:

Date :

Researcher Signature :

Date : 
Appendix C: Studies 1 and 2 Manipulation Articles and Measures

http://www.canada.com/ottawacitizen/news/story.html?id=6838

Monday, August 9, 2010

Part of the Canada.com Network Jump to: Newspapers, TV, Radio
local classifieds working driving obituaries celebrating shopping renting contractors dating
= See today's Digital Edition
= Subscribe to email newsletter
$=$ Subscriber Services
Ottawa Citizen Home Search for

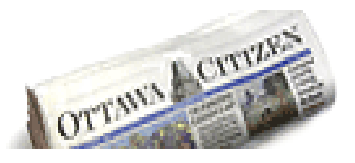

$\underline{\text { Inside the Ottawa Citizen }}$

"Not good enough" to be trained?

- News

- News Briefs

- Letters

$\circ \quad$ Editorials

○ Opinion

- Sports

- Sports Briefs

- Arts

- Life

$\circ$ City

- Columnists

- 30 days Archive

- Headlines Scan

\section{Lisa Campbell}

- Newspaper Ads

The Canadian Press Published on Monday, Aug 9, 2010 1:25PM EDT Last updated on Monday, Aug 9, 2010 8:30PM EDT

- $\underline{\text { Special Sections }}$

BURLINGTON, ON - Sam Barzun was born in England. Along with five other recent graduates, he was admitted to a managerial training program with the Links company in May 2010. However, he was dropped from the program three months later, well before the training program was completed. Based on his claim of discrimination, an investigation is ongoing.

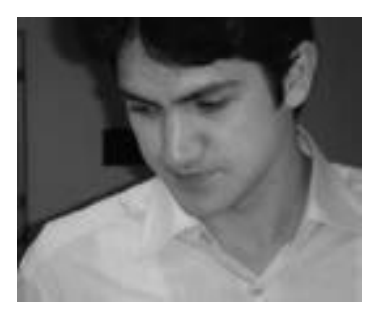

"At the beginning, the program director, John Andrews, was happy with my progress, and I successfully passed two evaluation assessments - at months one and two of the program. Later on, however, I started to get remarks regarding missing the training and being late on several occasions. In addition, although I put a great deal of effort into the training, the director was not satisfied with my progress and performance anymore." Barzun told the Ottawa 


\section{Citizen.}

At the third evaluation assessment, Barzun received poor scores from the program director and staff. The following day, he was told his training contract was terminated, and he was ineligible for re-enrolment.

"I don't think I've ever been treated like that," Barzun told the Ottawa Citizen. "This is the first time I have experienced discrimination." 
http://www.canada.com/ottawacitizen/news/story.html?id=6838

Monday, August 9, 2010

Part of the canada.com Network
local classifieds working driving obituaries celebrating shopping renting contractors dating
= See today's Digital Edition
= Subscribe to email newsletter
= Subscriber Services
Ottawa Citizen Home Search for

Inside the Ottawa

\section{Citizen}

$\circ \quad$ News

- News Briefs

$\circ \quad \underline{\text { Letters }}$

- Editorials

$\circ$ Opinion

- $\underline{\text { Sports }}$

- Sports Briefs

- $\underline{\text { Arts }}$

$\circ \underline{\text { Life }}$

$\circ$ City

- Columnists

- 30 days Archive

- Headlines Scan

- Newspaper Ads

- Special Sections
"Not good enough" to be trained?

\section{Lisa Campbell}

The Canadian Press Published on Monday, Aug 9, 2010 1:25PM EDT

Last updated on Monday, Aug 9, 2010 8:30PM EDT

BURLINGTON, ON - Sam Barzun was born in Iran. Along with five other recent graduates, he was admitted to a managerial training program with the Links company in May 2010. However, he was dropped from the program three months later, well before the training program was completed. Based on his claim of discrimination, an investigation is ongoing.

"At the beginning, the program director, John Andrews, was happy with my progress, and I successfully passed two evaluation assessments - at months one and two of the program. Later on, however, I started to get remarks regarding missing the training and being late on several occasions. In addition, although I put a great deal of effort into the training, the director was not 
satisfied with my progress and performance anymore." Barzun told the Ottawa Citizen.

At the third evaluation assessment, Barzun received poor scores from the program director and staff. The following day, he was told his training contract was terminated, and he was ineligible for re-enrolment.

"I don't think I've ever been treated like that," Barzun told the Ottawa Citizen. "This is the first time I have experienced discrimination." 
http://www.canada.com/ottawacitizen/news/story.html?id=6838

Monday, August 9, 2010

Part of the canada.com Network
local classifieds working driving obituaries celebrating shopping renting contractors dating
= See today's Digital Edition
= Subscribe to email newsletter
= Subscriber Services
Ottawa Citizen Home Search for

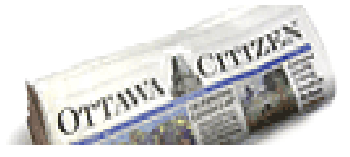

$\underline{\text { Inside the Ottawa Citizen }}$

- News

- News Briefs

- Letters

- Editorials

- Opinion

- Sports

- $\quad$ Sports Briefs

- $\underline{\text { Arts }}$

$0 \underline{\text { Life }}$

- City

- Columnists

- $\underline{\text { 30 days Archive }}$

- Headlines Scan

- Newspaper Ads

- $\underline{\text { Special Sections }}$
"Not good enough" to be trained?

\section{Lisa Campbell}

The Canadian Press Published on Monday, Aug 9, 2010 1:25PM EDT Last updated on Monday, Aug 9, 2010 8:30PM EDT

\begin{abstract}
BURLINGTON, ON - Sam Barzun was born in Canada. His parents immigrated to Canada from Iran thirty years ago. Along with five other recent graduates, he was admitted to a managerial training program with the Links company in May 2010. However, he was dropped from the program three months later, well before the training program was completed. Based on his claim of discrimination, an investigation is ongoing.
\end{abstract}

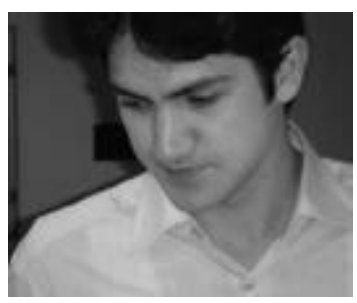

"At the beginning, the program director, John Andrews, was happy with my progress, and I successfully passed two evaluation assessments - at months one and two of the program. Later on, however, I started to get remarks regarding missing the training and being late on several occasions. In addition, although I put a great deal of effort into the training, the director was not satisfied with my progress and performance anymore." Barzun told the Ottawa 
Citizen.

At the third evaluation assessment, Barzun received poor scores from the program director and staff. The following day, he was told his training contract was terminated, and he was ineligible for reenrolment.

"I don't think I've ever been treated like that," Barzun told the Ottawa Citizen. "This is the first time I have experienced discrimination." 


\section{Summary of the article}

Please briefly describe what this article was about (1-2 sentences).

\section{Manipulation check}

The trainee blamed termination of his employment on discrimination

$\begin{array}{llllllll}1 & 2 & 3 & 4 & 5 & 6 & 7\end{array}$

Strongly

Strongly

disagree

agree

\section{Perceptions of discrimination in the situation}

1) Please indicate the extent to which the program director discriminated against the trainee.

$\begin{array}{lllllll}1 & 2 & 3 & 4 & 5 & 6 & 7\end{array}$

Not at all

Extremely

2) Please indicate the extent to which you personally believe the trainee experienced discrimination
1
2
3
4
5
6

7

Not at all

Extremely

\section{Outcome deservingness}

1) In your opinion, how much effort has the trainee (Sam Barzun) put into his training?

$\begin{array}{cccccc}1 & 2 & 3 & 5 & 6 & 7 \\ \text { No } & & & & \text { A lot of } \\ \text { effort at } & & & & \text { effort } \\ \text { all } & & & & \end{array}$


2) Do you agree or disagree that the trainee got what he deserved?

$\begin{array}{llllllll}1 & 2 & 3 & 4 & 5 & 6 & 7\end{array}$

Strongly Strongly

disagree agree

3) Do you agree or disagree that the director's decision was fair?

1

2

3

4

5

6

7

Strongly Strongly

disagree agree

\section{Support of government policies}

If you were asked to sign a petition in support of government policies to protect immigrant victims of discrimination, would you sign it?

$\begin{array}{lllllllll}-4 & -3 & -2 & -1 & 0 & 1 & 2 & 3 & 4\end{array}$

Would

Would

definitely not definitely

sign it sign it

\section{Demographics}

1. What is your age?

2. What is your sex (select one)?

Male

Female

3. Which of the following best describes Sam's racial background? (check one only) White

Asian

Black

Latin American

Arab 
East Indian

Other, Please specify

4. Were you born in Canada?

Yes

No

5. If you were not born in Canada, how long have you been a Canadian resident?

Please indicate your response in years.

6. Are you a Canadian citizen?

Yes

No

7. If not, please specify your citizenship:

\section{Study feedback}

In your opinion, what was this study about?

What do you think was the purpose of the study?

Do you have any suggestions or concerns about this study? 
Appendix D: Studies 1 and 2 Feedback Sheet

Meeting the needs of the Canadian workforce depends heavily on skilled immigrants and non-immigrants. However, these individuals sometimes face unfair treatment from their employers. At the same time, individuals may be reluctant to share their experiences with others because they may be perceived as not putting enough effort into their job. This study investigates Canadians' attitudes toward immigrants and nonimmigrants who have decided to report employment-related discrimination. It also looks at differences in perceptions of complaints made by immigrants from a variety of cultures. We are examining whether similarity of culture and perceptions of the individual claiming discrimination influence individuals' responses.

To help us understand people's reactions to the individual claiming discrimination, participants in this study read a fabricated article. This article was not really published, and was partially fabricated for the purpose of this study. The article varied across participants with the characteristics of the individual claiming discrimination varying. We were interested in your reactions to the individual described in the article, such as emotional reactions, attitudes toward the individual in the article, and support of government policies related to discrimination claimants.

We appreciate the time you spent answering this study's questionnaires. It is our hope that your answers will help us to get a good idea of Canadians' perceptions of individuals claiming discrimination, and to get a better feel for the factors that influence these perceptions. Results of this study may provide important information that can be considered in the formulation of policy initiatives that may be put in place for individuals reporting unfair treatment at work.

Finally, as we are not yet finished conducting this study, we would like to ask that you not tell the true purpose of this study to your friends or other students, as they may also wish to participate in this study in future. Thank you for your cooperation!

Please let us know if you have any questions, suggestions or concerns related to this study. 
Contacts: Natalia Lapshina, Graduate Student, Dept. of Psychology,

Victoria M. Esses, Professor, Dept. of Psychology,

If you have questions about your rights as a research subject, you should contact the Director of the Office of Research Ethics at

If you would like to read more about this topic, here are some references you might want to consult:

Kaiser, C. R., \& Major, B. (2006). A social psychological perspective on perceiving and reporting discrimination. Law and Social Inquiry, 36, 801-830.

Mackie, D. M., Devos, T., \& Smith, E. R. (2000). Intergroup emotions: Explaining offensive action tendencies in an intergroup context. Journal of Personality and Social Psychology, 79, 602-616. 
Appendix E: Study 2 Measures

Which of the following best describes Sam's ethnic background? (check one only)

African

Arab

British Isles

Eastern European

European

Northern European

Southern European

Western European

North American

East and Southeast Asian

South Asian

West Asian

Oceania

Caribbean

Latin, Central and/or South American

Other

If you chose "other" above, please specify Sam's ethnic background

\section{Demographics}

1. What is your age?

2. What is your sex (select one)?

Male

Female

3. Which of the following best describes Sam's racial background? (check one only) White

Asian

Black 
Latin American

Arab

East Indian

Other, Please specify

4. Were you born in Canada?

Yes

No

5. If you were not born in Canada, how long have you been a Canadian resident?

Please indicate your response in years.

6. Are you a Canadian citizen?

Yes

No

7. If not, please specify your citizenship:

Study feedback

In your opinion, what was this study about?

What do you think was the purpose of the study?

Do you have any suggestions or concerns about this study? 


\section{Appendix F: Study 3 Letter of Information and Consent Form}

\section{Western}

Psychology

\section{SocialScience}

Project Title: Media Perceptions-3

Principal Investigator:

Victoria Esses, PhD, Department of Psychology, Western University

\section{Letter of Information}

\section{Invitation to Participate}

You are being invited to participate in this research Media Perceptions-3 to contribute to research in psychology.

\section{Purpose of the Letter}

The purpose of this letter is to provide you with information required for you to make an informed decision regarding participation in this research.

\section{Purpose of this Study}

The purpose of this study is to investigate people's reactions to a newspaper article, including its content and how information is presented.

\section{Inclusion Criteria}

Individuals who are students in the psychology subject pool and are likely between the ages of 17 and 65 are eligible to participate.

\section{Exclusion Criteria}

There are no specific exclusion criteria.

\section{Study Procedures}

If you agree to participate, you will read a newspaper article randomly selected from a pool of articles of interest. After reading and evaluating this article, you will be asked to answer a number of questions about the article and about your attitudes more generally. It is anticipated that the entire task will take approximately 45 minutes to complete, over one session. The task(s) will be

Page 1 of $3 \quad$ Version Date: lanuary 29.2015

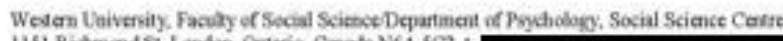
1151 Rodemand ST. London, Ontaria Cenada N6A SC2 it 
conducted in the lab and online via Qualtrics. There will be a total of 500 participants.

\section{Possible Risks and Harms}

There are no known or anticipated risks or discomforts associated with participating in this study.

\section{Possible Benefits}

You may not directly benefit from participating in this study but information gathered may provide benefits to society as a whole which include a greater understanding of reactions to media messages.

\section{Compensation}

You will receive 1 credit toward your research participation course requirement.

\section{Voluntary Participation}

Participation in this study is voluntary. You may refuse to participate, refuse to answer any questions or withdraw from the study at any time with no effect on your future academic status and without loss of promised credit.

\section{Confidentiality}

All data collected will remain confidential and accessible only to the investigators of this study. If the results are published, your name will not be used. If you choose to withdraw from this study, your data will be removed and destroyed from our database.

\section{Contacts for Further Information}

If you require any further information regarding this research project or your participation in the study you may contact Victoria Esses

or Natalia Lapshina e-mail: 
If you have any questions about your rights as a research participant or the conduct of this study, you may contact The Office of Research Ethics

and

\section{Publication}

If the results of the study are published, your name will not be used. If you would like to receive a copy of any potential study results, please contact Natalia Lapshina at

This letter is yours to keep for future reference. 
Project Title: Media Perceptions-3

Principal Investigator:

Victoria Esses, PhD, Department of Psychology, Western University

\section{Consent}

I have read the Letter of Information, have had the nature of the study explained to me and 1 agree to participate. All questions have been answered to my satisfaction.

Full Name (please print):

Participant Signature:

Date :

Researcher Signature :

Date: 
Appendix G: Study 3 Debriefing Form

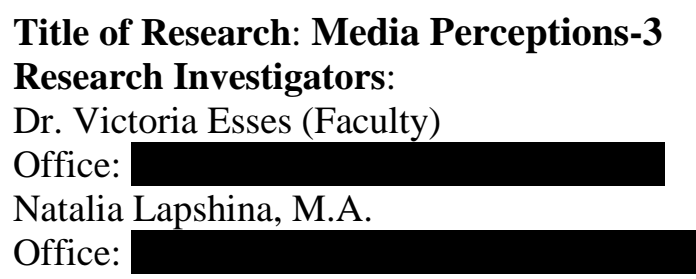

Meeting the needs of the Canadian workforce depends heavily on skilled immigrants and nonimmigrants. However, these individuals sometimes face unfair treatment from their employers. At the same time, individuals may be reluctant to share their experiences with others because they may be perceived as not putting enough effort into their job. This study investigates Canadians' responses to information about immigrants and non-immigrants who have decided to report employment-related discrimination. It also looks at differences in perceptions of complaints made by immigrants from a variety of cultures. We are examining whether similarity of culture and perceptions of the individual claiming discrimination influence individuals' responses.

To help us understand people's reactions to the individual claiming discrimination, participants in this study read an article that was developed specifically for the purpose of this research. This article was not really published. The article varied across participants with the characteristics of the individual claiming discrimination varying. We chose Iran as a country of origin based on Statistics Canada reports indicating that currently recent immigrants from Iran have the highest unemployment rate in Canada (Gilmore, 2009), and we are specifically exploring the role of prejudice in this phenomenon. In addition, this study is a follow-up from two previous studies where Iran was one of the source countries of the immigrant and we wish to build on the earlier research. We were interested in your reactions to the individual described in the article, such as emotional reactions, attitudes toward the individual in the article, and support of government policies related to discrimination claimants.

We appreciate the time you spent answering this study's questionnaires. It is our hope that your answers will help us to get a good idea of Canadians' perceptions of individuals claiming discrimination, and to get a better feel for the factors that influence these perceptions. Results of this study may provide important information that can be considered in the formulation of policy initiatives that may be put in place for individuals reporting unfair treatment at work.

Finally, as we are not yet finished conducting this study, we would like to ask that you not tell the true purpose of this study to your friends or other students, as they may also wish to participate in this study in the future and their results would be biased if they knew the full purpose of the study. Thank you for your cooperation!

Please let us know if you have any questions, suggestions or concerns related to this study. As in all research, if you are experiencing emotional discomfort or distress as a result of your participation, there are several resources here at Western that you may consider contacting. Please visit: http://ww.uwo.ca/uwocom/mentalhealth/ for more information on these resources. If you would like to talk to someone, please contact Student Health Services at If you have any further questions about this research please contact Dr. Victoria Esses (e-mail: or Natalia Lapshina, Graduate Student, Dept. of Psychology If you have questions about your rights as a research subject, you should contact the Director of the Office of Research Ethics 
References:

Kaiser, C. R., \& Major, B. (2006). A social psychological perspective on perceiving and reporting discrimination. Law and Social Inquiry, 36, 801-830.

Gilmore, J. (2009). The 2008 Canadian Immigrant Labour Market: Analysis of Quality of Employment. The Immigrant Labour Force Analysis Series. No. 5. Statistics Canada Catalogue no. 71-606-X.

Version Date: 10/8/2014 
Appendix H: Study 3 Manipulation Articles and Measures

\section{Ambiguous attribution - Iran}

http://www.canada.com/ottawacitizen/news/story.html?id=6838

Monday, August 11, 2014

Part of the Canada.com Network Jump to: Newspapers, TV, Radio
local classifieds working driving obituaries celebrating shopping renting contractors dating

a See today's Digital Ecition

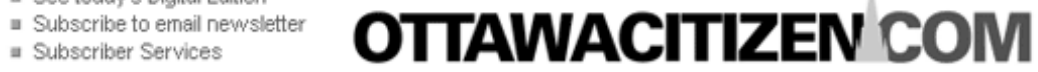

Ottawa Citizen Home Search for $\square$ in the Ottawa Caizen $\quad$ find $\square$

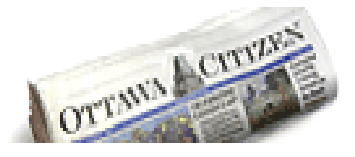

Inside the Ottawa Citizen

- News

- News Briefs

- Letters

- Editorials

- $\underline{\text { Opinion }}$

- $\underline{\text { Sports }}$

- $\underline{\text { Sports Briefs }}$

○ Arts

$\circ \underline{\text { Life }}$

- City

- Columnists

- 30 days Archive

- Headlines Scan

- Newspaper Ads

- $\underline{\text { Special Sections }}$

\section{"Not good enough" to be trained?}

\section{Lisa Campbell}

The Canadian Press Published on Monday, Aug 11, 2014 1:25PM

EDT Last updated on Monday, Aug 11, 2014 8:30PM EDT

BURLINGTON, ON - Sam Barzun was born in Iran. Along with five other recent graduates, he was admitted to a managerial training program with the Links company in May 2010. However, he was dropped from the program three months later, well before the training program was completed. Based on his claim of discrimination, an investigation is ongoing.

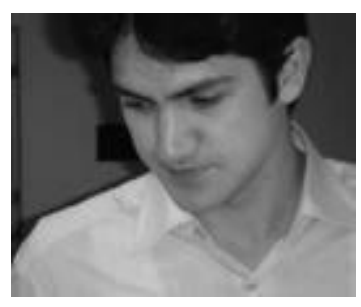

"At the beginning, the program director, John Andrews, was happy with my progress, and I successfully passed two evaluation assessments - at months one and two of the program. Later on, however, I started to get remarks regarding missing the training and being late on several occasions. In addition, although I put a great 
deal of effort into the training, the director was not satisfied with my progress and performance anymore." Barzun told the Ottawa Citizen.

At the third evaluation assessment, Barzun received poor scores from the program director and staff. The following day, he was told his training contract was terminated, and he was ineligible for reenrolment.

"I don't think I've ever been treated like that," Barzun told the Ottawa Citizen. "This is the first time I have experienced discrimination." 


\title{
Ambiguous attribution - Iranian Canadian
}

\author{
http://www.canada.com/ottawacitizen/news/story.html?id=6838
}

Monday, August 11, 2014
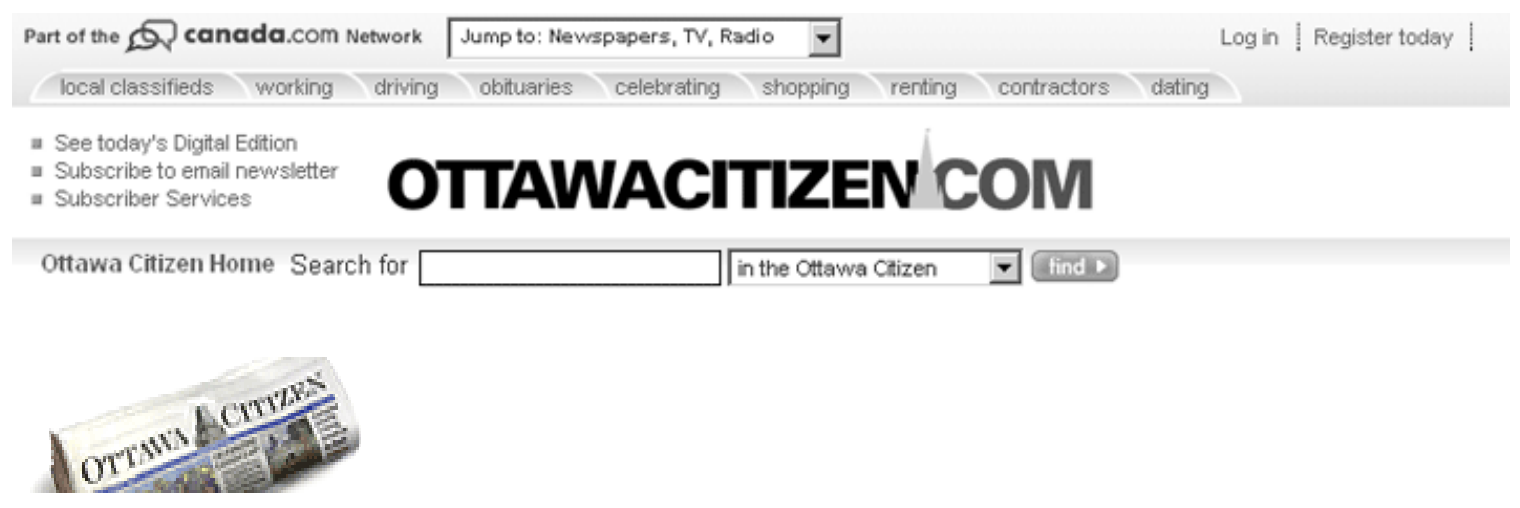

Inside the Ottawa Citizen

- News

- News Briefs

$\circ \quad \underline{\text { Letters }}$

- Editorials

- Opinion

- $\underline{\text { Sports }}$

- $\quad$ Sports Briefs

○ $\underline{\text { Arts }}$

- Life

$\circ$ City

- Columnists

- 30 days Archive

- Headlines Scan

- Newspaper Ads

- $\underline{\text { Special Sections }}$
"Not good enough" to be trained?

\section{Lisa Campbell}

The Canadian Press Published on Monday, Aug 11, 2014 1:25PM

EDT Last updated on Monday, Aug 11, 2014 8:30PM EDT

BURLINGTON, ON - Sam Barzun was born in Canada. His parents immigrated to Canada from Iran thirty years ago. Along with five other recent graduates, he was admitted to a managerial training program with the Links company in May 2010. However, he was dropped from the program three months later, well before the training program was completed. Based on his claim of discrimination, an investigation is ongoing.

"At the beginning, the program director, John Andrews, was happy with my progress, and I successfully passed two evaluation assessments - at months one and two of the program. Later on, however, I started to get remarks regarding missing the training and being late on several occasions. In addition, although I put a great deal of effort into the training, the director was not satisfied with 
my progress and performance anymore." Barzun told the Ottawa Citizen.

At the third evaluation assessment, Barzun received poor scores from the program director and staff. The following day, he was told his training contract was terminated, and he was ineligible for reenrolment.

"I don't think I've ever been treated like that," Barzun told the Ottawa

Citizen. "This is the first time I have experienced discrimination." 


\title{
Ambiguous attribution - Britain
}

\section{http://www.canada.com/ottawacitizen/news/story.html?id=6838}

\author{
Monday, August 11, 2014
}
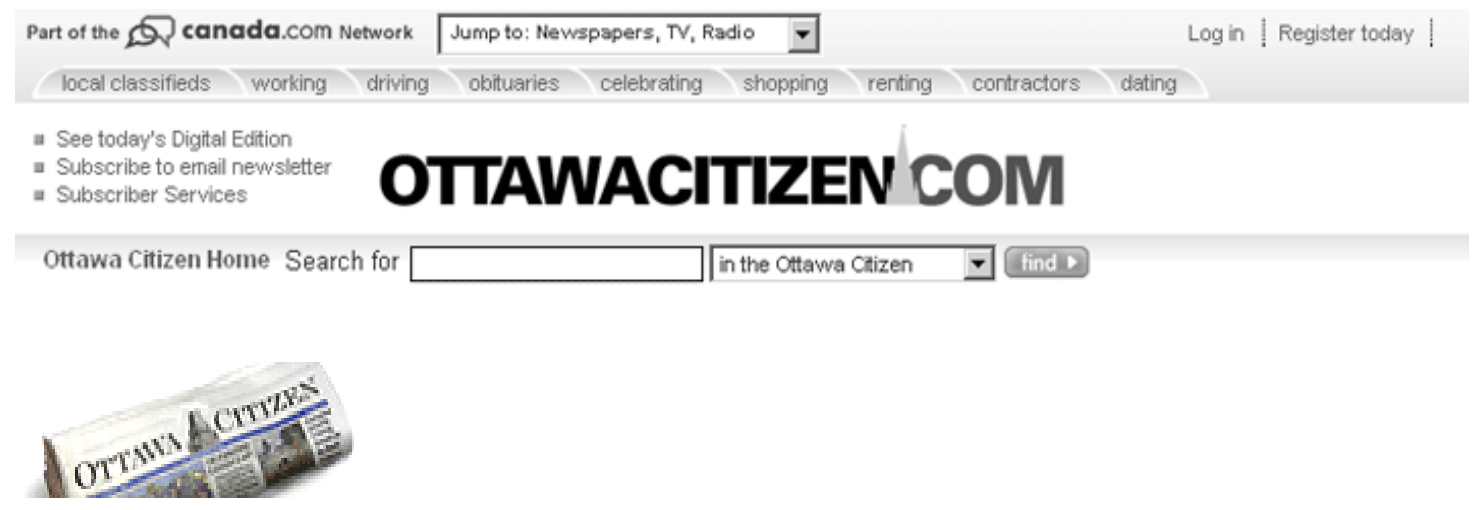

\section{Inside the Ottawa Citizen}

- News

- News Briefs

- Letters

- Editorials

- Opinion

- $\underline{\text { Sports }}$

- $\underline{\text { Sports Briefs }}$

$\circ \underline{\text { Arts }}$

$\circ \underline{\text { Life }}$

$\circ$ City

- Columnists

- 30 days Archive

- Headlines Scan

- Newspaper Ads

- Special Sections
"Not good enough" to be trained?

\section{Lisa Campbell}

The Canadian Press Published on Monday, Aug 11, 2014 1:25PM EDT Last updated on Monday, Aug 11, 2014 8:30PM EDT

BURLINGTON, ON - Sam Barzun was born in England. Along with five other recent graduates, he was admitted to a managerial training program with the Links company in May 2010. However, he was dropped from the program three months later, well before the training program was completed. Based on his claim of discrimination, an investigation is ongoing.

"At the beginning, the program director, John Andrews, was happy with my progress, and I successfully passed two evaluation assessments - at months one and two of the program. Later on, however, I started to get remarks regarding missing the training and being late on several occasions. In addition, although I put a great deal of effort into the training, the director was not satisfied with my progress and performance anymore." Barzun told the Ottawa Citizen.

At the third evaluation assessment, Barzun received poor scores from the program director and staff. The following day, he was told his training 
contract was terminated, and he was ineligible for re-enrolment.

"I don't think I've ever been treated like that," Barzun told the Ottawa Citizen. "This is the first time I have experienced discrimination." 


\title{
Internal attribution - Iran
}

\author{
http://www.canada.com/ottawacitizen/news/story.html?id=6838
}

Monday, August 11, 2014
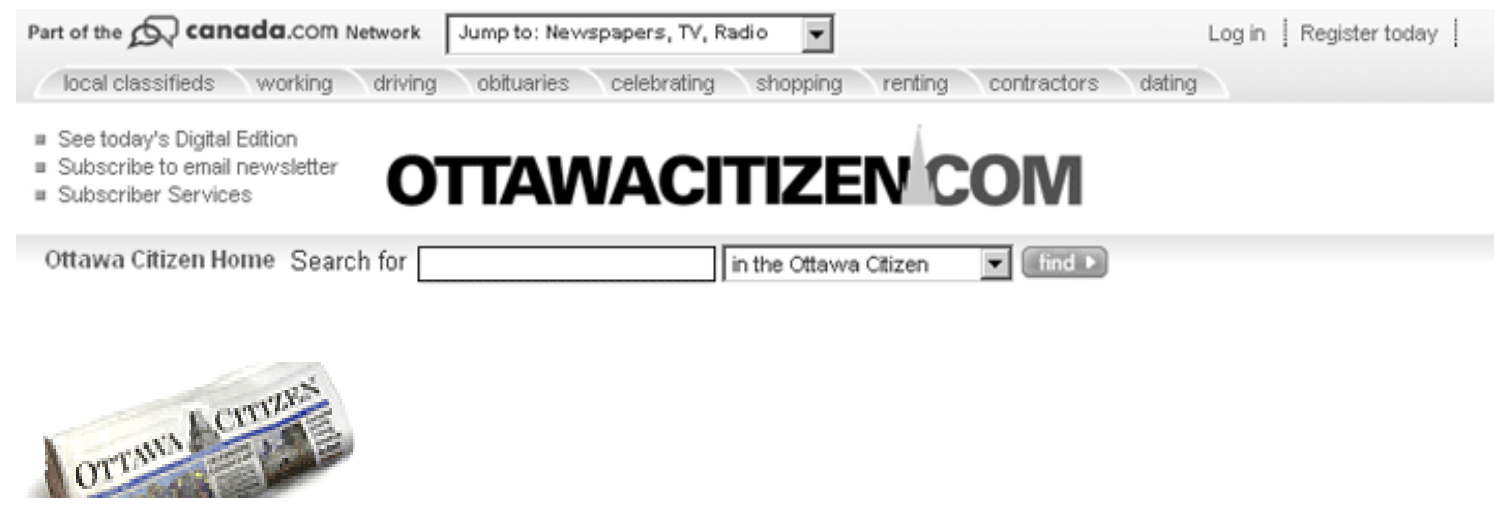

\section{Inside the Ottawa Citizen "Not good enough" to be trained?}

- News

- News Briefs

- Letters

- Editorials

○ Opinion

- $\underline{\text { Sports }}$

- $\underline{\text { Sports Briefs }}$

- $\underline{\text { Arts }}$

$\circ \underline{\text { Life }}$

$\circ$ City

- Columnists

- 30 days Archive

- Headlines Scan

- Newspaper Ads

- Special Sections

\section{Lisa Campbell}

The Canadian Press Published on Monday, Aug 11, 2014 1:25PM EDT Last updated on Monday, Aug 11, 2014 8:30PM EDT

BURLINGTON, ON - Sam Barzun was born in Iran. Along with five other recent graduates, he was admitted to a managerial training program with the Links company in May 2010. However, he was dropped from the program three months later, well before the training program was completed. Based on his claim of discrimination, an investigation is ongoing.

"From the very beginning, I was struggling with the program requirements. I passed the first two evaluation assessments - at months one and two of the program with borderline scores. Later on, however, I was not able to meet the program requirements and started to get remarks regarding missing the training and being late on several occasions. The director was not satisfied with my progress and performance anymore." Barzun told the Ottawa Citizen.

At the third evaluation assessment, Barzun received poor scores from the program director and staff. The following day, he was told his 
training contract was terminated, and he was ineligible for re-enrolment.

"I don't think I've ever been treated like that," Barzun told the Ottawa Citizen. "This is the first time I have experienced discrimination." 


\title{
Internal attribution - Iranian Canadian
}

\author{
http://www.canada.com/ottawacitizen/news/story.html?id=6838
}

Monday, August 11, 2014
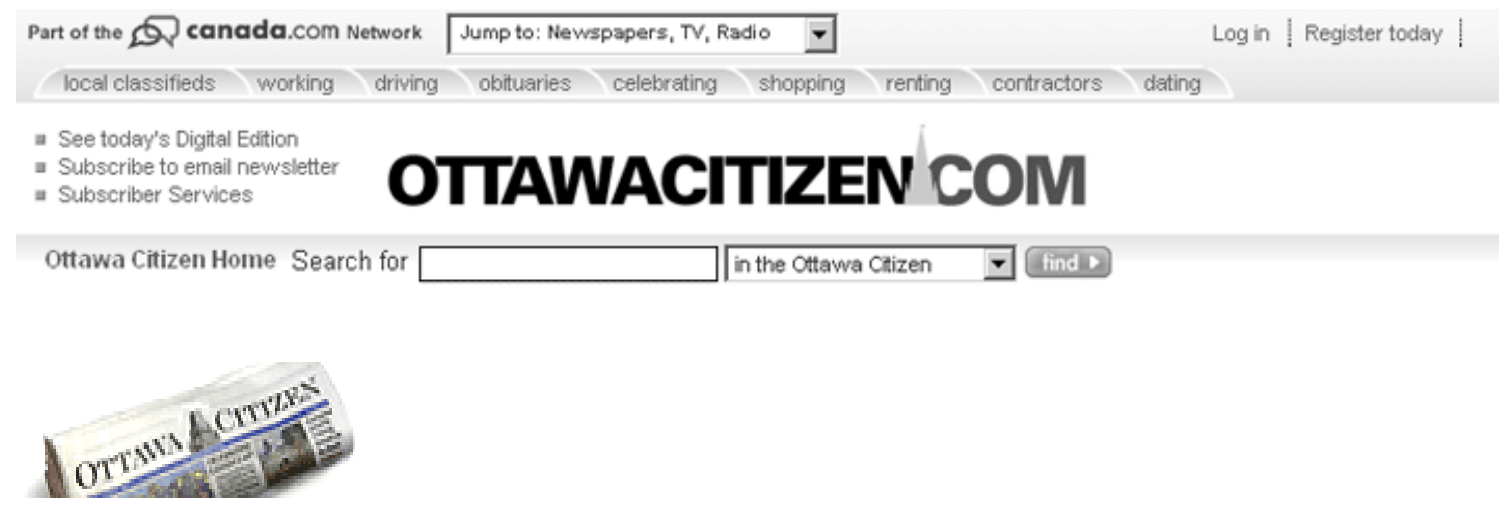

\section{Inside the Ottawa Citizen "Not good enough" to be trained?}

- News

- News Briefs

- Letters

- Editorials

○ Opinion

- $\underline{\text { Sports }}$

- $\underline{\text { Sports Briefs }}$

- $\underline{\text { Arts }}$

$\circ \underline{\text { Life }}$

$\circ$ City

- Columnists

- 30 days Archive

- Headlines Scan

- Newspaper Ads

- Special Sections

\section{Lisa Campbell}

The Canadian Press Published on Monday, Aug 11, 2014 1:25PM EDT Last updated on Monday, Aug 11, 2014 8:30PM EDT

BURLINGTON, ON - Sam Barzun was born in Canada. His parents immigrated to Canada from Iran thirty years ago. Along with five other recent graduates, he was admitted to a managerial training program with the Links company in May 2010. However, he was dropped from the program three months later, well before the training program was completed. Based on his claim of discrimination, an investigation is ongoing.

"From the very beginning, I was struggling with the program requirements. I passed the first two evaluation assessments - at months one and two of the program with borderline scores. Later on, however, I was not able to meet the program requirements and started to get remarks regarding missing the training and being late on several occasions. The director was not satisfied with my progress and performance anymore." Barzun told the Ottawa Citizen.

At the third evaluation assessment, Barzun received poor scores from the 
program director and staff. The following day, he was told his training contract was terminated, and he was ineligible for re-enrolment.

"I don't think I've ever been treated like that," Barzun told the Ottawa Citizen. "This is the first time I have experienced discrimination." 


\section{Internal attribution - Britain}

\section{http://www.canada.com/ottawacitizen/news/story.html?id=6838}

Monday, August 11, 2014

Part of the canada.com Network Jump to: Newspapers, TV, Radio
local classifieds working driving obituaries celebrating shopping renting contractors dating
= See today's Digital Edition
= Subscribe to ernail newsletter
= Subscriber Services
Ottawa Citizen Home Search for

$\underline{\text { Inside the Ottawa }}$

Citizen

- News

- News Briefs

- Letters

- Editorials

- Opinion

- Sports

- $\quad$ Sports Briefs

- $\underline{\text { Arts }}$

- $\underline{\text { Life }}$

$\circ$ City

- Columnists

- 30 days Archive

- Headlines Scan

- Newspaper Ads

- $\underline{\text { Special Sections }}$

\section{"Not good enough" to be trained?}

\section{Lisa Campbell}

The Canadian Press Published on Monday, Aug 11, 2014 1:25PM EDT Last updated on Monday, Aug 11, 2014 8:30PM EDT

\begin{abstract}
BURLINGTON, ON - Sam Barzun was born in England. Along with five other recent graduates, he was admitted to a managerial training program with the Links company in May 2010. However, he was dropped from the program three months later, well before the training program was completed. Based on his claim of discrimination, an investigation is ongoing.
\end{abstract}

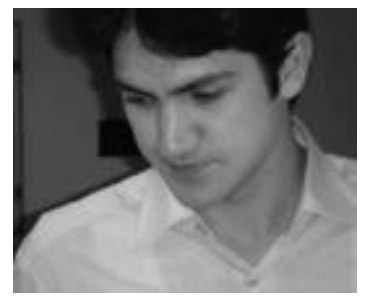

"From the very beginning, I was struggling with the program requirements. I passed the first two evaluation assessments - at months one and two of the program with borderline scores. Later on, however, I was not able to meet the program requirements and started to get remarks regarding missing the training and being late on several occasions. The director was not satisfied with my progress and performance anymore." Barzun told the Ottawa Citizen. 
At the third evaluation assessment, Barzun received poor scores from the program director and staff. The following day, he was told his training contract was terminated, and he was ineligible for re-enrolment.

"I don't think I've ever been treated like that," Barzun told the Ottawa Citizen. "This is the first time I have experienced discrimination." 


\title{
External attribution- Iran
}

\author{
http://www.canada.com/ottawacitizen/news/story.html?id=6838
}

Monday, August 11, 2014

Part of the canada.com Network Jump to: Newspapers, TV, Radio
local classifieds working driving obituaries celebrating shopping renting contractors dating
= See today's Digital Edition
= Subscribe to email newsletter
= Subscriber Services
Ottawa Citizen Home Search for

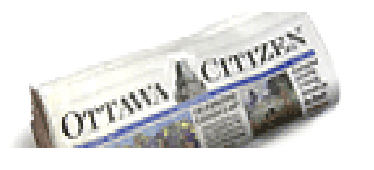

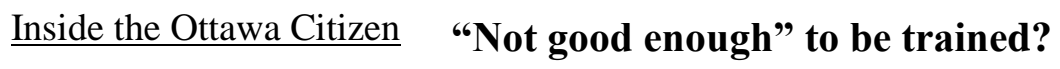

$\begin{array}{ll}\circ & \text { News } \\ \circ & \text { Lews Briefs } \\ \circ & \text { Edters } \\ \circ & \text { Opinion } \\ \circ & \text { Sports } \\ \circ & \text { Sports Briefs } \\ \circ & \text { Aifts } \\ \circ & \text { City }\end{array}$

- Columnists

- $\underline{30 \text { days Archive }}$

- Headlines Scan

- Newspaper Ads

- $\underline{\text { Special Sections }}$

\section{Lisa Campbell}

The Canadian Press Published on Monday, Aug 11, 2014 1:25PM EDT Last updated on Monday, Aug 11, 2014 8:30PM EDT

BURLINGTON, ON - Sam Barzun was born in Iran. Along with five other recent graduates, he was admitted to a managerial training program with the Links company in May 2010. However, he was dropped from the program three months later, well before the training program was completed. Based on his claim of discrimination, an investigation is ongoing.

"At the beginning, the program director, John Andrews, was happy with my progress, and I successfully passed two evaluation assessments - at months one and two of the program. Later on, however, I started to get remarks regarding missing the training and being late on several occasions. In addition, although I put a great deal of effort into the training, the director was not satisfied with my progress and performance anymore." Barzun told the Ottawa Citizen.

At the third evaluation assessment, Barzun received poor scores from the program director and staff. The following day, he was told his training contract was terminated, and he was ineligible for re-enrolment. The director provided negative comments about Sam's culture as an explanation for 
terminating Sam's contract. Later on, one of Sam's former coworkers shared with him that last year the program director fired another trainee for the same reason.

"I don't think I've ever been treated like that," Barzun told the Ottawa Citizen. "This is the first time I have experienced discrimination." 


\title{
External attribution - Iranian Canadian
}

\author{
http://www.canada.com/ottawacitizen/news/story.html?id=6838
}

Monday, August 11, 2014

Part of the canada.com Network Jump to: Newspapers, TV, Radio
local classifieds working driving obituaries celebrating shopping renting contractors dating
= See today's Digital Edition
= Subscribe to email newsletter
= Subscriber Services
Ottawa Citizen Home Search for

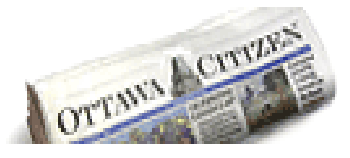

Inside the Ottawa

\section{$\underline{\text { Citizen }}$}

- News

- News Briefs

- Letters

- Editorials

○ Opinion

- $\underline{\text { Sports }}$

- $\underline{\text { Sports Briefs }}$

- $\underline{\text { Arts }}$

$\circ \underline{\text { Life }}$

$\circ$ City

- Columnists

- 30 days Archive

- Headlines Scan

- Newspaper Ads

- $\underline{\text { Special Sections }}$

\section{"Not good enough" to be trained?}

\section{Lisa Campbell}

The Canadian Press Published on Monday, Aug 11, 2014 1:25PM EDT Last updated on Monday, Aug 11, 2014 8:30PM EDT

BURLINGTON, ON - Sam Barzun was born in Canada. His parents immigrated to Canada from Iran thirty years ago. Along with five other recent graduates, he was admitted to a managerial training program with the Links company in May 2010. However, he was dropped from the program three months later, well before the training program was completed. Based on his claim of discrimination, an investigation is ongoing.

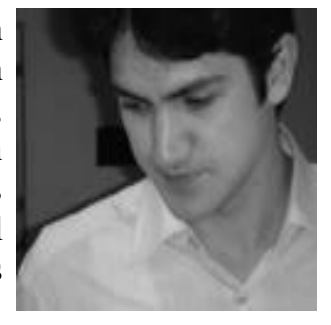

"At the beginning, the program director, John Andrews, was happy with my progress, and I successfully passed two evaluation assessments - at months one and two of the program. Later on, however, I started to get remarks regarding missing the training and being late on several occasions. In addition, although I put a great deal of effort into the training, the director was not satisfied with my progress and performance anymore." Barzun told the Ottawa Citizen.

At the third evaluation assessment, Barzun received poor scores from the program director and staff. The following day, he was told his training contract was terminated, and he was ineligible for re-enrolment. The director provided negative comments about Sam's culture as an explanation for terminating Sam's contract. Later on, one of Sam's former coworkers shared 
with him that last year the program director fired another trainee for the same reason.

"I don't think I've ever been treated like that," Barzun told the Ottawa Citizen. "This is the first time I have experienced discrimination." 


\title{
External attribution- Britain
}

\section{http://www.canada.com/ottawacitizen/news/story.html?id=6838}

\author{
Monday, August 11, 2014
}

Part of the Canada.com Network Jump to: Newspapers, TV, Radio
local classifieds working driving obituaries celebrating shopping renting contractors dating
= See today's Digital Edition
= Subscribe to email newsletter
= Subscriber Services
Ottawa Citizen Home Search for

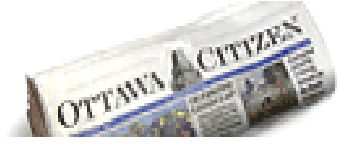

Inside the Ottawa Citizen

News

News Briefs

Letters

Editorials

$\underline{\underline{\text { Opinion }}}$

$\underline{\text { Sports }}$

Sports Briefs

$\underline{\text { Arts }}$

$\underline{\text { Life }}$

City

Columnists

30 days Archive

Headlines Scan

Newspaper Ads

$\underline{\text { Special Sections }}$

\section{"Not good enough" to be trained?}

\section{Lisa Campbell}

The Canadian Press Published on Monday, Aug 11, 2014 1:25PM EDT

Last updated on Monday, Aug 11, 2014 8:30PM EDT

BURLINGTON, ON - Sam Barzun was born in England. Along with five other recent graduates, he was admitted to a managerial training program with the Links company in May 2010. However, he was dropped from the program three months later, well before the training program was completed. Based on his claim of discrimination, an investigation is ongoing.

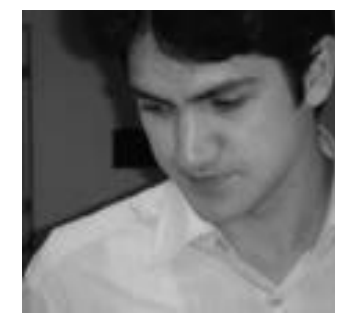

"At the beginning, the program director, John Andrews, was happy with my progress, and I successfully passed two evaluation assessments - at months one and two of the program. Later on, however, I started to get remarks regarding missing the training and being late on several occasions. In addition, although I put a great deal of effort into the training, the director was not satisfied with my progress and performance anymore." Barzun told the Ottawa Citizen.

At the third evaluation assessment, Barzun received poor scores from the program director and staff. The following day, he was told his training 
contract was terminated, and he was ineligible for re-enrolment. The director provided negative comments about Sam's culture as an explanation for terminating Sam's contract. Later on, one of Sam's former coworkers shared with him that last year the program director fired another trainee for the same reason.

"I don't think I've ever been treated like that," Barzun told the Ottawa Citizen. "This is the first time I have experienced discrimination." 


\section{Study 3 Measures}

Which of the following best describes Sam's ethnic background? (check one only)

- White

- Chinese

- South Asian (e.g., East Indian, Pakistani, Sri Lankan, etc)

- Black

- Filipino

- Latin American

- Southeast Asian (e.g., Vietnamese, Cambodian, Malaysian, etc)

- Arab

- West Asian (e.g., Iranian, Armenian, Afghani, etc)

- Korean

- Japanese

- Other

If you chose "other" above, please specify Sam's ethnic background

\section{Emotional Response Questionnaire}

Please indicate how much each adjective describes how you feel (or how you would expect to feel) about the trainee. There are no right or wrong answers; we just want you to be as honest as possible in indicating how you're feeling right now.

\section{Distressed}

12

Not at all

4

5

6

7

Extremely

2. Sympathetic

2

3

4

5

6

7

Not at all

Extremely

3. Trusting

12

3

4

5

6

7

Not at all

Extremely 
4. Irritated

12

Not at all

5. Threatened

1

Not at all

6. Upset

12

Not at all

7. Agitated

1

Not at all

8. Soft-hearted

12

Not at all

9. Annoyed

12

3

Not at all

10. Tender

3

3
4

5

6

7

Extremely

4

5

6

7

Extremely

4

5

6

7

Extremely

4

5

6

7

Extremely

4

5

6

7

Extremely 


$\begin{array}{lllllll}1 & 2 & 3 & 4 & 5 & 6 & 7 \\ \text { Not at all } & & & & & & \text { Extremely }\end{array}$

11. Disturbed

$\begin{array}{lllllll}1 & 2 & 3 & 4 & 5 & 6 & 7 \\ \text { Not at all } & & & & & & \text { Extremely }\end{array}$

12. Touched

12

3

4

5

6

7

Not at all

Extremely

13. Outraged

1

3

4

5

6

7

Not at all

14. Concerned

12

3

4

5

6

7

Not at all

15. Empathic

12

3

4

5

6

7

Not at all

Extremely

16. Angered 


$\begin{array}{lllllll}1 & 2 & 3 & 4 & 5 & 6 & 7 \\ \text { Not at all } & & & & & & \\ \text { 17. Grieved } & & & & & & \\ 1 & 2 & 3 & 4 & 5 & 6 & 7 \\ \text { Not at all } & & & & & & \text { Extremely }\end{array}$

18. Troubled

12

3

4

6

7

Not at all

Extremely

19. Alarmed

1

3

4

5

6

7

Not at all

Extremely

20. Bothered

12

3

4

5

6

7

Not at all

Extremely

21. Contemptuous

$\begin{array}{lllllll}1 & 2 & 3 & 4 & 5 & 6 & 7 \\ \text { Not at all } & & & & & & \text { Extremely }\end{array}$

22. Diffident

12

3

4

5

6

7 
Not at all

Extremely

23. Disgusted

12

3

4

5

6

7

Not at all

Extremely

24. Fearful

12

3

4

5

6

7

Not at all

Extremely

25. Anxious

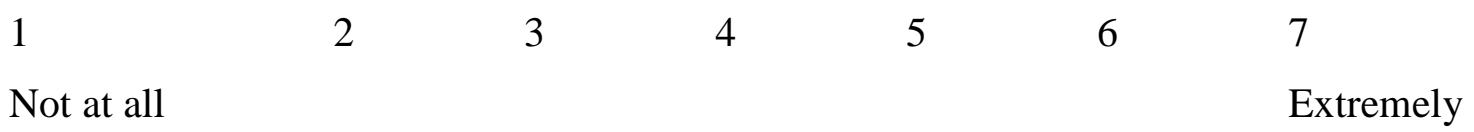




\section{Curriculum Vitae}

Name: $\quad$ Natalia Lapshina

Post-secondary Udmurt State University

Education and Izhevsk, Russia

Degrees: $\quad$ 1992-1998 B.A.

Carleton University

Ottawa, Ontario, Canada

2006-2008 M.A.

Western University

London, Ontario, Canada

2010-2015 Ph.D.

\section{Honours and Ontario Graduate Scholarship}

Awards:

2011-2012

Bill Jones' Award (Carleton University)

2007

\section{Related Work Graduate Researcher \\ Experience Western University, Carleton University \\ 2006-2008, 2010-2014 \\ Research Associate \\ Centre for Addiction and Mental health \\ 2013-2014}

\section{Senior Data Analyst}

Johns Hopkins University 


\section{Publications:}

Esses, V.M., Medianu, S., Hamilton, L., \& Lapishina, N. (2014). Psychological perspectives on immigration and acculturation. In J.A. Simpson \& J.F. Dovidio (Eds.), APA handbook of personality and social psychology Vol.2, Group processes. Interpersonal relations and group processes (pp. 423-445). Washington, DC: American Psychological Association.

Esses, V.M., Bennett-AbuAyyash, C., \& Lapshina, N. (2014). How discrimination against ethnic and religious minorities contributes to the underutilization of immigrants' skills. Policy Insights from Behavioral and Brain Sciences, 1, 55-62.

\section{Research reports}

Esses, V. M., Lapshina, N., \& Bitacola, L. (2010). Settlement Information Renewal Exercise: Results of Consultations with Newcomers in Montreal, Ottawa, Toronto, Winnipeg, and Vancouver. Report written for Citizenship and Immigration Canada. 76pp.

Ravanera, Z. R., Esses, V. M., Beaujot, R., Bozheva, A., Gilliland, J., Lapshina, N., Rangel, C.Y. (2012). Measurement of Outcomes of Local Immigration Partnerships: Baseline Indicators of Welcoming Communities. Report written for Citizenship and Immigration Canada. 270pp. 